\title{
PROPOSED OUTLINE OF SAFETY ANALYSIS REPORT FOR FACILITIES FOR GEOLOGIC ISOLATION OF RADIOACTIVE WASTES
}

\author{
Prepared for: \\ OFFICE OF WASTE ISOLATION \\ UNION CARBIDE CORPORATION \\ NUCLEAR DIVISION \\ OAK RIDGE, TENNESSEE 37830
}

This report was prepared by Stanford Research Institute under subcontract number 89Y-22320V with Union Carbide Corporation, Nuclear Division. Under Contract No. W-7405-eng-26 with the Energy Research and Development Administration. The subcontract was administered by the Office of Waste Isolation, Union Carbide Corp., Nuclear Division. 


\section{DISCLAIMER}

This report was prepared as an account of work sponsored by an agency of the United States Government. Neither the United States Government nor any agency Thereof, nor any of their employees, makes any warranty, express or implied, or assumes any legal liability or responsibility for the accuracy, completeness, or usefulness of any information, apparatus, product, or process disclosed, or represents that its use would not infringe privately owned rights. Reference herein to any specific commercial product, process, or service by trade name, trademark, manufacturer, or otherwise does not necessarily constitute or imply its endorsement, recommendation, or favoring by the United States Government or any agency thereof. The views and opinions of authors expressed herein do not necessarily state or reflect those of the United States Government or any agency thereof. 


\section{DISCLAIMER}

Portions of this document may be illegible in electronic image products. Images are produced from the best available original document. 
This report was prepared as an account of work sponsored by the United States Government. Neither the United States nor the Energy Research and Development Administration, nor any of their ernployees, nor any of their contractors, subcontractors, or their employees, makes any warranty, express or implied, or assumes any legal liability or responsibility for the accuracy, completeness or usefuiness of any information, apparatus, product or process disclosed, or represents that its use would not infringe privately owned rights. 


\section{PROPOSED OUTLINE OF SAFETY ANALYSIS REPORT FOR FACILITIES FOR GEOLOGIC ISOLATION OF RADIOACTIVE WASTES}

By: LEO W. WEISBECKER, LOIS L. GERCHMAN, BUFORD R. HOLT, SUSAN J. MARA, STUART L. MCHUGH, HENRY M. TAYLOR, JACK E. VAN ZANDT, DAVID R. ZOELLNER

Prepared for:

OFFICE OF WASTE ISOLATION UNION CARBIDE CORPORATIION NUCLEAR DIVISION

OAK RIDGE, TENNESSEE 37830

SRI Project EGD-6142

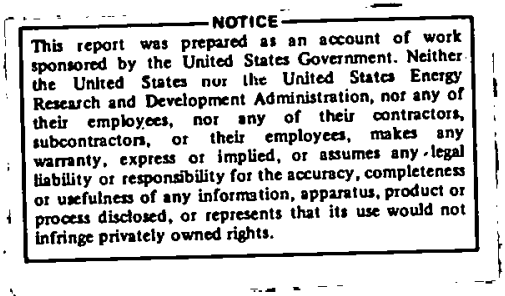

CENTER FOR RESOURCE AND ENVIRONMENTAL SYSTEMS STUDIES

Report No. 24 
THIS PAGE

WAS INTENTIONALLY

LEFT BLANK 
CONTENTS

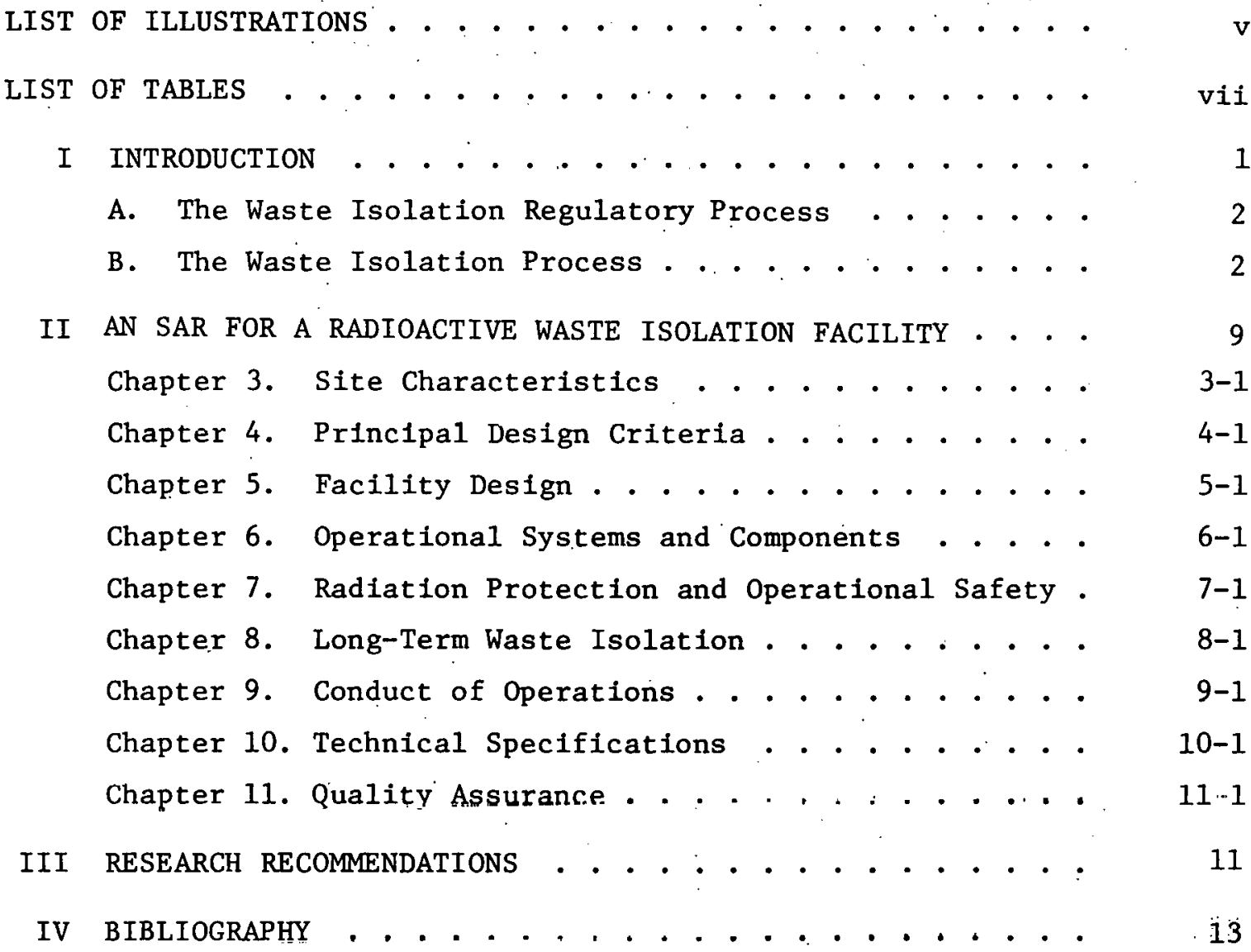


THIS PAGE

\section{WAS INTENTIONALLY}

LEFT BLANK 


\section{ILLUSTRATIONS}

1 Generalized Regulation Concept . . . . . . . . . . . . 3

2 Regulatory Concept for Waste Isolation Facility'. . . . . . . 4

3 Waste Isolation Processes . . . . . . . . . . . . . . . . 6

4 Waste Generation and Waste/Envirọment Microprocesses . . . . 7

5 Geophysical Macroprocesses . . . . . . . . . . . . . 8 
THIS PAGE

WAS INTENTIONALLY

LEFT BLANK 
TABLES

1 References-SAR Content Correlation . . . . . . . . . . . 
FOREWORD

This report was prepared under a subcontract with Union Carbide Corporation, Nuclear Division, a USERDA contractor. This subcontract was administered by the office of Waste Isolation (OWI), program manager for the National Waste Terminal Storage (NWTS) Program. The principal objective of the NWTS Program is to provide facilities in various deep geologic formations at multiple locations in the United States that will safely dispose of the radioactive waste generated by commercial operations and that must be delivered to a federal repository for terminal storage. These federal repositories will be licensed by the Nuclear Regulatory Commission (NRC).

The NRC generally requires that a safety analysis report be prepared by the applicant for a license for a major facility that is a part of the nuclear fuel cycle. ERDA also requires safety analysis reports (SARs) to be prepared for all new nuclear facilities constructed under its programs. Neither ERDA nor NRC has developed guidelines for the contents of SARs for federal waste repositories. Therefore, to provide guidance in planning, OWI has initiated this project to outline possible contents of SARs for federal repositories. This report presents the independent suggestions of the subcontractor retained for that purpose. The assumptions, views, and conclusions expressed in this document are those of the authors and are not to be interpreted as those of Union Carbide Corporation, Nuclear Division, or of ERDA. 


\section{INTRODUCTION}

This report is concerned with formulating the appropriate and necessary contents for a Safety Analysis Report (SAR) for safe, longterm radioactive waste isolation. An SAR provides a safety evaluation that is necessary before approvals can be obtained within the regulatory process to proceed with constructing Preliminary SAR--PSAR) and implementing (Final SAR--FSAR) facilities for long-term waste isolation. By separating approval to proceed with construction from that to proceed with implementation, the regulatory process is made much more flexible. Construction can proceed before approval for implementation is obtained, and the approval for implementation can be based on an "as-built" facility rather than on just a paper plan. The public interest is served by potentially shortening the time for implementation and by making the execution of the facility a matter for consideration in the approval for implementation.

Many SARs have already been submitted and approved for facilities that pertain to other, related facility operations of the nuclear fuel cycle. Accordiugly, these SAKs are useful in establishing both the format and the level of detail expected to be required in a waste isolation facility SAR.

The material here is presenled as a guide, rather than as an outline of a SAR. Although the two closely correspond, the guide format offers the opportunity to:

- Deal with alternatives in a general way.

- Address the problems from the reviewer's or regulator's perspective.

- Use exist Ing regulatory guide material when appropriate. 


\section{A. The Waste Isolation Regulatory Process}

Goals and objectives must be formulated with subsidiary instruments of regulation so that nuclear waste can be managed with minimal or no risk for present and future generations. The regulatory framework must be consistent and specific; each level of regulation must support those goals and objectives that fall within the limited scope of its influence. The basic regulatory process is shown in Figure 1. Figure 2 shows this process applied to the design, implementation, operation, and decommissioning of a waste isolation facility. This diagram also indicates the relationship of the SARs to other aspects of lle wastc icolatinn facility and its regulatory framework.

As documentation of demonstrated adherence to established regulations in past facility actions, and promised intent to adhere to these regulations in future actions, the PSARs and FSARs represent pivotal puints in informing the decision-making process.

\section{B. The Waste Isolation Process}

Because of alternatives presenled by spent fuel reprocessing and recycling of unfissioned uranium and plutonium in the fuel cycle, several altermalive wastcc may hour l.u be accommodated hy a waste lsulation facj]ity:

- Spent fuel elements.

- High-leve1 fission product wastes.

- Transuranic waslés.

- Plutonium.

Spent fuel elements will be packaged in sontainers that may be filled with heat transfer medium. High-level f1solun produr.t wastes wi.ll be solidified and packaged in steel cannisters. Transuranic wastes will be reduced in volume, incorporated into a solid matrix, and packaged in cannisters. Plutonium wastes could alco be parkaged in steel cannisters.

Processes taking place over long periods such as emanation of heat and penetrating radiation from high-level fission product wastes, and large-scale 


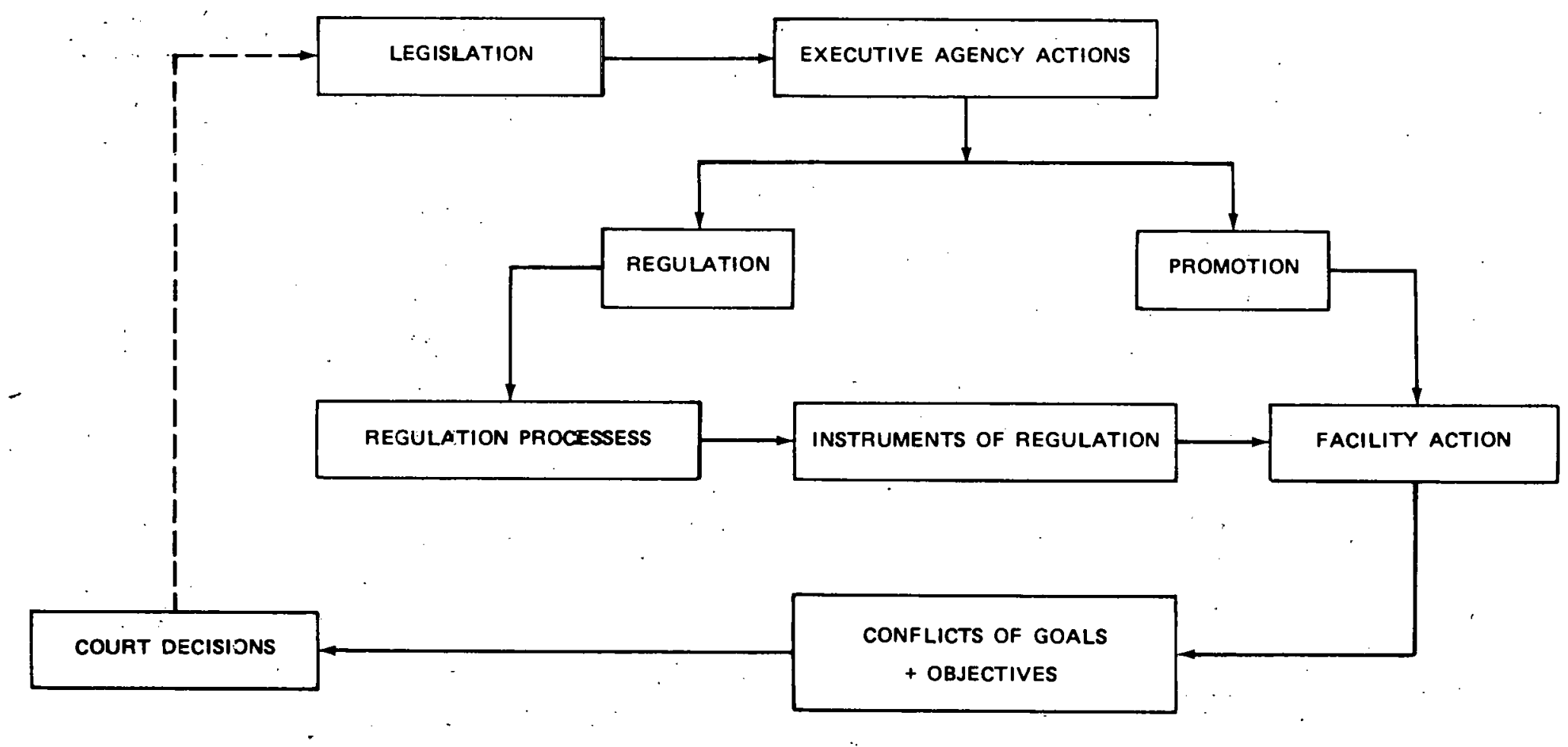

FIGURE 1. GENERALIZED REGULATION CONCEPT 


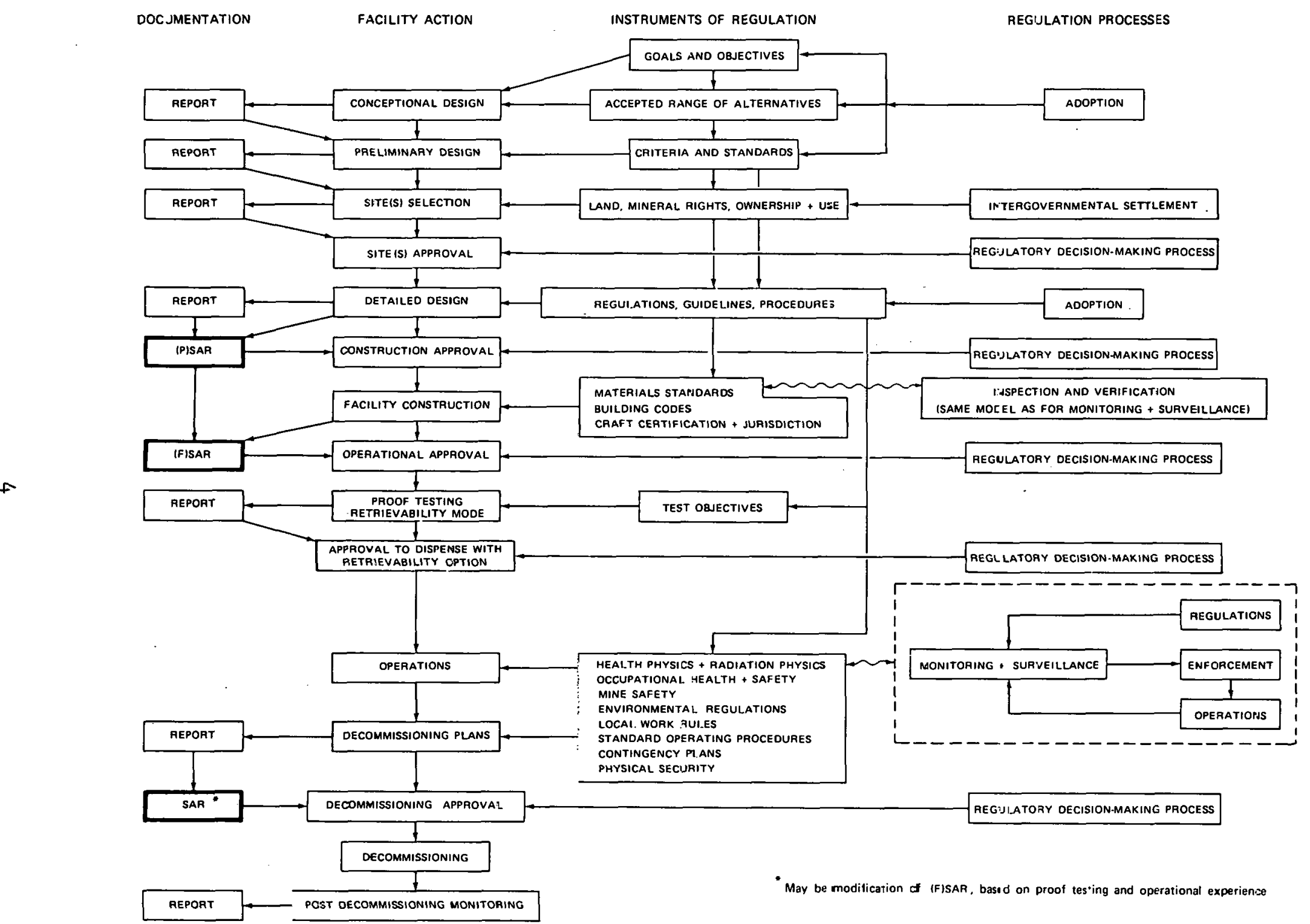

FIGURE 2. REGULATORY CONCEPT FOR WASTE SOLATION FACILITY 
geophysical processes may affect waste-rock interactions in the vicinity of the waste isolation facility. This combination of interacting processes may potentially lead to transport of waste material from the geologic formation to the biosphere as shown conceptually in Figure 3 .

If the waste should escape into the biosphere, it could interact with biological and ecological systems as it propagates through them. The waste preparation and isolation, and the potential waste and environment microprocesses are shown in more detail in Figure 4; the potential geophysical macroprocesses are shown in Figure 5.

In addition to naturally occurring processes, man can readily compromise the objectives of waste isolation--either by accident or by intent. The probability of accidental human intrusion, however, can be minimized by selecting sites that are free from deposits of valuable or potentially valuable resources.

Thus, the objective of waste isolation is to so emplace the waste materials that the probability of any of them returning to the biosphere through the potential microprocesses and macroprocesses and interactions is vanishingly small or, if and when it does occur, is of little importance. Hence, the SAR must show:

- That all potential waste and environmental microprocesses have been considered for alternative fullls and types of waste material and alternative geologic formations.

- That all geophysical macroprocesses that could potentially influence the isolation formation and interact with the macroprucesses taking place have been considered.

- That reasonable means have been taken to preclude accidental or purposeful intrusion of the isolation formation by humans.

- That all potential pathways by which waste material could return to the biosphere have been considered.

- That pathway mechanisms occur with vanishingly low probability or are so slow that the rate of release is so small and/or that the time to release is so long that the consequences are minimal. 


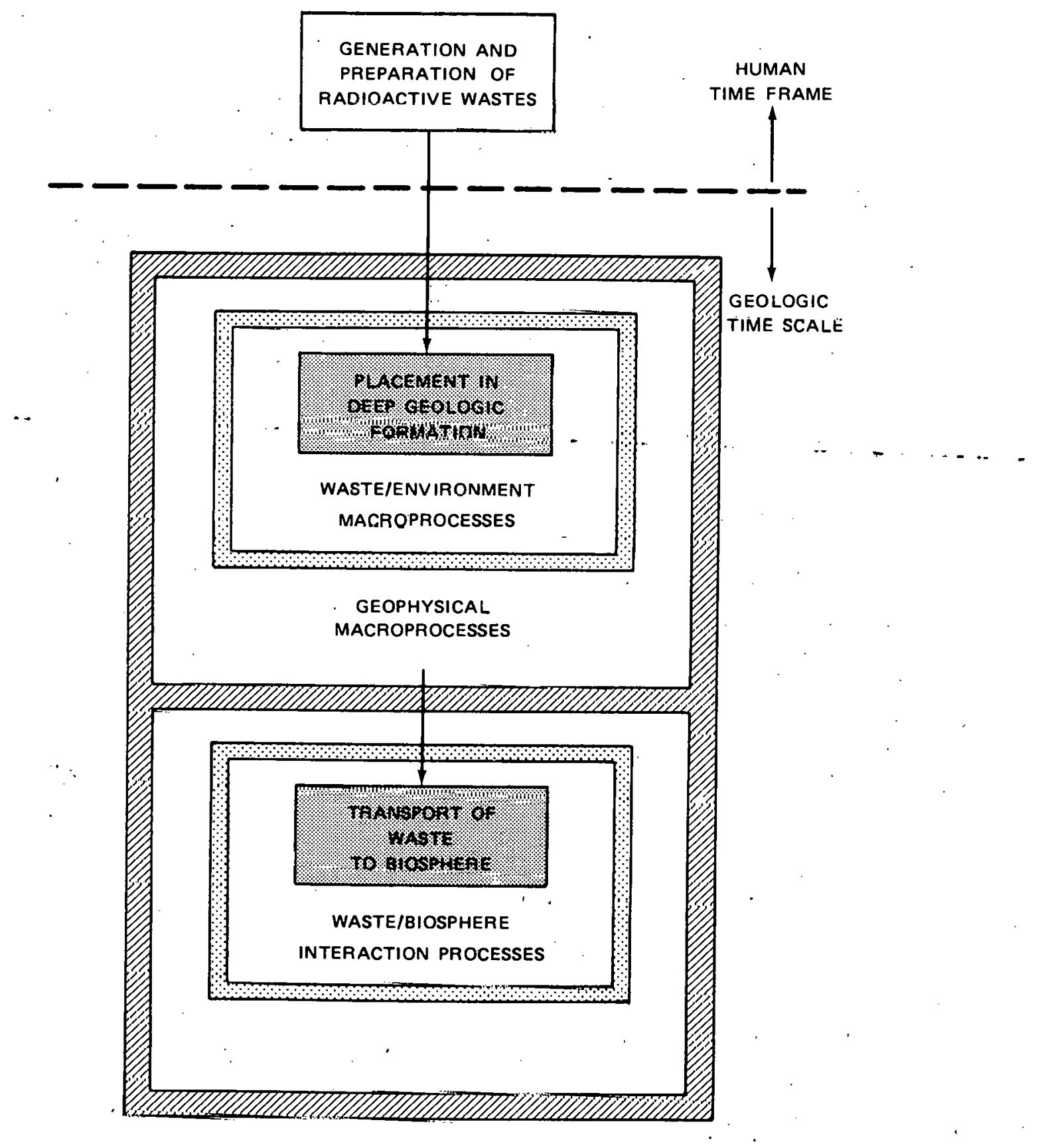

FIGURE 3. WASTE ISOLATION PROCESSES 


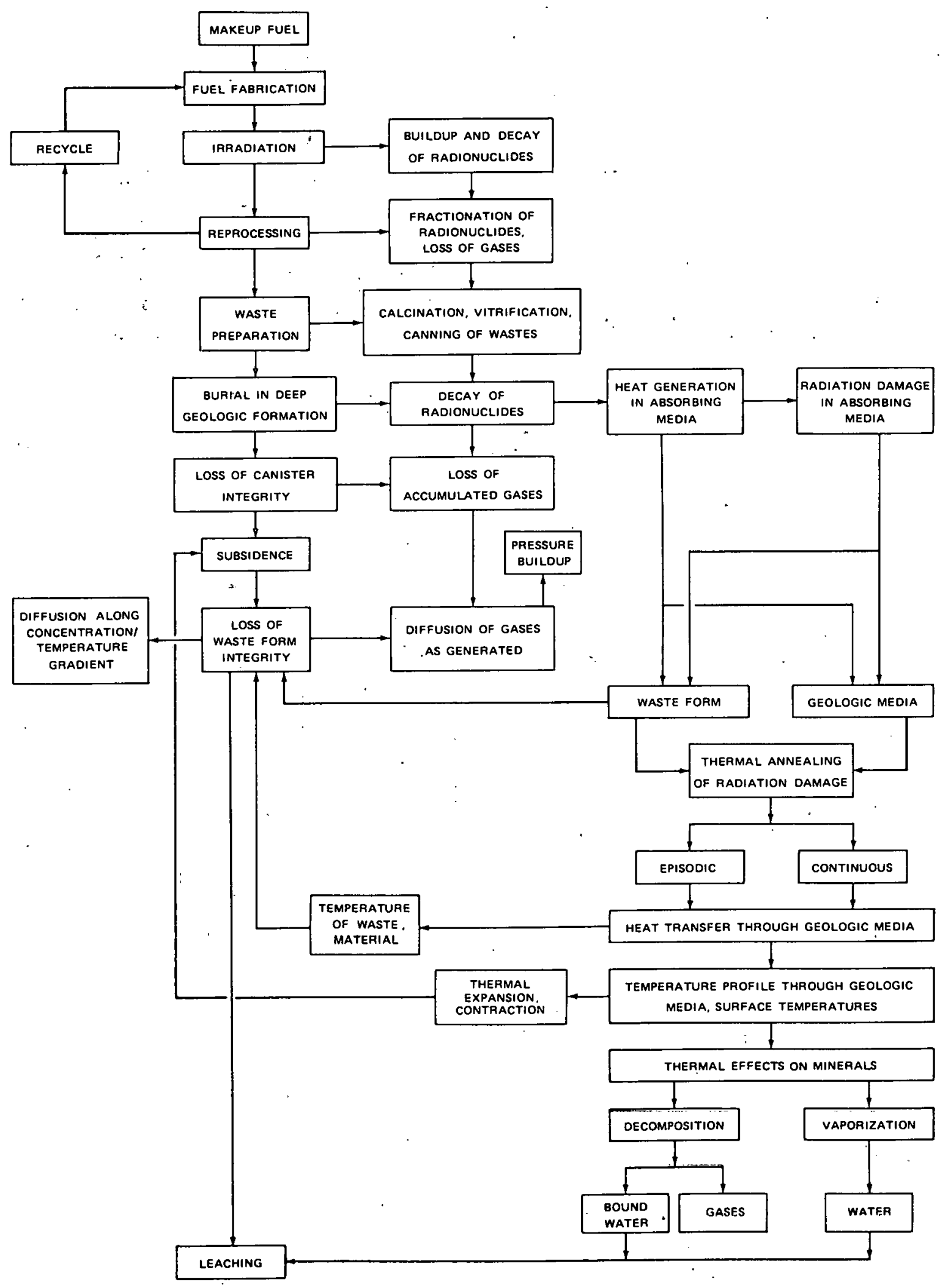

FIGURE 4. WASTE GENERATION AND WASTE/ENVIRONMENT MICROPROCESSES 


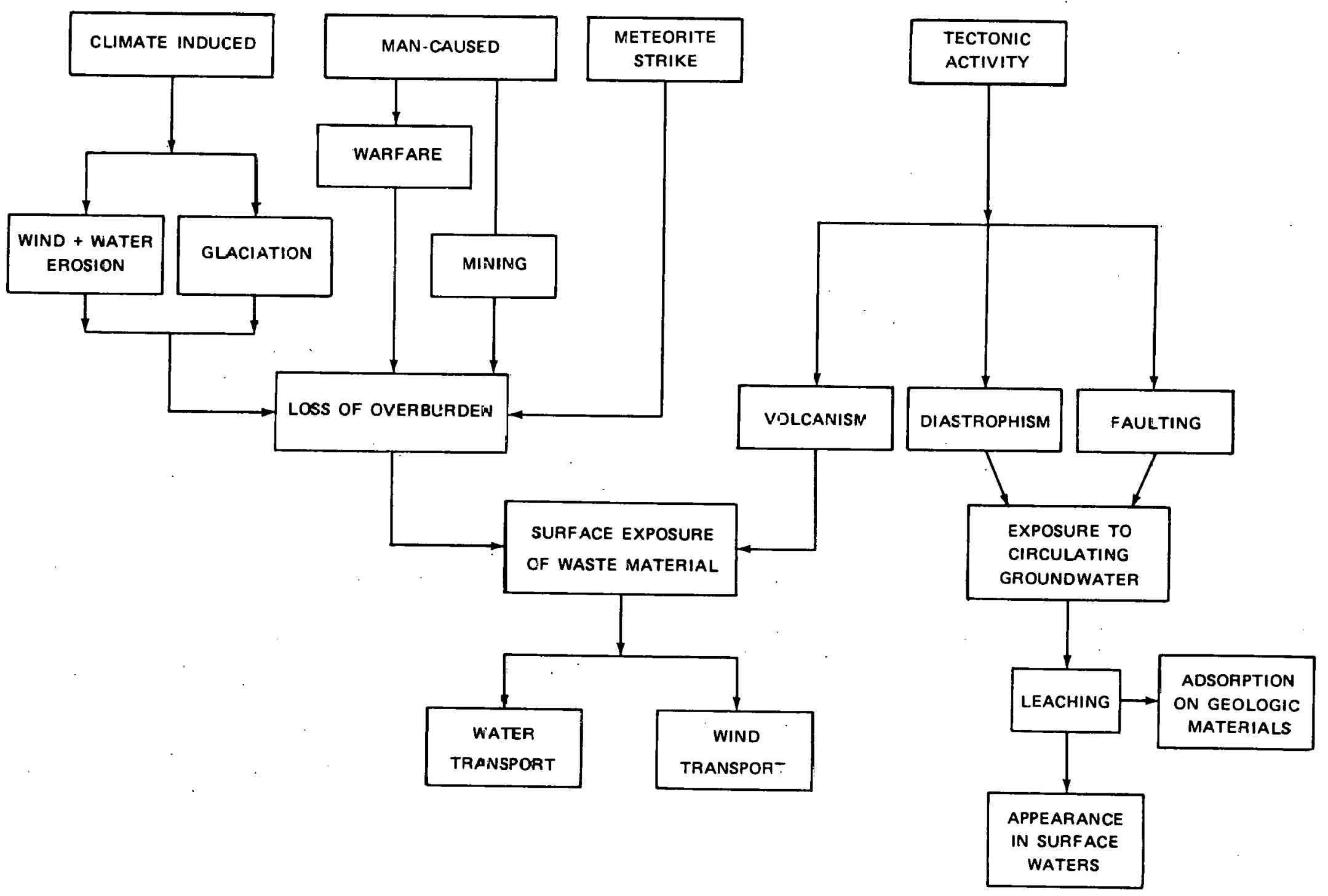

FIGURE 5. GEOPHYSICAL MACROPROCESSES 


\section{AN SAR FOR A RADIOACTIVE WASTE ISOLATION FACILITY}

An SAR for a waste isolation facility differs from that for other types of nuclear facilities because it must consider (1) a below-ground facility as well as a surface facility and (2) long-term postdecommissioning isolation processes, such as those described in Section IB, as well as short-term operation. In this last regard, the SAR portion that describes the surface facilities and their operational considerations will be like that for other nuclear facilities. The operational considerations for below-ground facilities, or mines, are'similar to those of the surface facilities with respect to safety considerations. However, some operational considerations are unique to mines, and design considerations are, of course, characteristic of mines.

This report uses an existing SAR regulatory guide ${ }^{*}$ for a nuclear surface facility for the starting point of the SAR requirements for a waste isolation facility. The guide is amended and modified to represent considerations unique to the waste isolation facility and to the concepts of evaluating long-term safety that are described above.

A fuel reprocessing plant handles radioactive materials similar to those stored in a waste isolation facility. But the physical and chemical processes in a fuel reprocessing plant include numerous transfers as fluids, whereas a waste isolation facility's activity consists of a few physical movements and transfers as solids. Nevertheless, even though the operations of a waste isolation facility are simpler and inherently safer than a fuel reprocessing plant, the regulatory guide for a fuel reprocessing plant SAR represents a reasonable point of departure for developing an outline of an SAR for a waste isolation facility.

\footnotetext{
${ }^{\star}$ U.S. NRC, Regulatory Guide 3.26 Standard Format and Content of Safety
} Analysis Reports for Fue1 Reprocessing P1ants (February 1975). 
Chapters 1 and 2 of the standard format of a regulatory guide ${ }^{*}$ for an SAR represent summaries. Accordingly, the following guide for an SAR for a waste isolation facility begins with Chapter 3 .

*U.S. NRC, op. cit. 


\section{Chapter 3}

SITE CHARACTERISTICS

This chapter must provide information about the facility location, and a description of the geographical, demographic, institutional, meteorological, hydrological, seismological, and geological characteristics of the site and its surroundings. The objective here is to indicate what site characteristics and institutional authorities influence facility design and process selection. The site's safety characteristics must be evaluated, with assumptions. identified that need to be applied in making the safety appraisal. These characteristics must be amplified by cross. referencing them with the criteria developed in Chapter 4, "Principal Design Criteria." The design bases that are set forth in subsequent chapters and that are used to meet the criteria must also be identified.

\subsection{GEOGRAPHY AND DEMOGRAPHY OF SITE SELECTED}

Information concerning the site and its geography, population, and land use is needed in the SAR.

\subsubsection{Sile Location}

Clearly indicate the location of the facility site so it is unambiguously situated in relation to features developed later in this chapter. Describe the site location by specifying the latitude and longitude of the waste isolation facility to the nearest second, and the Universal Transverșe Mercator coordinates* to the nearest $100 \mathrm{~m}$. Identify the state and county in which the site is located, as well as the location

*As found on U.S. Geological Survey topographical maps. 
of the site in relation to prominent natural and man-made features, such as rivers and lakes. To facilitate presenting this information, provide maps and aerial photographs. The general location map must include an area within at least a $80-\mathrm{km}$ radius of the facility. Provide additional maps to present details near the facility and site plots to establish orientation of buildings, rooms, tunnels, shafts, streams, ponds, transmission lines, and neighboring structures. Details in this section may be referred to in subsequent chapters to minimize repetition.

\subsubsection{Site Description}

As indicated above, Include a map of the site of suitable scale to define the boundary of the site and the distance from significant facility features to the site boundary. Clearly delineate the control of surface and subsurface access to surrounding areas, and relate these boundaries to those of the facility site. Indicate the applicant's legal rights with respect to the properties described (e.g., ownership, lease, or easements).

Describe the topography of the site and vicinity, using contour maps that indicate surface drainage patterns and the potential impact of surface winds.

Describe vegetative cover and surface soil characteristics in sufficient detail to indicate both potential erosion and fire hazards, and to permit evaluation of the present aesthetic, scientific, and economic value of the site. Animal habitat and species composition should be similarly characterized.

Identify traffic and transportation routes, and onsite transmission lines:

3.1.2.1 Sitc Boundary. Identify the boundaries for any applicant activity conducted within the area controlled by the applicant, but not related to the waste isolation facility operation. 


\subsubsection{Boundaries for Establishing Effluent Release Limits.}

Identify the restricted area, as defined in 10 Code of Federal Regulations (CFR) 20, Paragraph 20.3(a)(14) to show the boundary line that will be used to establish effluent release limits. This boundary line, which may or may not be the same as the plant property lines or the exclusion area boundary line, demarcates the area whose access will be actively controlled to protect individuals from exposure to radiation and radioactive materials. The licensee must control access to comply with the radiation. protection requirements of $10 \mathrm{CFR} 20$. The site map discussed in Section 3.1 .2 may be used to identify this area, or a separate map of the site may be used. Locate the boundary line with respect to nearby rivers and lakes, and clearly indicate distances from plant effluent release points to the boundary line.

\subsubsection{Population, Distribution, and Trends}

Set forth population information based on the most recent census data. to show the population distributions as a function of distance and direction. On a map that indicates significant population groupings, such as cities and towns within the $80-\mathrm{km}$ radius, draw concentric circles, with the waste isolation facility at the center point, at distances of $1,3,5,7,8$, $15,30,40,60$, and $80 \mathrm{~km}$. Divide the circles into $22-1 / 2^{\circ}$ segments, with each segment centered on one of the 16 cardinal compass points (i.e., north, north-northeast, and so on). Within each area thus formed by the concentric circles and radial lines, specify the current resident population. In addition, project the population by decade for the facility's operating life, with the basis for the projection given. Identify and discuss significant transient or seasonal population variations.

\subsubsection{Use of Nearby Land and Waters}

Describe land and water use within at least a $8-\mathrm{km}$ radius of the facility. Present sufficient details of farming, dairy, industrial, commerclal, residential, and.recreational activities to permit estimation of potential population radiation dose commitments resulting from plant 
effluents. Identify local populations in facilities, such as schools and institutions, with respect to their locations and numbers.

Describe the indigenous terrestrial and aquatic flora and fauna, and any migratory species that customarily uses the regional habitat for part of its life cycle. Identify any potentially endangered species. Define the potential of the regional habitat to support increased indigenous and migratory ecological systems. Describe the actual and potential commercial and recreational use of any species.

Identify the nature of activities conducted, if any, within the site boundarles other than those directly related to the operation of the facility. Explain the interrelation of these activities to the waste isnlation farilities.

\subsubsection{Potential Land Use}

Discuss the characteristics of the site and environs in terms of the potential for supporting alternative kinds and level of development. Discuss currently inadequate resources (e.g., surface water) that, if made available by resource development projects or long-term climate changes, could permit significant development.

\subsubsection{Institutional Authorities}

Describe local, regional, and state authorities that could influence or condition the implementation, operation, and decommissioning of the waste isolation facility.

\subsection{NEARBY INDUSTRIẠL, TRANSPORTATION, AND MILITARY FACILITIES}

Locate and identity nuclear facilities within a 80-km radius. Also, identify nearby industrial, transportation, and military installations on a map that clearly shows their distance and relationship to the facility. Delineate the products or material produced, stored, or transported by edch Installation, with maximum quantities for each. Emphasize items that could present a hazard to the safe operation of the waste isolation facility. 
Consideration must be given in Chapter 2 of the SAR to any features identified as potential safety problems.

\section{3 METEOROLOGY}

This section must provide a meteorological description of the site and its surrounding area. Meteorological conditions that may influence the design and operation of the facility, and the waste repository must be identified. Include sufficient information to permit an independent evaluation of atmospheric diffusion characteristics of the local area. State the sources of information and data supplied. In addition, analyze the paleoclimatology to provide the basis for extrapolating future climatic trends.

\subsubsection{Regiona1 Climate}

Describe the climate of the region, and point out characteristics attributable to the terrain. All information should be reported in sufficient detail to measure climatic impacts on facility design and operation and on long-term waste isolation.

\subsubsection{Prevailing Weather Patterns. Describe weather patterns,} including average temperature, diurnal and seasonal temperature changes, precipitation, relative humidity, and prevalent wind direction (Kose diagrams).

3.3.1.3 Historical Data. Provide the following historical data, graphically when possible: precipitation records, snow depth, insolation; evapotranspiration, frost depth; freeze-thaw characteristics; intensities, durations and frequencies of occurrence of precipitation events including snow, temperature extremes (minima and maxima), length of growing season, and frequency of convectional and frontal storm tracks. over the region.

3.3.1.3 Severe Weather. Summarize historical data about the intensity and frequency of severe weather in the region including thunderstorms, lightning strikes, gale-force winds (greater than $55-\mathrm{km} / \mathrm{h}$ or above 7 on 
the Beaufort Scale), tropical, storms, ice storms, hail storms, and tornadoes.

3.3.1.4 Data. Sources. Indicate the sources for all data presented: when possible, identify the methods and frequencies of data collection.

\subsubsection{Loca1 Meteorology}

3.3.2.1 Onsite Meteorologica 1 Measurement Program. Dcscribe the onsite meteorological measurement prngram being conductcd to develup local data and the programs that will be used during operations to estimate offsite concentrations of monitored stack effluents. Set forth the jnintfrequency distributions of wind speed, wind direction, and atmospheri.c. stability, based on meteorological measurement heights and data reporting periods. Identify collection methods, frequencies of collection, and problems associated with the sampling program.

\subsubsection{Normal and Extreme Values of Meteorological Parameters.} Provide monthly summaries of wind (direction and speed combined), temperature, atmospheric water vapor (absolute and relative), precipitation (rain and snow), fog, and atmospheric stability (if available), along with the daily high, low, and mean joint temperatures and specific humidity throughout the year.

3.3.2.3 Topography. Describe the topographic characteristics of the site in detail, including a topographic map to a radius of $80 \mathrm{~km}$ from the plant and topographic cross sections in 16 compass point sectors radiating from the plant to at least a distance of $8 \mathrm{~km}$. The map should indicate sufficient vertical differences to be used in meteorological analysis.

\subsubsection{Short-Term (Accident) Diffusion Estimates}

3.3.3.1 Basis. Conservatively estimate atmospheric dilution at the site boundary for appropriate time periods after an accident, based on 
onsite and local meteorological data. Include consideration of any influence the local topography may have.

3.3.3.2 Calculations. Describe the diffusion equations and the parameters used in the diffusion estimates.

\subsubsection{Long-Term (Routine) Diffusion Estimates}

3.3.4.1 Basis. Estimate atmospheric dilution realistically to a distance of $80 \mathrm{~km}$, based on appropriate meteorological data.

3.3.4.2 Calculations. Describe the diffusion equations and parameters used in the diffusion estimates.

\subsubsection{Paleoclimatology}

3.3.5.1 Pleistocene Climate. Describe the Pleistocene climate of the region, with discussion of the following elements: proximity to continental ice sheets; proximity to alpine glaciation; occurrence of, or proximity to such periglacial features as outwash plains, moraines, kettle holes, lake deposits, and strand lines; and estimates of average temperature, precipitation, relative humidity, and prevailing wind direction. Provide a map of the region. showing all features resulting from contin-. ental and/or alpine glaciation and associated Pleistocene erosional features.

3.3.5.2 Holocene Climate. Describe hypothesized changes in the Holocene climate to the present from approximately 10,000 years ago, as well as the results of dendrochronology, palynology, carbon-dating, or other studies in the region that provide measures of the Holocene climate.

\subsubsection{Climatic Change}

Describe the most recent predictions of future climatic trends and their probable influence on ambient site meteorological conditions. 
Describe possible climatic changes resulting from anthropogenic activities, as well as further geophysical consequences of these climate changes (e.g., melting of polar ice caps, rises in sea levels, etc.).

\subsection{SURFACE HYDROLOGY}

Provide sufficient information to allow independent review of all hydrolog1cally related design bases, performance requirements, and operating procedures important to safety. Describe the features that relate to the hydrology of the region, area, and site, including additional topographic maps of the site and area if required for clarity. Identify the sources of the hydrological information, the types of data collected, and the methods and frequency of collection. It is most important to provide detail that is sufficient for assessing the long-term integrity of the waste repository.

\subsubsection{Hydrologic Description}

3.4.1.1 Site and Facilities. Provide a topographic map of the site, with indication of planned facilities, including cooling ponds, rater supply ponds, and mine adits, and any proposed changes to natural drainage features. Indicate plans for rerouting drainage and minimizing erosion. from the standpoint of hydrologic considerations, describe the site, its safety-related structures, with their exterior accesses, and safety-related equipment and systems. In particular, discuss features that prevent water incursion into the mine and waste repository over the operational life.

3.4.1.2 Hydrosphere. Provide a regiona1. topographic map (80-km radius) showing the major hydrologic features, including streams (perennial, intermittent, and ephemera1), lakes, ponds, springs, and marshes. The map should also include the Location of water control structures. Describe the following characteristics: 
1. Streams (third order and higher)--average annual flow, hydrographs of historical flow patterns (if data are available), drainage area, drainage basin characteristics, base flow characteristics, peak runoff measurements and/or calculations for historical maximum events, annual sediment load, 100-year flood, historical or sampled water quality data [dissolved oxygen (DO), biological oxygen demand (BOD), chemical oxygen demand (COD), total dissolved solids (TDS), total suspended solids, total organic matter, dissolved organic matter, $\mathrm{pH}$, alkalinity, and turbidity].

2. Reservoirs, lakes, and ponds--surface acreage, volume, average depth, depth variations, inflow and outflow characteristics, bottom characteristics, and current flow patterns (in water bodies greater than $2.6 \mathrm{~km}^{2}$ in surface area); seasonal changes in depth, estimated ground water inflow, drainage area, and historical or sampled water quality data (as indicated in 1 above).

3. Springs and marshes--refer to Section 3.5.1.

3.4.1.3 Biological Composition. Describe the biological composition of the water bodies identified in Subsections 3.4.1.2, 1 and 2 above, including the following information: aquatic vegetation, fish species, species diversity indices, relative toxicity, shore characteristics, description of water birds and their habitats, lake classification (if applicable), and a general discussion of water quality.

3.4.1.4. Surface Water Supply. Identify locations and sizes of all population groups using surface water sources in the region (as identified in 3.4.1.2) as a potable supply, as well as their demand for it. List the owners, locations, and capacities of all surface water intakes in the region. (These local groups are the ones who could be adversely affected by accidental or normal releases of contaminants from the facility: refer to Section 3.5.1 for tabulation of ground water users.)

Discuss the implications of applicable laws and administrative procedures pertaining to water rights for the water diverted, used, and returned to surface streams; also indicate the relative priorities of upẹtream and downstream uses in times of shortage. 
3.4.1.5 Data Sources. Provide sources for all data presented, identifying the methods and frequencies of collection when possible.

3.4.1.6 Land Use Lmpacts. Calculate the runoff hydrograph for the new hydrologic regime created by the planned facilities by using information discussed in Section 3.3.1.2, especially maximum precipitation events, for the calculations. Estimate the water quality degradation expected from the new hydrologic regime in nearby lakes and streams.

\subsubsection{Sediment Characteristics. Discuss the sediment of nearby} streams and water bodies in terms of their habitat for bottom dwelling and feeding organisms, heavy metal and chlorinated hydrocarbon composition, and Ion exchange capacity of suspended solids and sediment.

\section{4 .2 Floods}

3.4.2.1 Flood History. Synopsize the flood history (date, level, peak discharge, and other pertinent features) in the site region, (A "flood" is defined as any abnormally high water state or overflow from a stream, floodway, lake, or coastal area that results in significant detrimental effects.) Include river or stream floods, seiches, surges, tsunami, dam failures, ice jams, and similar disturbances.

3.4.2.2. Flood Design Considerations. Discuss the general capability of safety-related facilities, systems, and equipment to withstand floods, tlood waves, and wave action erosion. The design flood protection for safety-related components, and for strurtures and farilities neceecary to protect these components from floods, erosion, and wave action on the facility, should be based on the highest calculated floodwater elevations and flood wave effects resulting from analysis of several different hypothetical floods. As the hasis for the design protection lovel for safety-related components and structures of the facility, consider all possible flood conditions up to and including the highest and most critical flood level resulting from any of several different probable maximum events. 
The probable maximum water level from a stream flood, surge, combination of surge and stream flood in estuarial areas, wave action, or tsunami (whichever is applicable and/or greatest) may cause the highest water level. Other possibilities include flood levels at the facility site resulting from the most severe flood wave caused by an upstream landslide, dam failure, or dam breaching resulting from a seismic or foundation disturbance or from inadequate design capability. The effects of coincident wind-generated wave action should be superimposed on the applicable flood leve1. The assumed hypothetical conditions should be evaluated both statically and dynamically to determine the design flood protection level and dynamically induced loadings. The topical information needed is generally outlined in Sections 3.4.3 through 3.4 .7 , but the types of events considered and the controlling event should be summarized in this section.

When a "probable maximum" event is defined in the following section through Section 3.4.7, relate the probability of that event, if possible, to the historical frequency distribution.

\subsubsection{Effects of Local Intense Precipitation. Summarize the design} criteria for site drainage facilities, and provide analyses that demonstrate the capability of site drainage facilities to protect safety-related facilities from flooding due to local high-intensity precipitation. Estimates of precipitation, based on publications of the National Oceanic and Atmospheric Administration (NOAA) (formerly the U.S. Weather Bureau) of the U.S. Department of Commerce, with the time distribution based on critical distributions such as those employed by the Corps of Engineers, usually provide acceptable bases. Provide sufficient detail (1) to allow an independent review of rainfall and runoff effects on safety-related facilities and (2) to judge the ádequacy of design criteria.

Describe local high-intensity precipitation in regard to its effect on adjacent drainage areas and site drainage systems, including the roofs of safety-related structures. Tabulate rainfall intensities for the selected and critically arranged time increments; provide characteristics and descriptions of runoiff models; and estimate the resulting water levels. 
Describe the design bases for ice accumulations on the roofs of safetyrelated structures and, on exposed safety-related equipment. Discuss any effects on the operational capabilities of the structures, the safetyrelated equipment within, and any exposed safety-related equipment. In addition, discuss the effect of ice accumulation on site facilities when such an accumulation could coincide with local probable maximum (winter) precipitation and cause flooding or other damage to safety-related facilities. Similarly, provide the design bases for snow accumulations on the roofs of safety-related buildings and on exposed safety-related equipment. Last, compare these ice and snow design bases with historical maximum events in the region, and discuss the consequences of exceeding the design bases for safety-related structures, systems, and components (including available design margin).

\subsubsection{Probable Maximum Flood (PMF) on Streams and Rivers}

Describe the PMF by using hypothetical flood characteristics (peak discharge, volume, and hydrograph shape) that are considered to be the most severe "reasonably possible" at a parlismlar lnratinn. Consider. all factors contributing to a PMF runoff, and summarize all locations and associated water levels. for which PMF determinations have been made, imiluding site drainage.

\subsubsection{Probable Maximum Precipitation (PMP). The PMP is the} theoretically greatest precipitation over the applicable drainage area that would produce flood flows that have. virtually no prohahility of being exceeded. These estimates usually involve detailed analyses of actual flood-producing storms in the general region of the drainage basin under study. They also involve modifications and extrapolations of historical data to reflect more severe rainfall-runoff relations than those actually recorded, insofar as they are deemed "reasonably possible" of occurrence on the basis of hydrometeorological reasoning. Discuss considerations of storm configuration (orientation of areal distribution), maximized precipitation amounts (including a description of maximization procedures and/or studies available in the area, such as reference to National Weather 
Service and Corps of Engineers determinations), time distributions, orographic effects, storm centering, seasonal effects, antecedent storm sequences, antecedent snowpack (depth, moisture content, and areal distribution), and any snowmelt model. Present the selected maximized storm precipitation distribution (time and space).

3.4.3.2 Precipitation Losses. Describe the absorption capability of the site drainage basin, including consideration of initial losses, infiltration rates, and antecedent precipitation. Verify these assumptions by referring to regional studies or by presenting detailed local stormrunoff studies.

3.4.3.3 Runoff Model. Describe the hydrologic response characteristics of the site watershed to precipitation (e.g., by unit hydrographs), verification from historic floods or synthetic procedures, and the nonlinearity of the model at high rainfall rates. Use such drainage basin information derived in Section 3.4.1.2 1, as subbasin drainage areas, size, and topographic features in the model simulation. Tabulate all drainage areas, and runoff, reservoir, and channel routing coefficients.

3.4.3.4 PMF Flow. Present the PMF runoff hydrograph--defined as resulting from the PMP (and snowmelt if pertinent). In the hydrograph, incorporate consideration of the hydrologic characteristics of the potential influence of existing and proposed upstream dams and river structures for regulating or increasing the water level. If such dams or structures are designed to withstand a PMF, consider their influence on the regulation of water flow and levels; however, if they are not designed or constructed to withstand the PMF (or inflow from an upstream dam failure), include maximum water flows and resulting static and dynamic effects from their failure by breaching in the PMF estimate (refer to Section 3.4.4.2). Discuss the PMF stream-course response model and its ability to compute floods of various magnitudes up to the severity of a PMF. Present reservoir and channel routing assumptions; include discussions of initial conditions, outlet works (both uncontrolled and controlled), spi.l.ways (hoth uncontrolled and controlled), the ability of dams to 
withstand coincident reservoir wind wave action (with discussions of setup, the significant wave height, the maximum wave height, and run-up), the wave protection afforded, and the reservoir design capacity (i.e., the capacity for PMF and coincident wind wave action). Finally, provide a similar hydrograph without upstream reservoir effects to allow evalution of reservoir effects and a regional comparison of the PMF estimate to be made.

3.4.3.5 Water Level Determinations. Describe the translation of estimated peak PMF discharge to elevation, using (when applicable) crosssection and profile data, reconstitution of historical floods (with consideration of high water marks and discharge estimates), ctandord step methods, roughness coefficients, bridge and other losses, verification, extrapolation of coefficients for the PMF, estimates of PMF water surface profiles, and flood outlines.

3.4.3.6 Coincident Wind Wave Activity. Discuss the run-up, wave heights, and resultant static and dynamic effects of wave action on each safety-related facility from wind-generated activity that may occur coincidentally with the peak PMF water level.

\subsubsection{Potential Dam Fai.lures}

Evalud le the effects of potential dam failures, related to seismic activity or human failure, on the upper limit of flood capability for sites along streams and rivers, consider the potcntial influence ur upstream dams and river structures on regulation of, or increasc in, the water level. Account for the maximum water flow and level resulting from failure of a dam or dams by breaching under the most severe probable modes of failure, including the potential for subsequent downstream. domino-type structural failures due to flood waves, when the structures cannot be shown to be of sufficient strength to withstand severe earthquakes. (The simultaneous occurrence of the PMF and an earthquake that can cause the upstream dams to fail is omitted from consideration because 
each of these events considered singly has a low probability of occurrence.) The suggested worst conditions at the dam site may be evaluated by considering: (1) a 25-year flood occurring when reservoirs are full, coincident with an earthquake determined by using a procedure like that for ascertaining the characteristics of the Safe Shutdown Earthquake (SSE);* and (2) a standard-project flood (as defined by the Corps of Engineers), or one-half the PMF, occurring when reservoirs are full, coincident with the maximum earthquake determined from historical seismicity data. When down-stream dams also regulate water supplies, discuss their potential failures. Include some discussion of failure due to poor construction or other human factors.

\subsubsection{Reservoir Description. Using the reservoir locations and} associated data from Section 3.4.1.2, describe the types of structures, ail appurtenances, ownership, seismic design criteria, and spillway design criteria. Indicate the elevation-storage relationships for pertinent reservoirs, and tabulate short- and long-term storage allocations.

\subsubsection{2 .. Dam Failure Permutations. Discuss the locations of dams} (both upstream and downstream), potential modes of dam failure, and results (floods or low water) of seismically induced and other types of dam failures that could most critically affect the site (see section 3.4.3.4). Consider possible landslides, antecedent reservoir levels, and river flows at the coincident flood peak (base flow). Determine the peak flow rate at the site for the worst possible dam failure, and summarize the analysis. that indicates that the condition is the worst permutation. Describe all coefficients and methods used as well.

\footnotetext{
* The Safe Shutdown Earthquake (SSE) represents the maximum possible level of earthquake ground shaking at the site. For this earthquake, the facility should be designed so that all systems necessary to protect the health and safety of the public will remain functional both during and after the event.
} 


\subsubsection{Unsteady Flow Analysis of Potential Dam Failures. When}

determining the effect of dam failures at the site (Section 3.4.4.2), the analytical methods presented must be applicable to artificially large floods with appropriately acceptable coefficients; they must also consider flood waves through reservoirs downstream of the failures. Consider domino-type failures due to flood waves when applicable. Discuss estimates of antecedent flow, and static and dynamic flood wave effects that are included analytically to attenuate the dam failure flood wave downstream.

\subsubsection{Water Level at. Facility Site. Describe the backwater,} unsteady flow, or other computations leading to the water elevation estimate (Section 3.4.4.2) for the most critical upstream dam failure, and discuss their reliability. In a manner similar to the method described in Section 3.4.3.6, superimpose wind wave conditions that may occur simultaneously.

\subsubsection{Probable Maximum Surge and Seiche Flooding}

\subsubsection{Probable Maximum Winds and Associated Meteorological}

parameters. The probable maximum wind is defined as a hypothetical hurricane or other cyclonic type of windstorm that might result from the most severe combinations of meteorological parameters that are considered reasonably possible in the region involved, with the hurricane or other type of windstorm moving along a critical path and at the most destructive rate. Determine probable maximum meteorological winds by detailed analyses of historical storm data in the region. Then modify and extrapolate the data to reflect a more severe meteorological wind than that actually recorded (insofar as such a wind is deemed "reasonably possible" of occurrence on the basis of meteorlogical reasoning). Present the results in detail.

The probable maximum conditions are the most severe combinations of hydrometeorological parameters (such as the meteorological characteristics in the probable maximum hurricane for the East and Gulf Coasts reported by 
NOAA in unpublished report HUR 7-97*, or the most severe combination of meteorological parameters of moving squall lines for the Great Lakes, and for other regions) considered reasonably possible that would produce a surge or seiche that has virtually no probability of being exceeded. This hypothetical event is postulated along a critical path at an optimal rate of movement from correlations of storm parameters on record. Provide sufficient bases and information to assure that the parameters presented constitute the most severe combination.

3.4.5.2 Surge and Seiche History. Discuss the proximity of the site to large bodies of water from which surge or seiche type flooding can reach safety-related facilities. The probable maximum water level (surges). for shore areas adjacent to large water bodies is the peak of the hypothetical surge or seiche stage hydrograph (still-water levels) and coincident wave effects. It is based on relatively comprehensive hydrometeorological analyses and the application of probable maximum meteorological criteria (such as hurricanes, moving squall lines, or other cyclonic windstorms), in conjunction with critical hydrological characteristics, and it is used to estimate the probable maximum water level at a specific location. The effects of the probable maximum meteorological.event are superimposed on the coincidental maximum annual. astronomical and ambient tide levels, and associated wave action to determine the effects of water levels and wave actions on structures. Describe the surge and/or seiche history in the site region.

3.4.5.3 Surge and Seiche Sources. Discuss considerations of hurricanes, frontal (cyclonic) type windstorms, moving squall lines, and surge mechanisms that are possible and that are applicable to the site. Include the antecedent water level (with reference to the spring tide for coastal locations, the average monthly recorded high water for lakes, and a

* This report, HUR 7-97, "Interim Report--Meteorological Characteristics of the Probable Maximum Hurricane, Atlantic and Gulf Coasts of the United States," is available upon request from the Hydrometeorological Branch, Office of Hydrology, NOAA, 8060 13th Street, Silver Spring, MD 20910. 
forerunner or ambient water level where applicable), the determination of the controlling storm surge or seiche (including such probable maximum meteorological parameters as storm tracks, wind fields, the fetch or directions of approach, bottom effects, with verification of the parameter with historical data), the method used, and the results of the computation of the probable maximum surge hydrograph graphically presented.

3.4.5.4 Wave Action. Discuss the wind-generated wave activity that can occur coincidentally with a surge or seiche, or independently thereof. Estimate the wave period, the significant wave height and elevations, and the maximum wave height and elevations, with the coincident water level hydrograph. Present specific data on the largest breaking wave height, set-up, and run-up that can reach each safety-related facility.

3.4.5.5 Resonance. Discuss the possibility of oscillations of waves at natural periodicity, such as, lake reflections and harbor resonance phenomena, and any resulting effects at the site.

3.4.5.6 Run-up. Estimate wave run-up on the facilities. Discuss the water levels on each affected facility and the protection to be provided against static effects, dynamic effects, and splash (refer to Sectlon 3.4 .3 .4 for breaking waves).

\subsubsection{Protective Structures. Discuss the location and design} criteria for special facilities designed to protect safety-related facllities against surges, seiches, wave reflection, and other wave action.

\subsubsection{Probable Maximum Tsunami Flooding}

l'or sites adjacent tó coustal areas, discuss historical tsunami, either recorded or translated and inferred, that provide information for use in determining the probable maximum water levels; also indicate the geoseismic generating mechanisms available for generating tsunami, with appropriate references to Section 3.6. 
3.4.6.1 Probable Maximum Tsunami. This event is defined as the most severe tsunami at the site that has virtually no probability of being exceeded. Consider the most reasonably severe geoseismic activity possible in determining the limiting tsunami-producing mechanism (such as fractures, faults; landslide potential, and volcanism). In the analysis, present such considerations as the orientation of the site relative to the earthquake epicenter or generating mechanism, the shape of the coastline, offshore land areas, hydrography, and the stability of the coastal area.

3.4.6.2 Historical Tsunami Record: Provide local and regional historical tsunami information.

3.4.6.3 Source Tsunami Wave Height. Estimate the maximum tsunami wave height possible at each major local generating source considered and the maximum offshore deepwater tsunami height from distant generators. Discuss the controlling genérators for both locally. and distantly generated tsunami.

3.4.6.4 Tsunami Height offshore. Estimate the tsunami height for each major generator in deep water adjacent to the site or before bottom effects appreci.ably alter wave configuration.

3.4.6.5 Hydrography and Harbor or Breakwater Influences on Tsunami. Present the routing of the controlling tsunami, including breaking wave formation, bore formation, and resonance effects (such as natural frequencies and successive wave effects) that enter the determination of the estimate of the maximum tsunami run-up on each pertinent safetyrelated facility. Discuss the analysis used to translate tsunami waves from offshore generator locations, or in deep water, to the site, including antecedent conditions. When possible, verify the techniques and coefficients used by reconstituting tsunami of record. 


\subsubsection{Ice Flooding}

Indicate design criteria established to protect safety-related facilities from the most severe ice jam flood, wind-driven ice ridges, or ice-produced forces from adjacent rivers, streams, lakes, and other bodies of water) that are reasonably possible and could affect safetyrelated facilities. Give the location of such facilities and their proximity to ice-generating mechanisms. Describe the regional ice and ice jam formation history.

\subsubsection{Water Canals and Reservoirs}

3.4.8.1 Canals. Tiesent the destgn bases for capacity and protection of canals against wind waves with acceptable freeboard, and (when applicable) the canals' ahillity ton withstand a PMF, surge, and ralatod occurrences.

3.4.8.2 Reservoirs. Provide the design bases for canal and reservoir capacity, the PMF design capability including wind wave protection, with verifled run-off models (unit hydrographs), flood routing, emergency spillway design, and outlet protection.

\subsubsection{Channe1 Diversions}

Discuss the potential for the upstream diversion or rerouting of such water sources as river cutoffs. ice jams, or suhsidenre, with respert to historical and topographical evidence in the region. Present the history of flow diversions in the region. Describe available alternative water sources if diversions occur.

\subsubsection{Flooding Protection Requirements}

Describe the static and dynamic consequences of all types of flooding on each pertinent safety-related facility. Present the design bases (refer to appropriate discussions in other sections of the SAR when implemented) required to ensure that safety-related facilities can survive all design 
flood conditions. In particular, describe the design bases for protecting the waste repository from surface water inflow when the facility is decommissioned. Describe separately the design bases unique to the surface facility and to the underground facility.

\subsubsection{Low Water Considerations}

\subsubsection{Low Flow in Rivers and Streams. If the water supply is} safety-related, estimate the probable minimum flow rate and level resulting from the most severe drought considered reasonably possible in the region. Examine scenarios of droughts of differing intensities and duration to determine the combined and cumulative influence on flow.

\subsubsection{Low Water Resulting from Surges, Seiches, or Tsunami.} Determine the surge-, seiche-, or tsunami-caused low-water level that could occur from probable maximum meteorological or geoseismic conditions. Describe the probable maximum meteorological event producing such conditions, its track, associated parameters, antecedent conditions, and the computed low-water level or tsunami conditions applicable. Also consider, when applicable, ice formation, or ice jams that cause low flow because such conditions may affect the water source.

3.4.11.3 Historical Low Water. Discuss historical low-water controls, minimum stream flows or minimum surges and elevations, and probabilities (unadjusted for historical controls and adjusted for historical and future controls and uses) only when statistical methods are used to extrapolate flows and/or levels to probable minimum conditions.

3.4.11.4 Future Control. If water is to be used for safety-related purposes, provide the estimated flow rate, durations, and levels for probable minimum flow conditions, considering future uses. Substantlate any provisions for flow augmentation available for the facility. Describe contingency plans to augment water supply if necessary to maintain safe operating conditions. 


\subsection{SUBSURFACE HYDROLOGY}

\subsubsection{Regional and Area Characteristics}

3.5.1.1. Regiona1 Characteristics. Describe hydrostratigraphic units, including vertical and horizontal porosity and hydraulic conductivity; identify all aquifers and aquicludes. Define groundwater recharge and discharge areas on a topographic map. Provide a water table map that incorporates the spring and marsh information generated for section 3.4.1.2. Assemble and tabulate existing groundwater quality information within a $80-\mathrm{km}$ radius.

3.5.1.2 Regional Flow System. Submit results of pump tests (including yield, specific capacity, drawdown, and recovery) and water quality analyeec conducted during the site selection process. Submit a piezometric head map of the major aquifers. Describe the groundwater flow systems (gradients) and interconnections between the hydrostratigraphic units. Map ground water quality variations in major cations, anions, and associated compounds of importance (such as radioisotopes or heavy metals).

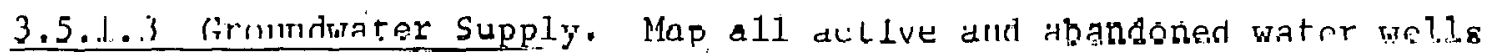
within a 40-km radius of the facility. Include depth, the geologic formations penetrated, casing type, casing size; well diametcr, perforations, and abandonment procedures (if applicable). Identify locations, demand, and the number of people using groundwater for their major potable watcr source. Describe any regulatory procedures that affert well drilling ni groundwater pumping in the region.

3.5.1.4 Data Sources. Provide sources for all data presented; identify the methods and frequencies of data collection when possible.

3.5.1.5 Groundwater-Surface Water Interactions. Describe the relationships apparent between the groundwater and surface water flow systems in the region. Show how pump tests affect surface water flow. 
Describe base flow variations. Indicate the water quality relationships between groundwater and surface water.

\subsubsection{Site Characteristics}

3.5.2.1 Groundwater Flow at Site. Provide data on groundwater levels, flow, permeability, porosity, flow, and gradients at the site, as well as chemical and radiochemical analysis of the groundwater. Also state the proposed sources and use anticipated by the facility. Provide a water table contour map that shows the location of monitoring wells used to detect possible radionuclide outleakage from the facility. Identify potential groundwater recharge areas within the boundary of the facility, and discuss the effects of construction, including dewatering, on such areas.

\subsubsection{Land Use Impacts. Use information presented in Section} 3.4.1.1 and Chapter 5 to evaluate potential alterations of the groundwater flow systems related to facility development. Develop a model of the waste repository, showing the rate of groundwater inflow, the change in gradients, water quality variations, and alterations in the overall groundwater flow system. Present the expected changes in the water table and near-surface aquifers related to the planned facility. Describe the mine shaft abandonment procedures, indicating how they minimize groundwater contamination. Include several case studies in model simulation that examine groundwater migration through the mine shaft into the waste repository. Examine several modes of migration, including migration through fractures, low-hydraulic conductivity material, high-hydraulic conductivity material, and slip faces along the shaft/sealant interfacc.

\subsubsection{Facility-Related Contaminant Transport Analysis}

Using the hydrological gradients and permeability, dispersion, dilution, ion exchange, and channeling characteristics at the site, develop a model that will allow evaluation of the extent to which contamination from facility operation could migrate in groundwater, including the time required to reach the nearest existing or potential future groundwater users. Contamination from long-term waste repositories is discussed in Chapter 8 . 


\subsubsection{Environmental Acceptance of Effluents}

Describe the ability of the surface water-groundwater environment to disperse, dilute, and/or concentrate normal and inadvertent or accidental liquid releases of radioactive effluents for the full range of anticipated operating conditions. Such releases may influence existing and/or potential future use of surface water or groundwater resources. Describe the safety-related effects of normal or accidental releases of radionuclides and heated water on surface water and groundwater (e.g., the potential for recirculation, sediment concentratinn, and the hydraulic short-circuiting of cooling ponds). Potentiat runtamination from longterm waste repositories is discussed in Chapter 8.

\subsection{GEOLOGY AND SEISMOLOGY}

Provide the geologic and seismic characteristics of the area and site; indicate how these investigations were performed and the conclusions reached; and identify information sources. Supplement the written description with tabular and graphic presentations as appropriate.

\subsubsection{Basic Geologic and Seismic Information}

Present the basic geologic and seismic information for the region and the site. Refer to information obtained from published reports, maps, private communications, or other sources. Adequately document information trom surveys, geophysical investigations, borings, trenches, or other investigations by descriptions of techniques, graphic logs, photographs, laboratory results, identification of principal investigators, and other data. Identify each area for which the data have been analyzed and selected for use in developing design criteria and bases, and accident analyses in subsequent chapters.

\subsubsection{Regional Gcology.}

1. Describe the regiona1. physiography, and discuss the relationship between the regional and the site physiography. Include a regional physiographic map showing the site location. 
2. Describe the regional geology, including geologic and tectonic maps of the region surrounding the site.

3. Discuss the regional geologic setting. Indicate the geologic province and its relation to other geologic provinces. Include regional geologic maps. indicating the site location, and showing both surface and bedrock geology.

4. Discuss the geologic history of the region.

5. Describe the lithologic, stratigraphic, and structural geologic conditions of the region surrounding the site, and relate these conditions to its geologic history. Provide geologic profiles showing the relationship of the regional and local geology to the site location.

6. Identify and describe such tectonic structures underlying the region surrounding the site as folds, faults, basins, and domes. Discuss the geologic history of the tectonic features. Include a regional tectonic map showing the site location. Discuss the regional tectonic structures of significance to the site in detail. Analyze faults in detail to determine their capacity for generating ground motions at the site and to determine the potential for surface faulting; refer to this information in Sections 3.6.2 and 3.6.3, respectively. Identify and describe areas of actual or potential surface or subsurface subsidence, uplift, or collapse resulting from: (1) natural features such as tectontc depressions, cavernous conditions or karst terrains, and potential landslides; (2) man's activities, such as withdrawal or addition of subsurface fluids, or mineral extraction; and (3) regional warping.

7. Discuss the regional groundwater conditions by cross-reference to Section. 3.5.

3.6.1.2 Site Geology--Surface. (Material pertaining to this section may also be included as appropriate in Section 3.6.4, Stability of Subsurface Materials, and cross-referenced in this section.)

1. Describe the site physiography, discussing the relationship between the regional and site physiography. Include a site topographic map that shows the locations of the principal facilities. Describe the. 
configuration of the land forms and relate the history of geologic changes that have occurred. Evaluate areas significant to the site for actual or potential landsliding, surface or subsurface subsidence, uplift, or collapse resulting from natural features such as tectonic depressions and cavernous or karst terrains.

2. Describe the lithologic, stratigraphic, and structural geologic conditions of the site, and relate them to geologic history and regional geology. Describe the thicknesses, physical characteristics, origin, and degree of consolidation of earh 7ithologic unit. Furnish summary lugs and borings and exravatinns such as trenchoo uocd in the gevlugic evaludtion.

3. Liscuce the otructural geology in Llie vllinliy of the site in detai1, with particular attention to structural units of significance to the site, such as folds, faults, synclines, antirlines; tnmes, and baoino. Provide a large-scale site structural geology map showing bedrock surface contours and include the locations of the facility structures.

4. Furnish a large-scale geologic map of the site area that shows surface geology and that indicates the locations of the facility's major structures. Distinguish areas of bedrock outcrop identified by direct observations from areas that are covered and that have been interpreted geologically by extrapolation. When the interpretation differs substantially from published geologic literature on the area, note the differences' and document the new conclusions presented.

5. Discuss the geologic history of the site and relate it to regional geologic history. Include a local geologic stratigraphic column.

6. Furnish a plot plan showing the locations of major facility structures, and the locations of all borings, trenches, and excavations; also include a description, logs, and maps of the borings, trenches, and excavations, as necessary, to indicate the results.

7. Provide geologic profiles showing the relationship of the major foundations of the waste repository to subsurface materials, including groundwater, and the signficant engineering.characteristics of subsurface materials. 
8. Provide plan and profile drawings showing the extent of excavations and backfill planned at the site, as well as the compaction criteria for all engineered backfill.

9. From an engineering geology standpoint, evaluate local geologic features that affect facility structures. Geologic conditions underlying al1 structures, dams, dikes, and pipelines should be described in detail.

From the lithologic, stratigraphic, and structural geologic studies, describe the physical evidence concerning the behavior during prior earthquakes of surficial geologic materials and substrata underlying the site. Identify and evaluate deformational zones, such as shears, joints, fractures, and folds, or combinations of these features in relation to structural foundations. Describe and evaluate zones of alteration or irregular weathering profiles, and zones of structural weakness composed of crushed or disturbed materials. Describe unrelieved residuals stresses in bedrock. Describe all rocks or soils that might be unstable because of their mineralogy, lack of consolidation, water content, or potentially undesirable response to seismic or other events. (Seismic response characteristics to be considered include iiquefaction, thixotropy, differential consolidation, cratering, and fissuring.) Evaluate the effects of man's activities, such as withdrawal or addition of subsurface fluids, or mineral extraction at the site.

10. Define site groundwater conditions and cross-reference them with Section $3 \cdot 6 \cdot 4 \cdot 6$.

11. Provide profiles and tables showing the results of any geophysical surveys.(e.g., seismic refraction, seismic reflection, acoustic, and aeromagnetic) conducted to evaluate the stratigraphic structure and bedrock, and subsurface material characteristics of the site. Provide the results of compressional and shear wave velocity surveys, and of cross hole and uphole velocity surveys if performed.

12. Furnish static and dynamic soil and rock properties of the site, including grain-size classification, Atterberg limits, water content, unit weight, shear strength, relative density, shear modulus, Poisson's ratio, bulk modulus, damping, consolidation characteristics, and strength under 
cyclic loading. Substantiate these properties with representative laboratory test records.

13. Detail the safety-related criteria, analysis techniques to be used, and safety factors for the materials underlying the foundations of all waste repository structures and for all embankments under dynamic shaking conditions combined with adverse hydrologic conditions.

3.6.1.3 Site Geology--Subsurface. When appropriate, repeat and cross-reference information provided in Section 3:6.1.2 (Site Geology-Surface) in this scction. 'lhis section is pilimdily cullentled whlh the implementation of the subsurface waste storage location until the site is decommissioned. Refer to Chapter 8 for criteria relating to the containment of the waste after the site is decommissioned.

1. Discuss the historiral stability of the geologic formation that will contain the waste material, as well as the formations above and below the disposal location. Determine whether the formations are currently undergoing deformation or movement; if so, indicate how this may affect operation until the facility is decommissioned. (For criteria concerning the containment of the waste after the facility is decommissioned, refer to Chapter 8.) Provide a map that shows the relationship of the proposed disposal location to the surrounding formations, with the major lithologic and structural units indicated..

2. Describe the 1ithologic, strategraphic, and structural geologic conditions of the formation(s) where the waste will be reposited. Describe the thicknesses, physical characteristics, and degree of consolidation of each lithologic unit. Furnish summary logs of borings used in the evaluation (refer to Section $3.6 .1 .2,2$ ).

3. Discuss the structural geology in the vicinity of the site, in detail, with particular attention to significant structural units of the disposal site, such as folds, faults, and synclines. Provide large-scale isopach maps of the formations involved with the structural features (e.g., faults) indicated (refer to Section 3.6.1.2, 3). 
4. Determine the presence or absence of pore fluids (liquids or gases) in formations affected by drilling, mining, and similar activities. Determine the composition of pore fluids, and the ability of pore fluids to migrate through the formation(s) involved and into the underground facility area. Determine the physical characteristics of the formations that may aid or retard fluid flow, such as the porosity and permeability of the lithologic units, presence or absence of fractures along which fluids may migrate, and formation pressures.

5. Describe the potential effect of the subsurface pore fluid (i.e., liquid or gas) pressures and migration on the disposal site, specifically in regard to the hazards such migration may present to personnel in the underground facility area or to personnel drilling into the formation(s).

6. Discuss the effect of pore fluids on waste containment. ${ }^{*}$ Consider the ability of pore fluids to degrade material containing the waste and to leach and transport the waste. In particular, (1) describe containerpore fluid and waste-pore fluid physical and chemical interactions; (2) determine the ways in which the waste containing materials may be degraded by interacting with available pore fluids; (3) determine possible pathways away from the disposal site that may become available to the waste once the integrity of the containment material has been breached; and (4) determine and evaluate procedures that may be used to prevent degradation of the waste containing materials and migiation of waste frull disposal site.

7. Determine the characteristics of subsurface disposal site, other than pore fluids, that may endanger personnel and/or interfere with proper waste containment. Consider temperature, overburden pressure, unrelieved stresses, and related factors. Evaluate the effects that each factor will have on the construction of the site and on the safety of the personnel. Also consider the effects these factors will have on waste containment, and determine and evaluate procedures necessary to mitigate these effects.

\footnotetext{
* Waste containment includes all barriers to the migration of radionuclide material into the immediate surroundings. This includes the metal rannister, which is not expected to last longer than a year in salt, and especially the physical-chemical form in which the waste material is bound. $3-29$
} 
8. Furnish a plan of the locations of all major structures of the subsurface workings, including borings. Describe each with logs, maps, locations of borings, and other materials necessary to document the plan.

9. Provide plan and profile maps showing the extent of the excavation and backfill planned at the site, as well as compaction criteria for all engineered backfill.

10. Include an engineering geology description of local features that will affect subsurface facility areas and the disposal site. Describe geologic conditions affecting underground facility areas in detail (refer to Section 3.6.1.9).

Describe physical evidence concerning the behavior of subsurface geologic materials and structures during earthquakes. Consider interactions of geologic materials and structures with subsurface facilities that llay occur during earthquakes. Also consider the effect of an earthquake on waste materials already emplaced in the disposal site.

Identify and describe deformation zones such as shears, joints, fractures, folds, or combinations of these features in relationo to subsurface facilities, backfilled areas, and disposal sites containing waste.

Describe zones of alteration and zones of structural weakness.

Describe unrelieved stresses in formation(s) affected by any mining or drilling operations during construction. Describe all geologic materials affected by mining or drilling that might be unstable because of their mineralogy, lack of consolidation, water content, or potentially undesirable response to seismic or other evente (e.g., conaider lidulelabbiun, thixotropy, differential considerations, or other characteristics that may adversely affect mining or drilling operations).

11. Define site suhsurface fluid flow conditions, with cruss reference to Sections 3.6 .4 .7 and $3.6 .1 .2,10$. 
12. Consider the effects of local seismic activity on subsurface fluid flow. Determine ways in which fluid flow may be altered by such activity.

13. Provide profiles and tables showing the results of geophysical surveys (e.g., seismic refraction, seismic reflection, acoustic, and aeromagnetic) conducted to evaluate the stratigraphic structure and bedrock, and subsurface material characteristics of the site. Provide results of compressional and shear wave velocity surveys with cross hole and uphole velocity surveys, when performed.

14. Furnish static and dynamic soil and rock properties of the site, including grain-size classification, Atterberg limits, water content, unit weight, shear strength, relative density, shear modulus, Poisson's ratio, bulk modulus, damping, consolidation characteristics, and strength under cyclic loading. These properties should be substantiated with representative laboratory test records.

15. Discuss the detailed safety-related criteria, analysis techniques to be used, and the factors of safety for the materials affected by all facility-related mining and drilling activities under dynamic conditions combined with adverse hydrologic conditions.

\subsubsection{Vibratory Ground Motion}

Describe how data were selected to determine the design basis for vibratory ground motion. Include the following specific information and determinations to clearly establish the design basis for vibratory ground motion. Information presented in other sections may be referred to and need not be repeated.

\subsubsection{Geologic Conditions of the Site. Describe the lithologic,} stratigraphic, and structural geologic conditions of the site and the region surrounding the site, including its geologic history.

\subsubsection{Underlying Tectonic Structures. Identify tectonic structures} underlying the site and the region surrounding the site. 


\subsubsection{Behavior During Prior Earthquakes. Describe physical}

evidence concerning the behavior during prior earthquakes of the surficial geologic materials and the substrata underlying the site from 1ithologic, stratigraphic, and structural geologic studies. Specifically consider the earthquake behavior of formations surrounding the site.

\subsubsection{Engineering Properties of Materials Underlying the Site.} Describe the static and dynamic engineering properties of the materials underlying the surface site and surrounding all subsurface workings. Include properties needed to determine the hehavior of the material during earthquakes and the characteristics of the material in transmitting earthquake-induced motions to the foundations of the surface facilities and to the subsurface workings, such as seismic wave velocities, density, water content, porosity, and strength.

\subsubsection{Earthquake History. List all historically reported earth-} quakes that affected or that could be reasonably expected to have affected the site. Include the date of occurrence and the following measured or estimated data: magnitude or highest intensity, and a plot of the epicenter or region of highest intensity. For the earthquakes of greatest magnitude or intensity, estimate the acceleration or intensity and duration of ground shaking at the locations of the foundations of the proposed surface facility or at the subsurface storage locations. Because earthquakes have been reported in terms of various parameters, such as magnitude, intensity at a given location, and effect on ground, structures, and people at a specific location, some of these data may have to be estimated by empirical relationships. When appropriate, consider the comparative characteristics of the material underlying the epicentral location or region of highest intensity and of the materin 1 at or near the site in regard to its ability to transmit earthquake vibratory motion. 
3.6.2.6 Correlation of Epicenters with Geologic Structures. When possible, correlate epicenters or regions of highest intensity of historically reported earthquakes with tectonic structures, any part of which is within $320 \mathrm{~km}$ of the site. Identify epicenters or regions of highest intensity (which cannot be reasonably correlated with tectonic structures) with tectonic provinces, ${ }^{*}$ any part of which is located within $320 \mathrm{~km}$ of the site.

\subsubsection{Identification of Active Faults. Determine whether faults,} any part of which is within $320 \mathrm{~km}$ of the site and that may be significant in establishing the design criteria for earthquake protection, should be considered as capable faults. ${ }^{\dagger}$

3.6.2.8 Description of Capable Faults. Determine the length of faults, any part of which is within $320 \mathrm{~km}$ of the site, that may be significant in establishing the earthquake criteria and that are considered as capable faults. Determine the relationship of the fault to regional tectonic structures, and the nature, amount, and geologic history of the maximum Quaternary displacement related to earthquakes along the fault.

*

A tectonic province is defined as a region whose geological structural features are relatively consistent. The boundaries of such a province are determined by regional analysis of the geologic and tectonic environments, and by the seismic history of the area.

${ }^{\dagger}$ A fault is a tectonic structure along which differential slippage of adjacent earth materials has occurred parallel to the fracture plane. The NRC's criteria indicate that a fault can be considered "capable" of permanent surface displacement during the useful lifetime of a facility if it is characterized by one or more of the following features:

- Movement at or near the ground surface at least once during the past 35,000 years or more than once in the past 500,000 years.

- Instrumentally determined microseismicity directly related to the fault.

- A relationship to an active fault such that movement on the one fault could be reasonably expected to be accompanied by movement on the other. 
3.6.2.9 Maximum Earthquake. Determine the historic earthquakes of greatest magnitude or intensity that have been correlated with tectonic structures. For capable faults, determine the earthquake of greatest magnitude related to the faults by taking into account geologic evidence. Assuming the epicenters of the earthquakes are situated at the point on the tectonic structures closest to the site, determine the vibratory ground motion at the site (both at the ground surface and in the subsurface).

When epicenters or regions of highest intensity of historically reported earthquakes cannot be related to tectonic structures but are identified with tectonic provinces in which the site is located, determine the accelerations at the site, assuming that these earthquakes occur adjacent to the site.

When epicenters or regions of highest intensity of historically reported earthquakes cannot be related to tectonic structures but are identified with tectonic provinces in which the site is located, determine the accelerations at the site, assuming that the epicenters or regions of highest intensity of these earthquakes are located at the closest point to the site on the boundary of the tectonic province.

3.6.2.10 Safe Shutdown Earthquake (SSE). ${ }^{*}$ Designate the earthquake producing the maximum possible vibratory accelerations at the site as the SSE for vibratory ground motion. The SSE should be defined by response spectra corresponding to the maximum possible vibratory accelerations.

* The Safe Shutdown Earthquake (SSE) represents the maximum possible level of earthquake ground shaking at the site. For this earthquake, the facility should be designed so that all systems necessary to protect the health and safety of the public will remain functional both during and after the event. 
3.6.2.11 Operating Basis Earthquake (OBE). ${ }^{*}$ Define the OBE selected by the application by response spectra.

\subsubsection{Surface Faulting}

Present information that describes whether or not the facilities need be designed for surface faulting, and if so, to what extent. Include the following information and determinations to the extent necessary to clearly establish the design basis for surface faulting. Information presented in Section 3.6.1 may be referred to and need not be repeated.

3.6.3.1 Geologic Conditions of the Site. Describe the 1ithologic; stratigraphic, and structural geologic conditions of the site, and the area surrounding the site, including its geologic history.

3.6.3.2 Evidence of Fault offset. Determine the geologic evidence of fault offset at or near the ground surface at or near the site.

3.6.3.3 Identification of Capable Faults. Determine whether faults longer than $300 \mathrm{~m}$, any part of which is within $8 \mathrm{~km}$ of the site, should be considered as capable faults.

\subsubsection{Earthguakes Assoclaeed W1ch Capable Faulcs. L1s al1}

historically reported earthquakes that can be reasonably associated with capable faults longer than $300 \mathrm{~m}$, any part of which is within $8 \mathrm{~km}$ of the site; include the date of occurrence and the following measured or estimated data: magnitude or highest intensity and a plot of the epicenter or region of highest intensity.

\footnotetext{
* The Operating Basis Earthquakes (OBE) represents the maximum level of ground shaking that can be expected to occur at the site during the operating life of the facility. This earthquake probably has occurred in the vicinity during historic times. For this earthquake, the facility should be designed so that features necessary for continued operation without undue risk will remain functional.
} 


\subsubsection{Correlation of Epicenters With Capable Faults. Correlate}

epicenters or regions of highest intensity of historically reported earthquakes with capable faults longer than $300 \mathrm{~m}$, any part of which is located within $8 \mathrm{~km}$ of the site.

\subsubsection{Description of Capable Faults. For capable faults longer} than $300 \mathrm{~m}$, any part of which is within $8 \mathrm{~km}$ of the site, determine: the length of the fault; the relationship of the fault to regional tectonic structures; the nature, amount, and geologic history of displacements along the fault; and the outer limits of the fault established by mapping fault traces for $15 \mathrm{~km}$ along its trend in both directions from the point or its nearest approach to the site.

\subsubsection{Zone Requiring Detailed Faulting Investigation. Determine} the zone that requires detailed fallting investigation.

\subsubsection{Results of Faulting Investigation. When the site is within} a zone that requires detailed faulting investigation, present the details and results of th1s Investigation to determine the need to take surface faulting into account in the design of the facility. When it is determined that surface faulting need not be taken into account, present sufficient data to justify the determination clearly.

\subsubsection{Stability of Subsurface Materials}

Present information concerning the stablity of soils and rock underneath the facility foundations and the materials surrounding the disposal lucation during the vibratory motion associated with earthquake design criteria. Evaluate the following geologic features that coml affert the foundations of the surface site or affert. the suhsurfare workinge. Information presented in other sections may be referred to and need not be repeated. 
3.6.4.1 Geologic Features. Describe the following geologic features:

1. Areas of actual or potential surface or subsurface subsidence, uplift, or collapse resulting from: natural features such as tectonic depressions and cavernous or karst terrains, particularly those underlain by calcareous or other soluble deposits; man's activities, such as withdrawal or addition of subsurface fluids, or mineral extraction; and regional warping.

2. Deformational zones, such as shears, joints, fractures, and folds or combinations of these features.

3. Zones of alteration or irregular weathering profiles, and zones of structural weakness composed of crushed or disturbed materials.

4. In situ. stress fields in bedrock.

5. Rocks or soils that might be unstable because of their mineralogy, lack of consolidation, water content, or potentially undesirable response to seismic or other events. (Seismic response characteristics to be considered include liquefaction, thixotropy, differential consolidation, cratering, and fissuring.)

3.6.4.2 Properties of Underlying Materials. Describe in detail the static and dynamic engineering properties of the materials underlying the site. Furnish the physical properties of foundation materials, such as grain-size classification, consolidation characteristics, water content, Atterberg 1imits, unit weight, shear strength, relative density, shear modulus, damping, Poisson's ratio, bulk modulus, strength under cyclic loading, seismic wave velocities, density, porosity, and strength characteristics. Substantiate these data with representative laboratory test records.

3.6.4.3 Subsurface Fluids. Indicate the presence or absence of pore fluids, their composition and migration patterns. Determine how the patterns of fluid flow may be disturbed by the surface site facilities and underground workings, including boreholes. 
3.6.4.4 Plot Plan. Provide a plot plan or plans showing the locations of all borings, trenches, seismic lines, piezometers, geologic profiles, and excavations, and superimpose the locations of all site structures or workings on the plan. Furnish profiles showing the relationship of the foundations of structures and workings to subsurface materials, including groundwater and significant engineering characteristics of the subsurface materials.

\subsubsection{Soil and Rock Characteristics. Indicate the results with} tables and profiles of compressional and shear wave velocity surveys performed to evaluate the characteristics of the foundation soils and rocks, and of the materials surrounding subsurface workings. Provide graphic core boring logs and the logs of trenches or other excavations.

3.6.4.6 Excavations and Backfill. Furnish plan and profile drawings showing the extent of excavations and backfill planned at the site, as well as compaction criteria for all engineered backfill. Substantiate the criteria with representative laboratory or field test records. (When pussible, those plans and profiles may bc combined with profiles in Sections 3.6 .4 .3 or 3.6 .4 .4$. )

\subsubsection{Grnundwater Conditione. Provide a history of groundwater} fluctuations of the site, and discuss groundwater conditions during construction of the site and operation of the facility (FSAR).

\subsubsection{Response of Soil and Rock to Dynamic Loading. Furnish} analyses of the responses of soil and rock to dynamic loading. Dcscribe the subsurface bedrock motions used as input to soil response analysis.

\subsubsection{Liquefaction Potential. Discuss the liquefaction potential} of material at the site. Either demonstrate that no liquefactionsusceptible soils exist at the site, or provide the following information regarding soil zones where the possibility for liquefaction exists: relative density, void ratio, ratio of shear stress to initial 
effective stress, number of load cycles, grain-size distribution, degrees of cementation and cohesion, and groundwater elevation fluctuations.

3.6.4.10 Earthquake Design Basis. Provide the earthquake design basis on which these analyses are based.

3.6.4.11 Static Analyses. Discuss the static analyses, such as settlement analyses (with representative laboratory data), lateral pressures (with backup data), and related factors.

3.6.4.12 Criteria and Design Methods. Briefly discuss the criteria, references, or methods of design employed (or to be employed), and factors of safety (documented by test data).

\subsubsection{Slope Stability}

Present information and substantiation concerning the stability of natural and manmade cut-and-fill slopes whose failure could adversely affect the site.

3.6.5.1 Slope Characteristics. Provide cross sections of the slopes; summarize the static and dynamic properties of embankment and foundation soil and rock underlying the slope; and substantiate them with representative laboratory test data.

3.6.5.2 Design Criteria and Analyses. Describe the design criteria and analyses used to determine slope stability; include factors of safety, along with the adverse conditions considered in the analyses such as sudden drawdown, earthquake, and steady seepage at anticipated pool levels.

3.6.5.3 Logs of Core Borings. Furnish logs of core borings or test pits taken in proposed borrow areas.

3.6.5.4 Compaction Specifications. Provide compaction specifications, along with representative laboratory data on which they are based. 


\subsection{NONHUMAN BIOLOGY}

\subsubsection{Major Landscape Units}

Define the major ecosystems subject to impact either by normal uperation of the facility or by accidental release of radionuclides; indicate their size and distribution, both within the project area and in the general area; characterize their current biological productivity, their successional status, and their potential productivity if managed either for economic yields or for maximum productivity of wildlife. Prnjert the estimates of biological productivity to account for the variations that might be expected over the operational life of the farility. Include the variations to be expected in response to natural variations, such as droughts or floods.

\subsubsection{Exceptiona1 or Unique Landscape Units}

Provide the same detail as required in Section 3.7.1.

\subsubsection{Baseline Sites}

Identify sites suitable for monitoring the biological effects of accidents or normal operation, and characterize them in sufficient detail, by aerial and ground photos and narrative, to allow these characterizations to be used as part of subsequent monitoring programs. The major plant, animal, and microbial taxa should be characterized with respect to their utility in monitoring programs, with reasons given for their inclusion or exclusion from such programs. The characterizations should be sufficiently detailed with respect to species life histories and their roles in the functioning of the ecosystems within which they oscur for a nnnspecialist to follow the rationale of the arguments presented regarding potential impacts and the design of monitoring programs. Maps, diagrams, and the like should be used as necessary to depict the functioning of the biological systems subject to impact. 


\subsubsection{Monitoring Program}

Describe a potential monitoring program in sufficient detail to allow such a program to begin before construction starts or at the same time. In the plan for a monitoring program, identify the sensitive properties of the ecosystems, and the radiosensitive species to be monitored; also explain the rationale for their selection. Outline the sampling methods and the statistical analyses to be used in the plan.

\subsection{SUMMARY OF CONDITIONS AFFECTING FACILITY CONSTRUCTION} AND OPERATING REQUIREMENTS

Summarize all factors developed in this chapter that are deemed significant for the selection of design bases for the surface site. facilities and underground workings. In particular, describe those criteria that pertain to the containment of the waste material. 
Chapter 4

PRINCIPAL DESIGN CRITERIA

The contents of this chapter partially describe the information required by $10 \mathrm{CFR}$ Parts 50 and 100. These regulations relate to waste isolation facilities only by inference. It is anticipated that they will be superseded by new regulations speciffcally addressing waste isolation facilities as $10 \mathrm{CFR}$ 60. However, in the meantime $10 \mathrm{CFR} 50$ and 100 form a basis for determining general regulatory requirements that can be inferred for waste isolation facilities. Principal design criteria are established by the applicant in the PSAR, and they should conform with the general criteria defined in applicable sections and appendices of 10 CFR Parts 50 and 100. Other criteria as may be proposed and/or set forth from time to time in 10 CFR Parts, Sections, and Appendices should be established in the respective chapters discussing them. When necessary, other sources of detailed design criteria, such as those from applicable governmental agencies, and from codes and standards groups, shall be referenced.

The waste isolation facility's design criteria will be analyzed to determine their adequacy before construction is authorized. Because it is not anticipated that the criteria will be changed, the applicant should include all considerations for alternatives required to fulfill the criteria.

\subsection{PURPOSE OF FACILITY}

In general lerms describc the facility, its functions and operation, throughput and storage capacity, type of waste products handled, and manner of burial. 


\subsubsection{Waste Characterization}

Describe in detail the physical, chemical, and radiological characteristics of the wasles to be handled and reposited in the facility, including such waste specifications as fissile material limits, forms of the material, and packaging. The radioactivity characteristics should include irradiation history, processing history, minimum cooling time at recelpt, handling times to burial, and fission product and transuranic concentrations, as well as heat generation, temperatures and heat transfer characteristics of the waste packages.

\subsubsection{Waste Isolation Description}

Describe in detail the method(s) nf wasto icolation, iniludiug buth retrievable and nonretrievable burial, mine shaft; tunnel and burial room specifications, thermal loads as a function of operation and isolatinn time, and the type of waste. Show the expected temperature profiles from the centerline of the waste package through geologic formations to the surface as a function of time.

\subsubsection{Facility Functions}

Provide information related to the overall functioning of the facility as a waste isolation uperatton. inciluting nneite wacto recciving, wanl. ب unloadiny, Inspection, and holding areas, transportation and burial, utility and water supplies, and disposal of site-originated waste of all types.

\subsection{STRUCTURAL AND MECHANTSAT, SAFETY GEITERIA}

Based on the site selected, identify and quantify the environmental and geologic features used as design critcria.

\subsubsection{Wind Loadings}

Provide information on wind velocity, including lhe vertical wind velocity and gust factor, and a determination of the following applied forces used for structural design: 
4.2.1.1 Design Wind Velocity. Present the design wind velocity and i.ts recurrence interval.

4.2.1.2 Basis for Wind Velocity Selection. Discuss the basis for selecting wind velocity; include wind histories and supporting data.

\subsubsection{Vertical Velocity Distribution and Gust Factor. Specify} the vertical velocity distribution and the gust factor employed for the selected design wind velocity.

4.2.1.4 Determination of Applied Forces. Describe the procedure used to translate the wind velocity into applied forces on the structures, including the wind force distribution and drag coefficients applied. Specify the applied force magnitude and distribution calculated for each structure.

\subsubsection{Tornado Loadings}

Provide the design parameters, such as translational and rotational velocity, pressure differential, and associated time interval, together with the methods used to translate these data into forces exerted on facility structures.

4.2.2.1 Applicable Design Parameters. Specify the design parameters applicable to the design tornado, such as translational velocity, rotational velocity, and the design pressure differential and its associated time interval.

4.2.2.2 Determination of Forces on Structures. Describe the methods used to convert the tornado loadings into forces on the structures including the distribution across the structures and the combination of applied loads. If factor loads arc ueed, indicate the basis for selecting the load factor used for tornado loading.

\subsubsection{Influence of Structures not Designed for Tornado Loads.} Present information to show that the failure of structures not designed for tornado loads wi.1.1 not affect the ability of other structures or systems to perform their intended design functions. 


\subsubsection{Water Leve1 (Surface Flood) Design}

As applicable, discuss dcsign load from forces developed by the PMF, including water height and dynamic phenomena such as velocity. Relate by reference the design criteria developed in Section 3.4 , Surface Hydrology.

\subsubsection{Flood Elevations. Indicate the flood elevations used} in the design of each structure in relation to buoyancy and static water force effects.

\subsubsection{Phenomena Considered in Design Load Calculations. Irentify} dul dlscuss the phenomena, such as flood current, wind wave, hurricane, or tsunam1, considered if dynamic water force is a design load for any st.rustire

4.2.3.3'Flood Force Application: Describe how the forces and other effects resulting from flood loadings are applied.

\subsubsection{Flood Protection. Describe the flood protection measures} for vital systems and components that are below grade or below flood 1 cvel.

\subsubsection{Groundwater Design Considerations}

Describe the design and load upon lined and unlined shafts, tunnels, rooms, and seals from forces developed by the maximum probable groundwater hỹdrostatic loadings; include such dynamic phenomena as gradient of groundwater flow.

4,2.4.1. Froundwater Force. Mrscibie luw Lhe furces and ollier effects resulting from groundwater are accounted for in the design.

4.2.4.2 Groundwater Protection. Show how vital systems and components below grade are protected from groundwater. 


\subsubsection{Blasting Shock Protection. Describe the measures that are} taken to ensure that shock waves from mining excavation during operation do not produce cracks in formations that might lead to subsequent water infiltration.

\subsubsection{Humidity Ventilation Criteria}

Identify expected diurnal extremes of external temperature and the associated humidity. Discuss the effect of the moisture loads on ventilation requirements below ground and on ventilation system performance.

\subsubsection{Humidity Protection. Describe measures taken to protect} vital below ground systems and components from excessive humidity. Describe the potential rock-water interactions that could result from humidity and the measures taken to minimize such effects.

\subsubsection{Mined Material}

Describe the transport of mined material to the surface from underground, and indicate the method of surface storage and protection. Indicate map elevations, wind erosion, water runoff, dissolved salts, and potential siltation to water bodies. Describe the use of this material in backfill and planned disposal of excess material.

\subsubsection{Missile Protection}

Describe the design criteria with respect to internal and external missile protection, providing detail on the assumed missile velocity and forces involved.

4.2.7.1 Missile Barriers and Loadings. Indicate the structures, shields and barriers that will be designed to withstand missile effects.

4.2.7.2 Missile Selection. Discuss the postulated missiles that have been used in designing each structure and the basis for their selection. For each missile selected, specify its origin, weight, and dimensions, its impact velocity and urientation, its material compnsition, and any other

$$
\text { 4-5 }
$$


parameters required to determine missile penetration.

\subsubsection{Seismic Design}

From data developed in Chapter 3 and defined in applicable sections and appendices of $10 \mathrm{CFR} 100$, present the seismic design criteria to be used in the construction of the facility and associated cquipment. Present sufficient detail to allow independent evaluation of the criteria selected. For clarity, refer to appropriate information presented in Section 3.6, Geology and Seismology.

4.2.8.1 Input Criteria. Discuss the input criteria for scismic design of the facility, including the following specifir information:

1. Design Response Spectra--Provide design response spcctra for the SSE. If applicable, also stibmit design response spectra fur the OBE. Discuss the effects of the following parameters: (a) earthquake duration; (b) earthquake distance and depths between the seismic disturbances and the site; and (c) existing earthquake records and the associated amplification response range where the amplificalion factor is greater than 1.

2. Design Response Spectra Derivation--Derive, the dcaign respunse spectra from the actual or synthetic earthquake time motion records. For the damping values used in the design, compare the response spectra derived from the time.history and the design response spectra. Identify the system period intervals at which the spectra values were ralculatod.

3. Critical Damping Values--Provide the specific percentage of critical damping values used for Category 1 structures, systems, componente, and soil (e.g., damping values for the type of construction or fabrlcarion, such as prestressed concrete and welded pipe, as well as the applicable allowable design stress levels for these facility features).

4. Bases for Site-Dependent, Analysis--Indicate the bases for a site-dependent analysis, if used to develop the shape of the design response spectra from bedrock time history or response spectra input. Specifical1y 
provide the bases for use of in situ soil measurements, soil layer location, and bedrock earthquake records. If the analytical approach used to determine the shape of the design response spectra neglects vertical amplification and possible slanted soil layers, discuss these assumptions as well as the effect of possible predominant thin soil layers on the analytical results.

5. Soil-Supported Structures--List all soil-supported structures; include the depth of soil over bedrock for each structure listed.

6. Soil-Structure Interaction--Describe the soil-structure interaction techniques used in the analyses of the structures, shafts, tunnels, mines, and vaults. Use nonlinear or equivalent linear finite element technique as the analytical tool for soil-structure interaction analysis for all structures whose foundations are deeply embedded in soil. For shallowly embedded structures on deep uniform soil strata, the soil spring model, based on the elastic half-space theory, is adequate. For shallowly embedded structures with shallow soil overburden over rock or layered soil with varying soil properties, use the finite element approach or multiple shear beam spring approach.

4.2.8.2 Seismic System Analysis. In this section, discuss the seismic system analyses applicable to structures, systems, and components. Include the following information:

1. Selsmic Analysis Methods--For all otructures, systems, and components above and below ground identified in Section 4.2, including any items to be designed for an OBE, identify (in the PSAR) the applicable methods of seismic analysis (modal analysis response spectra, modal analysis time history, equivalent static load, and the like). Specify applicable stress or deformation criteria and descriptions of typical mathellitical models used to detcrmine the response. If empirical methods (tests) are used in lieu of analysis, indicate the testing procedure, load-levels, and acceptable bases for structures, systems, components, shafts, tunnels, mines, rooms, and equipment (FSAR). Deecribe all seismir methods of analyses used (FSAR). 
2. Natural Frequencies and Response Loads (FSAR)--Summarize natural frequencies and response loads (e.g., in the form of critical mode shapes and modal responses) determined by the seismic system analysis. In addition, specify the response spectra at critical facility equipment elevations and points of support.

3. Procedures Used to Lump Masses (FSAR)--Describe the procedure used to lump masses for the seismic system analyses (the ratio of system mass and compliance to component mass and compliance, and the ratio of floor mass and compliance to supported equipment mass and compliancc):

4. Rocking and Translational Response. Summary (FSAR)--If a fixed base in the mathematical models for the dynamic system analyses is assumed, summarize the rocking and translational rcsponses. Briefly describe the method, mathematical model, and damping values (rocking vertical, translation, and torsion) that have been used to consider the. soil-structure interaction.

5. Methods Used to Couple Soil with Seismic System Structures-Describe the methods and procedures used to analytically couple the soil with the seismic system structures and compunenls if a finite element analysis for the layered site is used.

6. Development of Floor Response Spectra--If a modal response spectra multimass method of analysis is used to devclop floor response spectra, d1scuss the conservatism of this method. In the discussion, address the method's equivalency to a multimass time history method, or identify other equivalent theoretical or experimental methods.

7. Differential Seismic Movement of Interconnected Components-Provide the stress and deformation criteria that will be used to consider the differential seismic movement of interconnected compnnents betwcen floors and between mine elevations. 
8. Effects of Variations on Floor Response Spectra--In the analysis of the effects on floor response spectra (e.g., peak width and period coordinates), describe expected variations of structural properties, dampings, soil properties, and soil-structure interactions.

9. Use of Constant Vertical Load Factors--Identify the use of constant vertical load factors as vertical response loads for the seismic design of all structures, systems, and components in lieu of the use of a vertical seismic-system multimass dynamic analysis method.

10. Method Used to Account for Torsional Effects--Describe the method employed to consider the torsional modes of vibration in the seismic analysis of the structures. Consider both surface and below ground facilities, especially mine shafts and tunnels that have a long dimension on one axis. Indicate the use of static factors to account for torsional accelerations in the seismic design structures, or in lieu of the use of a combined vertical, horizontal, and torsional multimass system dynamic analysis.

11. Comparison of Responses (FSAR)--When applicable, submit the responses obtained from both modal analysis response spectrum and t1me history methods at selected points in the facility structure.

12. Methods for Seismic Analysis of Dams--Describe the analytical methods and procedures used for the seismic system analysis of dams that impound bodies of water and linings that may dam water, if applicable and safety-related. 
13. Methods to Determine Structure Overturning Moments--Describe the dynamic methods and procedures used to determine structure overturning moments, including a description of the procedures used to account for soil reactions and vertical earthquake effects.

14. Analysis Procedure for Damping--Describe the analytical procedure followed to account for the damping in different elements of the model of a coupled system; include the criteria used to account for composite damping in a coupled system with different clcments.

4.2.y.3 Seismic Subsystem Analysis--Discuss the seismic subsystem analysis, including the following sperifir information:

1. Determination of Number of Earthquake Cycles--Describe procedures that are used to determine the number of earthquake cycles during one seismic event. Specify the number of maximum amplitude loading cycles for which structures, systems, and components aboveground and belowground are designed.

2. Basis for Selection of Forcing Frequencies--Provide the basis for the selection of forcing frequencies to preclude resonance (i.e., Lle edrthquake specitied for the site, and the structure and component response characteristics produce forcing frequencies that are removed from the natural frequencies).

3. Koot Mean Square Basis--Define the term "root-mean-square hasis," mathematically, if it is used in describing the procedure for the combination of modal responses.

4. Procedure for Combining Modal Responses--Describe the procedure for combining modal responses (shears, moments, stresses, deflection, and/or accelerations) if a response spectrum modal analyais method ic used and normal frequencies are closely spaced. 
5. Significant Dynamic Response Modes--Discuss the inclusion of all significant dynamic modes of response under seismic excitation if static loads equivalent to the peak of the floor spectrum curve are used for the seismic design of components, structures, and equipment, both aboveground and belowground.

6. Design Criteria and Analytical Procedures for Piping--Provide the design criteria and describe the analytical procedures applicable to piping that account for the relative displacements between piping and support points (i.e., floors and components) at different elevations within a building and between buildings and below ground.

7. Basis for Computing Combined Response--Submit the basis for the methods used to determine the possible combined (two-component) horizontal and vertical amplified response loading for the seismic design of piping and equipment, including the effect of the seismic response of the supports, equipment, structures, and components.

8. Amplified Seismic Responses--If a constant load factor is used as the vertical floor response load for the seismic design of structures, components, and equipment, discuss the following considerations: (a) The possible comblned (two-component) horizontal and vertical amplified input loading incorporated in the seismic design of equipment and components due to the amplified response of the structures and floors; and (b) the possible combined (two-component) horizontal and vertical amplified input loading incorporated in the seismic design of piping and equipment due to the amplified response of structures, floors, supports, and components.

9. Use of Simplified Dynamic Analysis--If a simplified (e.g., other than a multimass mudal analysis) dynamic analysts is used for critical piping and ducts, indicate the magnitude by which the resonant periods of a selected span are removed from the predominant supporting building and component periods (FSAR). Summarize typical results, comparing the simplifled dynamic methods with response spectra modal analysis methods 
(FSAR). Provide the basis for simplified (e.g., other than a multimass modal analysis) dynamic analysis methods and procedures that will be used for seismic design of structures, systems, and components. In addition, indicate the criteria that will be used to avoid the predominant input frequencics produced by the response of structures, supports, and components to the earthquake input.

10. Modal Period Variation--Specify the procedures used to account for modal period variation due to variations in material properties in the mathematical models for facility structures above and below ground.

11. Torsional Effects of Eccentric Masses--Indicate the criteria that will be employed to account for the torsional effects of eccentric masses (e.g. valve operators) in the seismic piping and duct analyses.

12. Piping Outside Structures-With ropect to pipiny and ducts designed to withstand the earthquake and buried or otherwise located outside structures, describe the seismic design criteria and methods employed to ascertain that allowable piping and structural stresses are not exceeded because of differential movement at support points, at penetrations, and entry points into structures. Describe the interface between mine and surface building piping and ducts.

13. Interaction of Other Piping With Earthquake-Designed Piping-Describe the design criteria established to account for the seismic motion of piping and duct systems that are not earthquake-designed but that may interface with those that are.

14. Field Location of Supports and Restrainto (F\&AR) -Trovide Lhe criteria employed to determine the field location of seismic supports and restraints for earthquake-designed piping and ducts, piping and duct system components, and equipment, including placement of snubbers and dampers. Describe the procedures followed to ensure that the field location and the seismic design of these supports and restraining devices are consistent with the assumptions made in the dynamic seismic analysis. 
15. Seismic Analysis of Overhead Cranes--Describe the provisions taken to ensure that all overhead cranes in the buildings and belowground will not be dislodged from their rails in the event of seismic excitation.

16. Seismic Analysis of Specific Safety Features--Discuss the integrity of specific safety-related design features in the event of an earthquake.

\subsubsection{Snow Lodings}

Describe design load criteria used to ensure that a maximum snow load can be accommodated.

\subsubsection{Operating Equipment and Materials-Derived Loads.}

For structural purposes, establish the load criteria required to accommodate the contribution of equipment and the materials contained therein. For each system, list the facility conditions and design loading combinations (e.g., normal service or operating loads, and seismic loads) that provide the bases for design of components (or systems). Categorize the combination of design loadings (as applicable) with respect to facility conditions identified as "normal," "upset," "emergency," or. "Iaulled." Specify tho derign stress 1 imits and deformation criteria associated with each of these conditions.

\subsubsection{Combined Load Criteria}

Describe the criteria selected for combined loads to provide mechanical and structural integrity aboveground and belowground. Define the loads and loading combinations to which the facility is subjected, including the load factors selected for each load component when a. factored load approach is used. Specify the design approach used with the loading combination and any load factors. Describe loads acting on the structures, such as dead loads, live loads, and earth pressure loads, as well as the design basis accident loads, loads resulting from 
natural phenomena such as earthquakes, floods, tornadoes, hurricanes, humidity, and missile effects unique to the site. Provide the design loading combinations used to examine the effects on localized areas such as penetrations, structural discontinuities, prestressing tendon anchor zones, crane girder brackets, and local areas of high-thermal gradients, together with time-dependent loading such as the thermal effects, effects of creep and shrinkage, and other related effects.

Explain the use of an ultimate strength approach if used with a load factor of 1.0 .

\subsubsection{Subsurface Hydrostatic Loadings}

Describe the design bases for groundwater-induced hydrostatir. load= ings on subsurface portions of the safety-related structures, systems, shafts, tunnels, mines, rooms, and components. Discuss the development of these design bases. When dewatering during construction is critical to the integrity of safety-related structures, describe the bases for subsurface hydrostatic loadings assumed during construction and the dewatering methods to be employed in achieving these loadings. When wells are proposed for safety-related purpnses, disruss the hydrodynamic deoign bases for protection against seismically induced pressure waves. These design bases should be consistent with the groundwater conditions described in Section 3.6.4.7.

\subsection{SAFETY PROTECTION SYSTEMS}

\subsubsection{General}

Identify items requiring special consideration in design because of site selection, waste-handling selection, and decommission isolation requirements.

\subsubsection{Protection by Multiple Confinement Barriers and Systems}

4.3.2.1 Confinement Barriers and Systems. Discuss each method of confinement that will be used to ensure no uncontrolled release of radioactivity to the environment takes place. Include for each: 
1. Criteria for protection against postulated internal accidents or external natural phenomena;

2. Design criteria selected for piping and ducts, effluent systems, and backup confinement;

3. Delineation for each case of the extent to which the design is based on achieving the lowest practical level of releases from the operation of the facility.

When the limits selected are consistent with proven practice, a referenced statement to that effect will suffice; when the limits exceed present practice, provide an evaluation and an explanation, based on developmental work and/or analysis. These criteria may be expressed as explicit numbers or as general conditions.

\subsubsection{Ventilation. Describe the criteria selected for providing:} suitable ventilation by showing capacity standards for normal and abnormal conditions, zone interface flow velocity and differential pressure standards, the flow pattern and assured continuity of operation under accident conditions, and special control instrumentation.

Establish the criteria for the design of the ventilation systems, including ( 1 ) air flow patterns and velocity with respect to contamination control, (2) minimum negative pressures at key points in the system to maintain proper flow control, (3) interaction of multiple ventilation systems, (4) minimum filter performance with respect to particulate removal efficiency and maximum pressure drop, (5) minimum performance of other radioactivity removal equipment, (6) minimum performance of dampers and instrumented controls, and (7)" ensured continuity of operation under a 11 r.redible operating conditions.

\subsubsection{Protection by Equipment and Instrumentation Selection}

\subsubsection{Equipment. Itemize design criteria for key equipment} items that have been specifically selected to provide protection. 
4.3.3.2 Instrumentation. Similarly, discuss the design criteria for the instrumentation selected, with particular emphasis on features that enable testing the instrumentation, and allow contingency for safety purposes.

\subsubsection{Nuclear Criticality Safety}

Provide the criteria required to indicate that the safety margins chosen ensure that a subcritical situation exists at all times.

4.3.4.1 Control Methods for Prevention of Criticality. Present the methods to be used to ensure subcritical situations during uperation and storage, and under the worst credible conditions.

4.3.4.2 Error Contingency Criteria. To support the information in 4.3.4 and 4.3.4.1, define the error contingency criteria selected for the facility. This is the margin of safety added to the criteria to account for possible error in their determination or in meeting them operationally.

4.3.4.3 Verification Analyses. Present the criteria for establishing verification.

\subsubsection{Radiological Protection}

A portion of the radiological protection design criteria is discussed in Section 4.3.2, Protection by Multiple Confinement Barriers and Systems. Present additional radiological protection design criteria as appropriate.

4.3.5.1 Access Control. Describe the methods and proccdurca to be designed into the facility to limit perconnel accoss to minimize radia-. tion exposure.

4.3.5.2 Shielding. Estimate personnel expnsures in man-rem per year in each area. When special provisions such as time and distance are to be included in the estimate, determine the design dose rate in 
occupancy areas. Show that further reduction of exposure is not practicable in terms of cost per man-rem reduction.

\subsubsection{Radiation Alarm Systems. Describe the radiation alarm} systems criteria used to take actions.

\subsubsection{Fire and Explosion Protection}

Provide the design criteria that have been selected to ensure that all safety functions will successfully withstand credible fire and explosion conditions.

\subsubsection{Thermal Design Criteria}

Discuss the thermal effects from the storage of wastes on the site and its geological formation.

4.3.7.1 Thermal Impact. Discuss the heat release rate from the waste emplaced in storage rooms and its effect on the structural integrity of the mine during operation, and on the overlying formations as a function of time; indicate the related temperature rise in freshwater aquifers and at the surface with time. . Discuss how established thermal design criteria will be met.

\subsubsection{Industrial and Chemical. Safety}

Describe specific design criteria that are important to personnel and facility safety. Effects of such industrial accidents as Fines and explosions should be presented, as well as such hazardous chemical reactions as vigorous chemical reactions and hydrogen explosions.

\subsubsection{Safety Pnticy}

Describe the operating safety policy.

\subsubsection{Qualifications and Training}

Describe the qualifications and training of personnel who will plain and implcment the safery program, with particular emphasis on their relevant experience. $\quad 4-17$ 


\subsubsection{Safety Functions}

Describe the organizational interfaces for the safety function. How will people with safety responsibility interact with engineering, design, planning, operating, and supervisory personnel? How will they dcal with mild infractions of safety and severe safety failures from whatever cause?

\subsubsection{Mine Safety Construction Criteria}

Describe the safety criteria established for developing the underground uine sections from initial shaft penetrations through room and ventilation completion. Describe systems for determining the need for bar down, timbering, rock bolting, and shotcrete application, as well as shaft and tunnel dimonoiono.

\subsection{CLASSIFICATION OF STRUCTURF., ROMPONFNTS, IND SYSTEME}

Classify the structures, components, and systems selected in the design according to their importance in regard to the safety function they perform, seismic considerations, and the relationship of the specified performance criteria of an item with respect to its function. As appropriate, relate these classifications to details presented in Chapter 5, Facility Design, and Chapter 6, Operational Systems and Components.

Define the criteria used to select the categories for the claceifications related to safety, seismic resistance, and quality assurance.

\subsection{ENGINEERED RETRIEVABILITY}

Describe the design criteria for the "proof testing" phase of initial operations that will incorporate engineered retrievability of some of the waste containers. Discuss the objectives of the test, the criteria by which test results will be evaluated to determine if the objectives have been met, and the procedures to terminate the test and commence "nurmal operations." 


\subsection{DECOMMISSIONING}

As required by $10 \mathrm{CRF}$ 50, "Policy Relating to the Siting of Fuel Reprocessing Plants and Related Waste Management Facilities," include arrangements for safe decommissioning of the facility. Provide in this section the design criteria for fulfilling this requirements. Discuss the design approach to be used to allow for ease of facility decontamination and for future isolation of all radioactive materials from the public.

\subsubsection{Mine Backfilling}

Discuss the method used to backfill the mine. Include the substance and composition of fill material, the reconsolidation, and the recrystallization of material around the emplaced waste units.

4.6.1.1 Equipment. Indicate the fate of underground operational hardware and equipment.

4.6.1.2 Shafts. Discuss thoroughly the procedures for filling the mine shafts and the materials used to do so. Include information concerning precautions to prevent water intrusion.

\subsubsection{Surface Facilities}

Discuss the decontamination and disposal of surface facilities.

\subsubsection{Topography}

Compare the final topography of the decommissioned site with the preexcavation elevations.

\subsubsection{Area Plot. Locate all significant surface penetrations} on a topographical plot of the site, and indicate changes in elevation since facility start-up at all penetration points.

\subsubsection{Ground Cover. Describe the final "walk-away" ground} cover and its expected fate. And describe the design, emplacement, utility, and expected fate of site markers.

$$
\text { 4-19 }
$$




\section{Chapter 5}

\section{FACILITY DESIGN}

For PSAR evaluation, provide descriptive information on the buildings, other installed surface features, and underground excavations for the facility and their locations on the site. Use drawings and maps as appropriate. Describe and evaluate each part of the facility, with emphasis on those features that serve a confinement function. Fully describe and evaluate special design features employed to withstand environmental forces and accident forces. Relate the design bases and use of industrial codes to the design criteria presented in Chapter 4. Reference those features that require inclusion in the Quality Assurance Program.

For the FSAR, identify areas that have been changed or added, the reasons for the changes, and the safety implications of the changes. Also present the results of research and development activities related to construction and/or operating criteria. The FSAR will describe in detail the final facility design and complete technical specifications.

\subsection{SUMMARY DESCRIPTION}

\subsubsection{Location and Facility Layout}

On an appropriately scaled map or drawing, locate the buildings and other installed surface features, as well as openings to underground of the waste isolation facility. Also show roadways, railroad lines, parking areas, and utility and water service locations, with north-point direction indicated. Indicate the prevailing wind direction and the most frequent range for natural air velocity. 


\section{1 .2 Principal Features}

5.1.2.1 Site Boundary. Show the boundary that encompasses the area owned and/or leased by the applicant. Indicate existing and proposed fenced areas.

5.1.2.2 Exclusion Area. Show the area in which underground activities by the public will be controlled but in which some restricted access will be allowed for limited surface activity.

\subsubsection{Reslrluled Ared. In like manner, show the area in which} no restrictions over surface use will be imposed but in which no drilling will be allowed.

\subsubsection{Site Utility Supplies and Systems. Identify utility} supplies and systems, as well as the source or sources of water and electric power. Include, as applicable, the location of test wells, the cooling tower, the sanitary waste disposal area, and the electric substation. Include water petroleum, gas, and other exploratory holes. Indicate when and how the exploratory holes and test wells may have been plugged.

\subsubsection{Storage Facilities. Show the location of holding ponds,} water tanks, heating and emergency standby fuels storage vessels, or other outside tankage. Indicate the magazine location for commercial explogives.

5.1.2.6 Stack. Show the location, plan, and elevation of the exhaust stack or stacks emanating from the central exhaust filter station in relation to the other facilities. Show the stacks from both surface and underground facilities, and indicate their relation to separate or combined ventilation systems. Relate stack heights to a common reference. 
5.1.2.7 Underground Facilities. Show the contour of underground shafts, tunnels, mines, and rooms.

\subsection{FACILITY BUILDINGS}

Provide the design bases for the facility's buildings; include analysis and design procedures for tornado, earthquake, missile, fire, flood, and explosion effects; the general analysis and design procedures for normal, abnormal, and special loading and load combinations; allowable foundation loads and deflections and deformation stresses for structures; and provisions and methods for connecting existing buildings with future modifications and additions. These design bases and analyses emphasize buildings and structures directly associated with waste handling operations, such as waste receiving buildings, hoist houses, mine operations buildings, exhaust fan filter houses, and mine air supply fan houses. They may also include such support structures as the administration and warehouse buildings, and the magazine, gatehouse, and other auxiliary buildings.

\section{2 .1 Structural Specifications}

Establish the bases and engineering design required to maintain the confinement integrity of applicable facility bulldings. Identify applicable nationally recognized codes and standards, and the materials of construction, fabrication, and inspelliun lu be used; in tabular form, itemize features that will be used in the Quality Assurance Program discussed in Chapter 11, Quality Assurance. Identify the specifications and design details required to comply with the information discussed in Section 5.2. Indicate the consideration given to combination stress loadings.

\section{2 .2 Building Layouts}

5.2.2.1 Building Plans. Using engineering drawings, show the laynut of the functional features of each building. Provide plans and elevations in sufficient detall to identify all features discussed later in this chapter. Include sufficient spatial and equipment identification data directly on the layouts; also list these data in tabular form. 
5.2.2.2 Building Sections. Include sectional drawings to clearly depict all features discussed later in this chapter.

5.2.2.3 Confinement Features. Identify and discuss general layout criteria for the building portions that have been included in the design to ensure confinement of radioactivity. (This should be a general discussion, with details presented in accordance with applicable parts of this chapter.) Discuss ventilation, filters, piping, gasket sealing, air lock entryways, and other physical means such as barriers, encasements, liners, and protective coatings. Identify the interfaces between these systems and discuss the safety aspects of the interfaces. Detalls un ventilation operation are to be presented in Chapter 7, Radiation Protection and Operational Safety.

\subsubsection{Description of Operational Areas}

For each waste-handling building, list individual operational areas sequentially from the receiving unit through the various operations to the mine transfer unit. Typical items would be: container (or cask) unloading and storage; decontamination, welghing, assaying, and transfer; cask cooling; recanning cell and gallery; waste casling (i.e., facility originated); transfer galleries; control rooms, nonconfined operational areas for personnel, equipmenc, and materlals; aud remote and contact maintenance shops. Locate each area on engineering drawings.

5.2.3.1 Function. Describe the function of each operational area, and discuss performance objectives for that area.

\subsubsection{Components. Discuss the components in each operational}

axea. Use individual equipment sketches and layouts of equipment locations to identify critical components, and limits that may be imposed on component design to achieve safety.

5.2.3.3 Design Bases and Safety Assurance. Present the design bases developed, design codes uses, and additional specifications that are 
necessary to provide a sufficient margin of safety under both normal and accident conditions so that a single equipment failure, operational accident, or faulty waste container, can, or cask will not release significant radioactivity. Include details on backup provisions and . interface with other areas, other buildings, or mine areas. Also discuss the features used to ensure radiation protection and to prevent criticality.

\subsection{TRANSURANIC AND HIGH-LEVEL SHAFTS, TUNNELS, MINES, AND VAULTS}

Provide the design bases for the openings below ground, including analysis and design procedures for earthquake, missile, fire, flood, and explosion effects, the general analysis and design procedures for normal, abnormal, and special thermal and radiation levels, allowable deflections and deformation stresses for mechanical equipment, and provisions and methods for connecting existing tunnels with future plant modifications and additions.

\subsubsection{Construction Specifications}

Establish the bases and engineering design required to maintain the confinement integrity of the shafts, tunnels, mine, and rooms. When applicable, identify nationally recognized codes and standards and the materials of construction, fabrication, and inspection to be used; itemize in tabular form, features that will be used in the Quality Assurance Program discussed in Chapter 11, Quality Assurance. Identify the specifications and design details required to meet the conditions discussed in Section 5.3. Indicate the consideration given to combination stress effects.

\section{3 .2 Underground Layout}

5.3.2.1 Underground Plan. Using engineering drawings, show the layout of the functional features of the underground facilities. Provide plans and elevations in sufficient detail to identify all features discussed later in this chapter. Include sufficient spatial and equipment 
identification data directly on the layouts; also record these data in tabular form.

5.3.2.2. Underground Sections. Include sectional drawings to clearly depict all features discussed later in this chapter.

5.3.2.3 Confinement Features. Identify and discuss the general layout criteria for the underground storage that have been included in the design to ensure confinement of radioactivity. (This should be a general discussion, with details presented in the applicable part of this chapter.) Nisruss ventilation, filters, pipiug, and other physical means such as barriers, encasements, liners, and protective coatings. Identify the interfaces between the systems, and discuss the safety aspects of the interfaces. Details on ventilation operation are to be presented in Chapter 7, Radiation Protection and Operational Safety.

\subsubsection{Individual Facility Description}

List each facility sequentially from the underground receiving facility through the various operations. Typical facilities include: receiving and storage, transfer cells and gallery, transport, low- and high-level waste isolation, and remote and contact maintenance shops if. beluwground. Locate each facility on engineering drawings.

\subsection{SUPPORT SYSTEMS}

Provide information about those systems that support the main operational and confinement features. Emphasize provisions made to cope with accidents. Define the design bases, codes, specifications, and standards that will provide a safety margin so that a single failure within a support systen will not result in the release of radioactivity.

\subsubsection{Development of Support Requirements}

For certain auxiliary systems involving ventilation, electricity, air, and water, three categories of loads are possible: 
1. Loads determined by normal operations.

2. Reduced load situations resulting from primary power failure and/or accident conditions.

3. Emergency load, defined as the minimum requirement for the total safety of a shutdown operation, including surveillance requirements.

Minimum loads are further defined as the required loads for those confinement systems that must remain functional following a maximum hypothetical incident to prevent the release of radioactivity. Summarize the auxiliary systems, their service, and required confinement operations. Also include details of support systems, such as the fire protection system, and design provisions for maintenance.

\subsubsection{Arrangement of Support Systems}

Discuss the location of the various support systems in relation to their functional objectives by reference to drawings developed in Section 5.2.2. Present additional details to identify the detailed physical arrangement. For each system, as appropriate, provide single-line drawings and a narrative description of its operating characteristics and safety considerations.

\subsection{DESCRIPTION OF SERVICE AND UTILITY SYSTEMS}

\subsubsection{Ventilation (Aboveground and Belowground)}

Provide in detail the design bases, design operating features, and limitations for performance of the ventilation-filtration systems to show that sufficient backup, excess capacity, repair and replacement capability, and structural integrity exist to ensure controlled continuous airflow in all credible circumstances to minimize release of radioactive particulates. Supplement the discussion with drawings that show the flow distribution, pressure differentials, air locks, flow quantity, velocity, filtering, and fan housing arrangements. Identify each area serviced and the interfaces between areas listed in the following subsections. Discuss the design limits selected for operation and the 
performance limits that must be met for safety. Also, discuss the program established to determine the efficiencies of each component during the operating life of the facility.

\subsubsection{Major Componcnts and Operating Characteristics. Describe} the components making up the system; their relation to one another in terms of air supply; their collection and distribution systems, and their sequence of filtration, filter protection, exhaust fans, upcast venting, interconnection of mine exhaust streams, and the stack. Provide engineering drawings and sketches for reference in the discussion. Also, discuss, wlih reference to engineering drawings and tables, the interrelation of component parts and controls to:

1. Prevent the spread of radioactivity in normal facility operations.

2. Minimize the spread of radioactivity during abnormal operations or under accident conditions.

3. Control contamination between operational areas.

4. Control air contamination when personnel access doors or cell or bulkhead hatches are opened.

5. Limit the spread of radioactivity within the ventilation system.

6. Provide for ventilation exhaust in the event of stack failure that results in plugging the system.

7. Provide for power outages.

8. Limit radioactivity in the stack effluent.

5.5.1.2 Safety Considerations and Controls. Set forth the safety considerations and controls in such a way that the provisions therein for orructural integrily, deslgn velocity, flow and flow-direction, control instrumentation, and features for testing and monitoring the system ensure continued performance integrity.

Viscuss in detail the evaluations made that show that the ventilation system by itself and in conjunction with other ventilation systems will be operable: Also, show that such sufficient margins exist between norma1 
and accident conditions that a single component failure will not result in an uncontrolled release of radioactivity.

Emphasize those ventilation design features that assure confinement of radioactivity under conditions of power failure, adverse natural phenomena, breakdown of equipment, fire and explosion, improper flow of air, contaminated spills, and loss of filter integrity.

Estimate the radioactivity discharged by the ventilation system. Present source terms by type of material, concentration, activity, and total quantity. per unit time to be used in determining radiation exposure data.

\section{5 .2 Electrical}

\subsubsection{Major Components and Operating Characteristics. Discuss} the source and characteristics of the primary electrical system that provides normal power to the facility. If a secondary electrical system. is to be provided, describe its source. Describe the design provisions for emergency power source(s) and the means for ensuring an uninterruptible service to those facility functions requiring it. For each of these latter items, list the equipment and systems serviced, locations, required kilowatts, and type of startup system.

\subsubsection{Safety Considerations and Controls. Itemize and discuss} the mechanisms, and sequence of timing of events designed to ensure safe operation and shutdown, both for a partial loss of normal power and for a total loss of normal power. Present the design features that make possible an automatic restart sequence on emergency power. Also, describe the procedure for subsequent reestablishment of normal load service.

\subsubsection{Compressed Air}

5.5.3.1 Major Components and Operating Characteristics. Present the design bases for supplying the compressed air needs of the facility, and the supply air required for protective masks and clothing; list the 
components, their location, and their operating characteristics. Describe the compressurs, receivers and dryers, and distribution systems.

5.5.3.2 Safety Considerations and Controls. Discuss in detail the backup provisions for the instrument air system and its relation to providing emergency functioning.

\subsubsection{Heating Fuel(s) Supply and Distribution}

5.5.4.1 Major Components and Operating Characteristics. Provide the design basts for supplying heating fuel(s) to the facility, including a discussion of fuel type and supply, storage vessels, boilers, and methods of तistrihution.

5.5.4.2 Safety Considerations and Controls. Discuss featires of tho heating fuel(s) supply system in relation to continuity of operations and safety shutdown features.

\section{5 .5 Water supply}

5.5.5.1 Major Components and Operating Characteristics. Provide the primary source of the water supply, alternative sources, storage facilitico; and distribution looping system. Itemize design considerations to demonstrate a continuity of water supply. $\Lambda 1 s o$, itemize by service (potable, process, and fire) the quantities of water used under normal conditions and the minimum requirement.s under emergency shutdown opcrations.

\subsubsection{Safety Considerations and Controls. Discuss the effects of} loss of the water supply source, failure of main supply pump(s) or supply lines, and power failure. Also, discuss the means for coping with drought and flood. 


\subsubsection{Waste Disposal}

5.5.7.1 Sanitary Sewage. Describe the sanitary sewage handling and disposal system to show that no radioactive material can be discharged in the sewage effluent, except perhaps trace amounts in laboratory wash water.

5.5.7.2 Solid Wastes. Describe the system that may be used for handling and disposing of nonradioactive facility wastes.

\subsubsection{Safety Communications and Alarms}

5.5.8.1 Major Components and Operating Characteristics. Discuss the external and internal communications systems, with particular emphasis on the components to be used under emergency conditions.

5.5.8.2 Safety Considerations and Controls. Describe how the communication systems and alarms function in response to normal and abnormal operations, and under accident conditions.

\section{5:5.9 Fire Protection System}

\subsubsection{Design Basis.}

1. Identify (PSAR) the fires that could indirectly or directly affect safety-related structures, systems, and components. Describe and discuss those fires that provide the bascs for the design of the fire protection system (i.e., fires that are considered to be the maximum fire that may develop in local areas, assuming that no manual, automatic, or other fire-fighting measures have been started and that the fire has passed flashover and is reaching its peak burning rate before fire fighting can start). Consider fire intensity, location, and (depending un Llie effecliveness of fire protection) its duration and effect on adjacent areas. 
2. Discuss such fire characteristics (PSAR) as maximum fire intensity, flame spreading, smoke generation, production of toxic contaminants, and the contribution of fuel to the fire for all facility areas that have combustible materials and are associated with safety-related structures, systems, and components. Tnclude in the discussion the use and effect of noncombustible and heat-resistant materials. Provide a list (FSAR) of the hazardous combustibles, indicating the maximum amounts estimated to be present, and state where these will be located in the facility in relation to safety systems.

3. Discuss and list (PSAR) those underground and surface facility building and structure arrangements, and the structural design features that aid in fire prevention and provide for fire extinguishing. fire, control, and control of hazards created by fire. List and describe the personnel egress, fire barriers, firewalls, and the isolation and containment features provided for flame, heat, hot gases, smoke, and other contaminants. Discuss the isolation of combustion products from the surface facilities and the underground facilities.

4. Specify (PSAR) seismic design requirements for each type of fire protection system incorporated in the facility, and the fire protection system requirements incorporated in the basic designs of the overall water supply and water distribution systems; also indicate fire pumping and delivery capacity.

5. List (PSAK) the codes and standards considered and used for the design of the fire protection systems, including published standards of the National Fire Protection Association.

6. When applicable, discuss (PSAR) potential fire hazards during operations, with the additional fire prevention and control that will be provided when mining, waste emplacement, and backfitting are occurring simul taneously.

7. Discuss the avallability, response capacity, and general coverage of the local (public) fire department. Specify responsibilities and authorities of facility and public fire department personnel when dealing with a facility fire incident. 


\subsubsection{System Description.}

1. Provide a general description of the fire protection system, including preliminary drawings (PSAR) that show the physical characteristics of each facility location and outline the fire prevention and fire suppression systems to be provided for all areas associated with safetyrelated structures, systems, and components.

2. Discuss (PSAR) the protection and suppression systems provided in the control rooms and other operating areas that contain safety-related equipment.

3. Describe (PSAR) the design features of detection, alarm, automatic fire suppression, and manual systems for fire detection, confinement, control, and extinguishing. Discuss the relationship of the fire protection system to onsite power sources.

4. Discuss (PSAR) smoke, heat, and flame control; combustible and explosive gas control, as applicable; and toxic contaminant control including the operating functions of the ventilating and exhaust systems during the period of fire extinguishing and control. Discuss the fire annunciator warning system, the appraisal and trend evaluation systems provided with the alarm detection system in the proposed fire protection systems, and backup measures of public fire protection if these are to be available to the installation. Include drawings (FSAR) and an equipment and device list that adequately defines the principal and auxiliary fire protection systems.

5. Describe (PSAR) electrical cable; transformer, and switch gear fire protection and detection, and the fire containment, control, and extinguishing systems provided. Define the integrity of the essential electric circuitry needed during the fire for safe shutdown of the facility and for fire fighting. Describe the provisions made for protecting essential electrical circuitry from the effects of fire-suppressing agents.

\subsubsection{System Evaluation. Evaluate those fires identified in} Section 5.5.9.1; in the evaluation, consider the quantities of combustible materials present, facility design, and the fire protection systems 
provided. Describe the estimated severity, intensity, and duration of the fires, and the hazards created by the fires. For each of the postulated events, indicate the total time involved for each event and the time for each step from the first alert of the fire hazard until it is safely controlled or extinguished. Provide a failure mode and efforts analysis that demonstrates that operation of the fire protection system in areas containing operational safety features will not produce an unsafe condition. Evaluate the effects of failure of any portion of the fire protection system not designed to seismic requirements, with regard to the possibility of its damaging other equipment. Analyze the fire detection and protection system with regard to its design features that will withstand the effects of single failures.

5.5.9.4 Inspection and Testing Requirements. List and discuss testing and inspection planned during construction of the firp prntertinn systems to demonstrate the integrity of the systems as installed (PSAR). Describe the operational checks, inspection, and servicing required to maintain this integrity (FSAR). Discuss the testing necessary to maintain a highly reliable alarm detection system (FSAR). .

5.5.9.5 Personnel Qualification and Training. State the qualification requirements for thc fire protection engineer or consultant who will assist in the design and selection of equipment, and who will inspect and test the completed system, develop the fire protection program, and assist in the fire-fighting training (PSAR). Discuss initial personnel training in tire protection measures and indirate lpdating provisions such ae firc drills provided for maintaining the competenre of the statinn fire-fighting and operating crews, including personnel responsible for maintaining and inspecting the fire protection equipment (FSAR).

\subsubsection{Maintenance Systems}

5.5.10.1 Major Components and Operating Characteristics. Provide the design bases, locations, and modes of operation that relate to the maintenance programs for the facility. Emphasize the provisions for 
remote work; decontamination and disposal of materials, equipment, piping, and appurtenances; and for quality control and testing features.

\subsubsection{Safety Considerations and Controls. Discuss the means for} conducting required maintenance with a minimum of personnel radiation exposure or injury and the provision for assured confinement of radioactive wastes.

\subsection{ENVIRONMENTAL SAFETY DESIGN}

Functionally describe the safety evaluation of englnes, boilers, pressure vessels, mechanical and electrical devices, and systems aboveground and belowground. Include how often these evaluations take place.

\subsubsection{Equipment Listing, Personne1, and Location}

List all safety equipment. Include portable and fixed-installation types, personnel protection (such as garments), as well as environmental barriers, and emergency as well as routinely used equipment. Enumerate this equipment and relate its adequacy to the number of personnel normally underground. Prepare a map to indicate equipment location.

\subsubsection{Instrument Listing, Personnel, and Location}

List all safety instruments, including portable and fixed-installation types. Indicate the number of personnel on each shift who will be familiar with these instruments. State the storage area for these instruments, and indicate how often they are calibrated. Detail the use of personinel monitoring dosimeters.

\subsubsection{Safety Indoctrination}

Describe methods of safety indoctrination for facility personnel, including lectures, first aid demonstrations, mine rescue techniques, exhibitions, sanitation, hygiene, publications, and signs.

\subsubsection{Safety Committee}

Discuss the role and membersh1p of the salely committee. 


\subsubsection{Safety Evaluation Frequency}

Indicate how often working areas are evaluated for possible safety failures, whether due to environmental factors or operational practice.

5.6.5.1 Personnel and Underground Roster. Indicate where the 1ist of personnel currently working underground will be maintained.

\section{6 .6 Personnel Transport}

Describe in detail the safety prerantions (devicco and practices) fui personnel transport undergrouid.

\subsubsection{Liability Risk Protection}

Indicate the nature of liability risk prolection for the facility and its personnel.

\subsection{MINE ENFORCEMENT AND SAFETY ADMINISTRATION}

Describe specifically how the requirements of the Mine Enforcement and Safety Administration, $30 \mathrm{CFR} \cdot 57$, are met in the design and operation of the underground facility.

\subsection{LTEMS REQUIRING FURTHER DEVELOPMENT}

Identify, describe, and discuss those safety features or components for which further technical information will be required in support of authorization of construction but which have not been supplied in the PSAR. 'I'his section could:

1. Identify and distinguish between those technical information development programs that will be required to determine the adequacy of a new design and those that will be used to demonstrate the margin of conservatism of a proven design.

2. Characterize the specific technical information that must be obrained to demonstrate an acceptable solution. 
3. Outline each program in sufficient detail to show how the information will be obtained.

4. Provide a schedule of completion of each program in relation to the project start-up date of the proposed facility.

5. Discuss the design alternatives or operational restrictions available if the program does not demonstrate an acceptable solution. Also provide reasonable assurance that the alternatives considered will be acceptable substitutes.

\subsection{CHANGES FROM THE PSAR}

[This section will appear only in the FSAR.] Describe the results of the development work identified in the PSAR. Evaluate the results and the application made of them, and identify and justify the changes made. Each item should be cross-referenced to the appropriate section in the FSAR that describes the changes and the reasons for them. Summarize special technical information development programs undertaken to establish the final design and/or to demonstrate the conservatism of the design, and discuss any programs that will be conducted during operation in order to demonstrate the acceptability of contemplated future changes in design or modes of operation. 


\section{Chapter 6 : \\ OPERATIONAL SYSTEMS AND COMPONENTS}

\subsection{OPERATIONS DESCRIPTION}

In this chapter, describe all operations in detail, including procedures, systems, components, equipment, and instrumentation; include their operating characteristics; and identify potentially hazardous operational systems. Designate provisions made for safety engineered features to ensure against hazards, including those systems necessary for safe suspension of waste receiving and handling operation under normal and abnormal conditions. Also refer to items that will require attention for the Quality Assurance Program during construction. For each system, describe how the lowest reasonable levels of radioactivity in facility effluents are achieved and how subcritical conditions are ensured at all times. In the FSAR show changes from the PSAR and the reasons for the changes; define the limits and parameters for developing the technical specifications as well.

\section{1 .1 Narrative Description}

Describe the proposed operations, and relate them to the equipment and associated controls. Include ancilliary activities pertinent to the use of the main facility (i.e., maintenance of equipment, offgas handling and ventilation, volume reduction of wastes, and decontamination). Identify the interfaces between systems, and discuss the safety aspects of the interfaces.

\section{1 .2 Flowshects}

To support the description, supply flowsheets.showing the operations, materials and heat balances, and instrumentation. Identify the operations and materials movements in sufficient detail that an independent review 
can be made to assess safe operation. Include waste quantities, numbers of waste containers, activities, decay heat, compositions, properties, sample points, and identification of primary transfer points. Provide the flow input and output characteristics for effluent control equipment to show the efficiencies obtained. Give sufficient detail to provide source terms for the radiation exposure determinations to be developed in Chapter 7, Radiation Protection and Operational Safety. With the equipment descriptions, include dimensions, design and operating temperatures and pressures, materials of construction, special design features, and process limitations. Also provide engineering and instrumentation details and material flow diagrams.

\subsubsection{Identification of Items Pertinent to Safety Analysis Concerns}

Identify areas or items pertinent to safety analysis concerns. Refer. to this part of the chapter in subsequent discussions of the design and operaling features and items discussed in Chapter 2, Summary Safety Analysis.

\subsubsection{Criticality Prevention: Summarize the principal policies,} approaches, and special techniques used to preplude sriticality throughout the facility.

6.1.3.2 Chemical Safety. Summarize the prinripal rhemical hazard! and the approaches used to preclude accidents associated with thnse haparis.

\subsubsection{Operations Suspension Modes. Describe general facility} conditions and surveillance needs in the following operations suspension modes: extended, short-term, and emergency. Indicate the times required to suspend operations in each mode and to resume operations after each mole.

\subsubsection{Instrumentation. Summarize the instruments used to monitor} operational conditions and the systems used to control the operations. Include instrument testability, redundancy, and failure conditions. Also describe effluent monitors and data loggers. 


\subsubsection{Remote and Contact Maintenance Techniques. Discuss the}

rationale of remote and contact maintenance techniques to be used. Indicate the transfer cells where the techniques apply. Include system and component spares.

\subsection{MECHANICAL PROCESS SYSTEMS}

In the following sections, indicate the functions, design bases, and pertinent design features of an operational system as they relate to facility or environmental safety. Use sketches to aid in describing unique equipment or design features.

\subsubsection{Waste Receiving, Storage, Handling, Transfer, and Isolation}

Describe the systems associated with waste receipt, storage, transfer, and isolation. From the design criteria, present the provisions for cooling; for cleaning pool water, when used; for maintaining waste canisters in subcritical form; and for shielding.

\subsubsection{Functional Description. Present a flow diagram and functional} description of the waste receiving, storage, transfer, and isolation system. Include drawings or references to drawings as needed.

\subsubsection{System Description. Describe the waste unloading system,} leak checking and canister overpacking equipment, decontamination procedures and equipment, waste transport and transfer systems, and canister emplacement equipment. Use sketchẹs and dimenoions as needed.

\subsubsection{Safety Features. Describe all safety-related features,} systems, or special handling techniques included in the system for safe operation under both normal and abnormal conditions. Include the limit(s) selected as a basis for corrective action.

\subsection{OPERATIONAL SYSTEMS}

Relate each operational component to the operational description and to the appropriate material flowsheets. If applicable, identify the 
component as a source of the effluents and wastes discussed in Chapter 7 , Radiation Protection and Operational Safety. Refer to physical layout presentations in Chapter 5, Facility Design. Use subscctions to present the information on each component.

\subsubsection{Operational System}

Name the operational component described in this subsection. Continue additional process systems sequentially (e.g., 6.3.2, 6.3.3, $\ldots)$.

6.3.1.1 Functional Description. Describe the portion of the operation to be discussed, its function, and hna it will be accomplished.

\subsubsection{Major Components. If more than one component is included} in a particular system, explain the relationships of the components with one another and how they are combined within the system.

\subsubsection{Design Description. Discuss the design bases, including} materials of construction; performance ratings; pressure and temperature limits; detailed dimensions; corrosion allowances; and standards or codes used. Itemize the material and fabrication specifications pertaining Lu Lhe system in sutticient detail to relate them to the Quality Assurance Program in Chapter 11, Quality Assurance. Include such items as materials of construction, identification, assembly, welding, installation, and testing. Rather than repeating this information in Chapter 11, use suitablc cross references.

\subsubsection{Safety Criteria and Assurance. From the parameters} discussed in the preceding suhsertinns, summarizc thc safety erilerla, and the means of ensuring a safe system as constructed, operated, and maintained. Also summarize those limit(s) selerted as a basis for corrective action. Identify items characterized as engineered safcty features and considered additionally necessary beyond normal operations and control. Emphasize criticality considerations. 
6.3.1.5 Operating Limits. Sufficiently identify limits, conditions, and performance requirements to enable evaluation of whether or not a technical specification may be necessary. Clearly describe the interface with other systems.

\subsubsection{Component and Equipment Spares}

Describe in detail design features that incorporate spare or alternative equipment that provides safety continuity under normal and abnormal conditions. In particular, emphasize designs chosen to minimize radiation exposure for maintenance operations. Describe the bases for inspection, preventive maintenance, and testing programs that ensure continued safe functioning.

\subsection{OPERAT IONAL SUPPORT SYSTEMS}

\subsubsection{Instrumentation and Control Systems}

By reference to instrumentation engineering flowsheet(s) and the operations, discuss the instrumentation and control features associated with operational control, monitors, and alarms, and the relationship of the various elements to one another. Identify aspects that must be relied on to establish (1) adequate reliability and (2) the inclusion of provisions in the design to ensure continued safe operation or safe shutdown under accident conditions. Relate these aspects to the design criteria presented in Chapter 4, Principal Design Criteria. Discuss how instrumentation and control systems monitor safety-related variables and operating systems over anticipated ranges for normal operation, for abnormal operation, for accident conditions, and for suspended operations. Describe the redundancy of engineered safety features required to ensure adequate safety of waste handling and utility operations. (The safetyrelated variables and systems that require constant surveillance and control include the overall confinement system, each confinement barrier and its associated systems, and other systems that affect the overall safety of the plant.) Discuss the provisions for in situ testability of the instrumentation and control systems. Describe how instrumentation 
and control systems are designed to be fail-safe or to operate acceptably if they undergo conditions such as disconnection, loss of energy or motive power, or adverse environments. For each, provide the following information:

\subsubsection{Functional Description.}

6.4.1.2 Major Components.

6.4.1.3 Detection System and Locations.

6.4.1.4. Operating Characteristics.

6.4.1.5 Safety Criteria and Assurance.

\subsubsection{System and Component spares}

Describe in detail the installation of spare and alternative instrumentation designed to provide continuity of operation under normal and abnormal conditions. Also describe the bases for inspection, preventive maintenance, and testing programs to ensure continued safe functioning.

\subsection{CONTROL ROOM}

Discuss how the control room and/or control areas will be designed for safe operation under normal conditions and for safe occupancy and operation under accident or other abnormal conditions. Describe the redundancy that allows the plant to be maintained in a safe condition $1 f$ any control room or control area is removed from service.

\subsection{SAMPLING--ANALYTICAL}

D1scuss provisions for obtaining samples for analysis and the control necessary to ensure that sampling operations are within prescribed safety limits. Describe the facilities and analytical equipment that will be available to perform the analyses, as well as the destination of laboratory wastes. 


\subsection{WASTE HANDLING}

For the wastes resulting from operation of the nuclear power plant fuel cycle, indicate the system and the methods that will be used for their handling and isolation.

\subsubsection{High-Level Waste Handling and Isolation Systems}

\subsubsection{Functional Description.}

6.7.1.2 Major Components. Describe the receiving, storage, handling, transfer, and isolation systems and equipment, both buffer storage before isolation and isolation. Include accountability and decontamination measurements for the discarded portion of the waste.

\section{7:1.3 Design Description.}

\subsubsection{Safety Criteria and Assurance.}

\subsubsection{Operating Limits.}

\subsubsection{Intermediate-Leve1 Waste Handling and Isolation Systems}

\subsubsection{Functional Description.}

6.7.2.2 Major Components. Describe the receiving, storage, handling, transfer, and isolation systems and equipment, both buffer storage before isolation and isolation. Include accountability and decontamination measurements for the discarded portion of the waste.

6.7.2.3 Design Description.

6.7.2.4 Safety Criteria and Assurances.

6.7.2.5 Operating Limits. 


\subsubsection{Low-Level Transuranics Waste Handling and Isolation Systems}

\subsubsection{Functional Description.}

6.7.3.2 Major Components. Describe the receiving, storage, handling, transfer, and isolation equipment and procedures. Include special features for accountability.

\subsubsection{Design Description.}

6.7.3.4 Safety Crilet ld all Assurance. Describe àll satety-related features, systems, and special techniques to be employed to ensure the safety of the operation. Include systems needed for criticality control and for radiological safety.

\subsubsection{Operating Limits.}

\subsection{ITEMS REQUIRING FURTHER DEVELOPMENT}

As described in Section 5.9, present in the PSAR the details for each item requiring the development of additional information or data. Identify the item, what is needed, and how and when the informatinn wi11. be obtained. Indicate the dates when data are expected to be available and options that are available if satisfactory results are not obtained. Reference this information with Section 1.6, Comparison of Final and Preliminary Information.

\subsection{CHANGES FROM THE PSAR}

In the FSAR, describe in detail the results of the development work idcntificd in the PSAR. Evaluatc the results and thcir application, and identify and justify the changes made. 


\section{Chapter 7}

RADIATION PROTECTION AND OPERATIONAL SAFETY

\subsection{FACILITY-GENERATED WASTE MANAGEMENT CRITERIA}

By reference to Chapter 4, Principal Design Criteria, and $10 \mathrm{CFR}$ 50, Appendix F, "Policy Relating to the Siting of Fuel Reprocessing Plants and Related Waste Management Facilities," provide the primary design bases and supporting analysis for demonstrating that all radioactive waste materials will be contained safely over the operational life of the waste isolation facility. Include considerations for offsite disposal of solid waste materials and contaminated equipment. The waste confinement objectives, equipment, and program should implement, in part, the considerations necessary for protection against radiation.

\subsubsection{Radiological Wastes}

Classify all anticipated radioactive wastes with respect to source, chemical and radiological composition, method and design for handling, and mode of storage (temporary or permanent). Identification may be made by reference to previous flowsheets and diagrams.

\subsubsection{Nonradiological Wastes}

As in Section 7.1.1, identify nonradioactive waste sources. Account for combustion products and for all chemicals leaving the plant. Include this information to assist the staff in their determination that no radioactivity will be added to such sources, particularly to effluents.

\subsubsection{Ventilation}

Indicate the radioactive wastes that will be produced by removal from the radioactive gases cleaned by ventilation systems. Discuss such items as filters and scrubbers, which collect wastes, to indicate 
the destination of the wastes when the filters or scrubbers are regenerated or replaced. If the wastes enter other waste treatment systems, indicate how such transfers are made and the possible radiological effects of the transfer. Provide equipment and process flowsheets, tabular information (if it can improve clarity), and discuss the wastes in sufficient detail to demonstrate that:

1. "As low as reasonably achievable" (ALARA) radioactivity releases will be achieved during normal operation.

2. Ventilation capacity is sufficient to confine and/or contain radioactivity during abnormal opcrations or under postulated accident. conditions :

3. Provisions are incorporated to adequately monitor ventilation performance.

4. Satisfactory design features are incorporated to interface with other effluent and ventilation systems.

\subsubsection{Operating Characteristics}

Describe the function and performance objectives of each ventilation treatment system. Discuss how each performs.

\subsubsection{Safety Criteria and Assurance}

Evaluate each system to show that it will be operable or noncontributory to release of radioactivity under all credible circumstances.

\subsubsection{Liquid Waste Treatment and Retention}

Show how all liquid wastes are generated and enter liquid treatment systems. Include such items as laboratory wastes, liquid spills, and cleanup solutions. As part of the design objectives, indicate the inventory levels expected, and provisions for interim and long-term storage; identify those streams that will be processed to achieve volume reduction or solidification. Relate the discussion on process and equipment to the radioactivity level.

$$
7-2
$$


7.1.6.1 Design Objectives. Describe the design objectives for the system under discussion. Identify, in particular, criteria that incorporate backup and special features to ensure that the waste will be safely contained.

7.1.6.2 Equipment and Systems Description. Describe the equipment and systems to be installed. Accompany the description with engineering drawings that show equipment location, flow paths, piping, valves, instrumentation, and other physical features. Describe safety-related features, systems, or special handling techniques included in the systems to provide for the safety of the operation.

7.1.6.3 Operating Procedures. Describe the procedures associated with operation of the system(s). Include performance tests, action levels, action to be taken under normal and abnormal conditions, and methods for testability to ensure functional operation.

\subsubsection{Liquid Waste Solidification}

Describe the process and equipment to be used for volume reduction and/or solidification of the liquid wastes identified in Section 7.1.6.

7.1.7.1 Design Objectives. Identify and state the means that will be used to meet the requirements in 10 CFR 50, Appendix F. Describe other objectives of the system(s) consistent with the processes selected.

\subsubsection{Equipment and Systems Description. Describe the equipment} and systems to be installed. Accompany the description with appropriate engineering drawings to show equipment location and associated features that will be used for volume reduction, containment and/or packaging, cooling, and storage.

7.1.7.3 Operating Procedures. Describe the procedures associated with equipment operation, including performance tests, process limits, and means for controlling. and monitoring those limits. 
7.1.7.4 Characteristics, Concentrations, and Volumes of Solid Wastes. Describe the physical, chemical, and thermal characteristics of the solid wastes, and estimate concentrations and volumes generated.

7.1.7.5 Packaging. Describe solid wastes packaging where required, and identify aspects of the packaging process that should be incorporated in the Quality Assurance Program. Describe the package itself in detail to show: (1) materials of construction, including welding information; (2) the maximum temperatures for waste and container at the highest desigll heat loads; (3) homogeneity of the waste contents; (4) corrosive clidacteristics of the waste on the materials of construction; (5) means to prevent overpressurization of the package; and (6) the containment provided by the package under abnormal conditions.

7.1.7.6 Storage Facilities. Indicate those stordge facility operational procedures that demonstrate that the likelihood of arridental puncture or other damage to a package from natural phenomena or other causes is very low. Discuss external corrosion of the package caused by storage surroundings, if applicable. Indicate the procedures for cafcly moving packages inco and out of storage locations and how the packages will be monitored over their storage life.

\section{1 .8 Solid Wastes}

List all solid wastes, other than the highly radioactive wastes, that are produced during facility operation. Describe the syetem used to treat, package, and contain them.

\subsubsection{Design Objectives. Describe the objectives of the methods} and the equipment selected for dispocal of the solid wastet that are classified as less than highly radioactive.

7.1.8.2 Equipment and Systems Descriptions. Describe the equipment and systems to be installed. Accompany the description with engineering drawings that show equipment location and associated features that will 
be used for volume reduction, containment and/or packaging, cooling, and storage.

7.1.8.3 Operating Procedures. Describe the procedures associated with equipment operation, including performance tests, process limits, and means for monitoring and controlling these limits.

7.1.8.4 Characteristics, Concentrations, and Volumes of Solid Wastes. Describe the physical, chemical, and thermal characteristics of the solid wastes, and estimate the concentrations and volumes generated.

7.1.8.5 Packaging. When applicable, describe how solid wastes are packaged, and identify aspects of the packaging operation that should be incorporated in the Quality Assurance Program.

7.1.8.6 Storage Facilities. For those solid wastes to be retained onsite for the operational life of the facility, show in detail the containment methods used. Discuss corrosion aspects and monitoring of the containment. Describe the ultimate disposition of these wastes.

\subsubsection{Items Requiring Further Development}

In this section of the PSAR, present those safety aspects that require development of additional information or data. Identify and discuss each item, the projected schedule for obtaining the required information, and alternatives that may be considered should the results obtained be unsatisfactory.

\subsubsection{Changes from the PSAR}

\subsection{RADLALILON YRO'LECTION}

In this section of the SAR, provide information on methods for radiation protection and on estimated occupational radiation exposures to operating personnel during normal and abnormal operation; include 
radioactive material handling, use, storage, and disposal; maintenance; routine operational surveillance; inservice inspection; and calibration. Provide information on facility and equipment design, the planning and procedures programs, and the techniques and practices employed by the applicant in meeting the standards for protection against radiation of 10 CFR 20 and the guidance given in the appropriate regulatory guides. Specifically, refer to other chapters for information needed in this chapter when required.

\subsubsection{Assuring ALARA Occupational Radiation Exposures}

7.2.1.1 Policy Considerations. Describe the management policy and organizational structure related to assuring that occupational radiation exposures are ALARA. Describe the activities of the individuals responsible for radiation protection. In the PSAR, describe policy with respect to designing the facility; in the FSAR, emphasize policy with respect to operation.

7.2.1.2 Design Considerations. In the PSAR, describe facility and equipment design considerations that are directed toward ensuring that occupational radiation exposures are ALARA. Describe how experience from any past designs is used in developing an improved design for ensuring that occupational radiation exposures are ALARA. Include both general and specific design guidance given to designers. Describe how the design is directed toward reducing equipment maintenance, radiation levels, and time spent when maintenance is required. Detail these descriptions in the PSAR.

Discuss the arrangements and plans for dernntamination of the facility, as referred to in $10 \mathrm{CFR}$ 50, Appendix F, "Policy Relating to the Siting of Fuel Reprocessing Plants and Related Waste Management Facilities." (The detailed facility design practices regarding radiation protection are to be covered in Section 7.2.3.1.) 
7.2.1.3 Operational Considerations. In the PSAR, describe the methods used to develop the detailed plans and procedures that ensure that occupational radiation exposures are ALARA. Describe how these plans and procedures will affect facility design and how such planning has incorporated information from other designs.

In the FSAR, identify and describe procedures and methods of operation that are used to ensure that occupational radiation exposures are ALARA. Describe how operational considerations are reflected in the design described in Section 7.2.1.2 and the radiation protection design features described in Section 7.2.3.1. Provide the criteria and/or conditions under which various procedures and techniques for ensuring that occupational radiation exposures are ALARA are implemented for all systems that contain, collect, store, or transport radioactive liquids, gases, and solids. Include those from the radioactive waste treatment, handing, and storage systems.

\subsubsection{Radiation Sources}

7.2.2.1 Contained Sources. In the PSAR, describe the sources of radiation that are the basis for the radiation protection design for use as input for the shield design calculation. Tabulate all sources by isotopic composition or gamma ray energy groups, strength (curie content), and geometry; provide the basis for the values. In the FSAR, provide additional details (and any changes) of source descriptions that are used to develope the final shield design.

7.2.2.2 Airborne Radioactive Material Sources. In the PSAR, describe the sources of airborne radioactive material in areas easily accessible to or normally occupied by operating personnel in the manner required for design of personnel protective measures and dose assessment. In the FSAR, tabulate the calculated concentrations of airborne radioactive material by nuclides expected during normal and abnormal operation in areas normally occupied, by operating personnel. Provide the 
models and parameters for calculating airborne radioactivity concentrations. Describe any changes or additions to the source data since the PSAR was prepared.

\subsubsection{Radiation Protection Design Features}

7.2.3.1 Facility Design Features. In the PSAR, describe equipment and facility design features used for ensuring that occupational radiation exposures are ALARA.

Provide illustrative examples of the facility design features used in the PSAR design stage as applied to the systems addressed in Section 7.2.1.3. Provide an illustrative example for components of each of the following systems: waste receiving, leak checking, decontamination, buffer storage, transfer, and isolation. Refer to other chapters and sections as appropriate.

In the PSAR, provide scaled layout and arrangement drawings of the facility, showing the locations of all sources described in section 7.2.2, including those contained in vaults, basins, transfer facilities, storage containers, and isolation shafts throughout the facility. Include specific activity, physical and chemical characteristics, and expected concentrations of fission products, activation products, and transuranic elements. On the layouts indicate the radiation zone designations, including zone boundaries, shield wall thicknesses, controlled access areas, personnel and equipment decontamination areas, contamination control areas, traffic patterns, location of the health physics facilities, location ${ }^{\frac{1}{*}}$ of airborne radioactivity and area radiation monitors, location of control panel(s) for radioactive waste equipment and components, location of the orisite laboratory for analysis of radioactivity samples, and location of the counting room. Summarize the design radiation dose rate for each area and activity. Specify the design basis radiation licucl in the counting room during normal operation and anticipated operational occurrences. Describe the facilities and equipment, such as hoods, gloveboxes, filters,

\footnotetext{
* In the PSAR if available, and updated in the FSAR
} 
and special handling equipment. In the FSAR, describe changes or additions to the radiation protection design since the PSAR was prepared.

7.2.3.2 Shielding. In the PSAR, provide information on the shielding for each of the radiation sources identified in Section 7.2.2, including the criteria for penetrations, the material, the method by which the shield parameters (such as attenuation coefficients, buildup factors, and similar factors) were determined, and the assumptions, codes, and techniques used in the calculations. Describe special protective features that use shieldings, geometric arrangement (including equipment separation), or remote handling to ensure that occupational radiation exposures will be ALARA in normally occupied areas. Describe the procedures that will be used to verify the integrity of the constructed shielding. In the FSAR, describe changes or additions in the shielding since the PSAR was prepared.

7.2.3.3 Ventilation. In the PSAR, describe the personnel protection features incorporated in the design of the ventilation system by ampiifying the discussions on building and mine ventilation and offgas treatment in Chapters 5 and 6 to show that the designs selected will satisfy the ALARA provisions of $10 \mathrm{CFR} 20$ and appropriate guides.

Refer to the discussion on building and mine ventilation in Section 5.5.1 and to applicable engineering sketches and drawings to further discuss the interrelation of component parts and controls to:

1. Maintain internal exposure as low as reasonably achievable.

2. Prevent spread of radioactivity in normal facility operations.

3. Minimize spread of radioactivity during abnormal operations or under accident conditions.

4. Control contamination between areas.

5. Control air contamination when personnel access doors or cell hatches are opened.

6. Limit the spread of radioactivity within the ventilation system. 
7. Provide for ventilation exhaust in the event of stack failure.

8. Provide for power outages.

9. Limit radioactivity in the stack effluent.

Describe the function and performance objectives of the building and mine ventilation system. Discuss the areas and equipment serviced and the criteria for providing continuity of service to the total system. Include in the description, with reference to drawings, the interface considerations between components of the systems. Discuss the design limits selected for operation and the performance limits that must be met for safely. Alsu, discuss the program established to determine the efficiencies of each component during the operating life of the facility.

Discuss in detail the evaluations that indicate the system will uperate alone and in conjunction with other ventilation systems. Also, show that sufficient margins exist so that a single component failure will not result in an uncontrolled release of radioactivity. Describe how the system can cope with loss of electrical power.

In the FSAR, include any changes or additions in the ventilation system design protective features since the PSAR was prepared.

\subsubsection{Area Radiation and Airborne Radioactivity Monitoring}

Instrumentation. In the PSAR, describe the fixed area radiation and criticality monitors and the continuous airborne radioactivity monitoring instrumentation, as well as the criteria for placement.

In the FSAR, provide information on the auxiliary and/or emergency power supply, range, sensitivity, accuracy, calibration methods and frequency, alarm set points, recording devices, and location of detectors, readouts, and alarms for the monitoring instrumentation. Provide the location of the criticality detectors, and describe or refer to the readout system and neutron dose assessment technique to be used. In the FSAR, provide the location of airborne monitor sample collectors. 


\subsubsection{Estimated Man-Rem Onsite Dose Assessment}

In the PSAR, provide the estimated occupancy of the facility radiation areas during normal operation and anticipated operational occurrences. For areas with expected airborne radioactivity concentrations (as described in Section 7.2.2.2), provide estimated man-hours of occupancy. Provide the objectives and criteria for design dose rates in various areas, and an estimate of the annual man-rem doses associated with major functions. Provide the basis, models, and assumptions for these values.

In the FSAR, tabulate the estimated annual occupancy for each radiation zone in the plant, and provide the bases for the values. Provide updated estimates of annual man-rem doses for the functions listed above and the assumptions used in determining these values.

\subsubsection{Health Physics Program}

7.2.5.1 Organization. In the PSAR, describe the administrative organization of the health physics program, including the authority and responsibility of each position identified. In the FSAR, describe the experience and qualifications of the personnel responsible for the health physics program; and for handling and monitoring radioactive materials.

\subsubsection{Equipment, Instrumentation, and Facilities. In the PSAR,} provide the criteria for selection of portable and laboratory technical equipment and instrumentation for performing radiation and contamination surveys, for airborne radioactivity sampling, for area radiation monitoring, and for personnel monitoring during normal and abnormal operation, and accident conditions. Describe the instrument storage, calibration, and maintenance facilities. Describe the health physics facilities, laboratory facilities for radioactivity analyses, protective clothing, respiratory protective equipment, decontamination facilities (for equipment and personnel), and other contamination control equipment and areas that will be available. In the FSAR, provide the locations of the respiratory protective equipment, protective clothing, and portable and laboratory technical equipment and instrumentation. Describe the type of detectors and monitors, and the quantity, sensitivity, range, and frequency 
and methods of calibration for the technical equipment and instrumentation above.

7.2.5.3 Procedures. In the FSAR, describe the methods, frequencies, and procedures for conducting radiation surveys. Describe the health physics procedures that have been developed for assuring that occupational radiation exposures will be ALARA. Describe the physical and administrative measures for controlling access to, and exposure time in, radiation areas. Refer to Section 7.2.1, as appropriate. Describe the bases and methods for monitoring and controlling personnel, equipment, and surface contamillallull. Describe radiation protection training programs.

Describe the methods and procedures for personnel monitoring (external and internal) for normal operations and criticality accidents, including methods of recording and reporting results. Describe how dosimetric results are used as a guide to operational planning. Provide the criteria for performing whole-body counting and bioassays.

Describe the methods and procedures for evaluating and controlling potential airborne radioactivity concentratinns, including requirementa for special air sampling, and the issuance and use of respiratory protective devices, including training and respiratory protertive equip= ment fitting programs.

\subsubsection{Estimated Man-Rem Offsite Dose Assessmcnt}

Describe the program and the andytical approach for monitoring the radioactivity content of the effluent streams of the facility. Relate the monitoring program to material flow diagrams. Estimate the contribution by the facility to the offsite radioactivity level.

7.2.6.1 Effluent and Environmental Monitoring Program. In the PSAR, describe the program for monitoring and estimating the contribution of radioactivity to the environment. Present the details of the approach, and the results obtained for determining the background levels and the estimate of subsequent contribution of the facility. 
1. Gas Effluent Monitoring--Describe the features of the sampling systems to be used, their locations, and the items to be monitored. For each, show the expected reliability and $\mathrm{Ci-s-m^{-3 }}$ sensitivity in double the instrument response time and in 1 week for each device. Justify the selection of each system and instrument. Discuss the frequency of sampling, the limits for action, and the procedures to be used to maintain containued integrity of analyses.

2. Liquid Effluent Monitoring--As with gas effluent monitoring, describe the features of the liquid sampling systems to be used, their.locations, and the items to be monitored. For each, show the expected reliability and $\mathrm{C} i-s-\mathrm{m}^{-3}$ sensitivity in double the instrument response time and in 1 week for each device. Justify the selection of each system and instrument. Discuss the frequency of sampling, the limits for action, and the procedures to be used to maintain continued integrity of analysis.

3. Solid Waste Monitoring--Describe the procedures, equipment, and instrumentation used to monitor all radioactive solid waste.

4. Environmental Monitoring--Describe in detail the program for monitoring possible contribution of radiation to the site and environs. Identify the samples of atmosphere, soil, flora, and fauna that will be taken; the frequency of obtaining the samples; the analyses to be performed; and the method of reporting. Include in this section the program for continuing meteorological data collection and evaluation to supplement the estimates previously developed.

\subsubsection{Analysis of Multiple Contribution. Analyze incremental} and total exposures that would result from present or projected nuclear facilities in the vicinity (i.e., within a $80-\mathrm{km}$ radius), and compare them with background man-rem of the same population.

\subsubsection{Estimated Exposures. Present the man-rem annual exposures} estimated to be attributable to facility effluents in each of 16 compass sectors about the plant between each of the arcs having the radii, 1,3 , $5,7,8,15,30,40,60$, and $80 \mathrm{~km}$. Provide details of assumptions, and 
give sample calculations with emphasis on critical pathways to man. Relate to the meteorological data presented in Chapter 3, Site Characteristics. In addition to the man-rem whole body determinations, provide details on man-rem uptakes by critical organs.

1. Identification of Sources--For each radioisotope of biological. significance, describe the in-process inventory, the release mechanisms, and the characteristics of the isotope pertinent to its release and eventual biological impact.

2. Analysis of Effects and Consequences. Support an analysis of effects and the attendant consequences by information, including, for exallyle: (a) jolnt stability-trequency and speed wind data; (b) methors, assumptions, and conditions employed; (c) biological pathways and critical organs; and (d) dose models.

Indicate the consequences for each significant isotope and critical organ in terms of maximum rem per year, average rem per year, and total man-rem per year for the population within a $80-\mathrm{km}$ radius.

Discuss the considerations of uncertainties in the calculational methods and equipment performance. Describe the conservatism inherent in assumptions. Refer to published data to support the analysis.

Discuss the mathematical or physical model employed, including any simplification or approximation used in performing the analyses. Provide the applicable parameters listed in Table 7.1 in tabular form. l'he table should have two columns: one indicating the conservative assumptions used in the analysis and the other indicating those assumptions that are believed to be realistic.

Identify digital computer programs or analog simulation used in the analysis. Include adequate flow charts on the analytical model, computer listing, and input data. Refer to computer models already available to the NRC by summary only.

7.2.6.4 Liquid Release. Describe radioactive 1 iquid effluents, indicating the contribution that the liquid discharged to the atmosphere as water vapor has on the gaseous radioactive source terms. Describe 
Table 7.1

PARAMETERS TO BE TABULATED FOR POSTULATED CHRONIC RELEASES

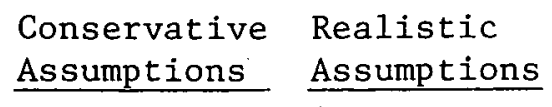

I. Data and Assumptions Used to

Estimate Radioactive Source
A. Fission product inventory
(burnup, cooling time, etc.)
B. Partition mechanisms to ventilation system
C. Form (physical, chemical)
D. Particle size
E. Physical and chemical data related to transport or removal functions

II. Data and Assumptions Used to Estimate Activity Released
A. Partition fractions
B. Leakage fractions
C. Aboorption and filtration effirienries
D. Release flow rates and pathways

III. Dispersion Data
A. Stack or building leakage source
B. Building wake (ground source)
C. Boundary distances
D. $x / Q s$ (continuous annual release)
E. Deposition, decay and washout coefficients

As applicable to the event described 
Table 7.1 (Concluded)

Conservative

Realistic

Assumptions

Assumptions

IV. Dose Data

A. Method of dose calculation

B. Dose conversion assumptions

C. Biological pathways

D. Doses 
the radioactive and nonradioactive wastes from the following sources and include the same type of information (as applicable) described in 7.2 .6 .3 , item 2 .

1. Treated facility effluent

2. Cooling towers (blowdown)

3. Sewage

4. Drinking water

5. Rain run-off

6. Laundry waste

\subsubsection{Items Requiring Further Development}

\subsubsection{Changes from the PSAR}

\subsection{ACCIDENT SAFETY ANALYSIS}

The safety of a waste repository facility is evaluated in part by analysis of the reponse of the plant to postulated accident events in terms of minimizing the causes of such events, the quantitative identification and mitigation of the consequences, and the ability to cope with each situation should it occur. An example of such an event is a criticality accident. These analyses are an important aspect of the reviews made by the NRC before authorizing construction and operation.

The PSAR should present an in-depth discussion of accident analysis to the extent the technology and design is known or determined at the time of its submittal. The FSAR should additionally present details that have been revised or developed since the PSAR submittal. These may result from changes in design and process or from development of additional information during the interim period.

In previous chapters, features important to safety have been identified and discussed. In this section, identify and analyze a range of credible accident occurrences (from minor accidents to design basis accidents) and their causes and consequences. For each situation, 
refer to the appropriate chapter and section describing the considerations to prevent or mitigate the accident.

\subsubsection{Abnormal Operations}

Present in this section the consequences that could occur from malfunctions of systems, operating conditions, or operator error. In general, the magnitude of the events discussed in this section should not have a significant effect beyond the exclusion area. The following format should be used in presenting the desired detail.

7.3.1.1 Event. Identify the occurrence, including the location of the event, type of failure or maloperation, and system or systems involved.

1. Postulated cause of the Event--Describe the sequence of occurrences that could initiate the event under consideration and the bases upon which credibility or probability of each occurrence in the sequence is determined. The following should be provided: (a) starting conditions and assumptions; (b) a step-by-step sequence of the course of each accident, identifying all protection systems required to function at each step; and (c) identitication of any operacor acclons necessidy.*

Indicate the extent to which protective systems must function, the effect of failure of protective functions, the mitigation credit taken

* An example of a methodology for such an analysis is the use of an event tree; it shows pathways that arrive at alternative outcomes as a result of purposeful choice and/or the result of chance occurrences. This methodology has been further refined into so-called "faull Lree didiysis" in which probabilities are assigned to the chance occurrences. For very complex systems, multiple chance occurrences that result in the use of joint probabilities are of ten required to reach an outcome. 'l'hese probabilities may arise from experience, analogy, and informed judgment. Such analyses have been conducted on the safety of nuclear power plants and may be required by the NRC--for other nuclear facilities. If this should occur, the NRC will probably establish procedural and substantive criteria for the analysis. 
for engineered safety features; and the performance of back-up protective systems during the entire course of the event analyzed. Also include the credit taken for the functioning of other systems and consequences of failure.

Present an analysis that permits an independent evaluation of the adequacy of the protection system, as related to the event under study. Use analysis to determine which functions, systems, interlocks, and controls are safety-related and what actions are required by the operator under anticipated abnormal operational and accident conditions.

2. Detection of the Event--Discuss the means or methods to be provided to detect the abnormal operation by using visual or audible alarms or routine inspections performed at a stated frequency. Provide for each an assessment of response time.

3. Analysis of Effects and Consequences--Analyze the effects and, particularly, any radiological consequences of the event. In the analysis show: (a) the methods, assumptions, and conditions used in estimating the course of events and the consequences; (b) the time-dependent characteristics, activity and release rate of fission products, or other transmissible radioactive materials within the confinement system that could escape to the environment; and (c) the margin of protection provided by whatever system is depended on to limit the extent or magnitude of the conquencos.

4. Corrective Actions--For each event, give the corrective actions necessary to return to a normal situation.

\subsubsection{Accidents}

In this section, analyze situations in which primary and/or secondary cunfinement may credibly be brearhed to the extent of releasing radioactive materials beyond the exclusion area or in quantities that may endanger personnel within the exclusion and restricted areas. Also, consider those industrial accidents that would not result in a release of radioactivity but could endanger onsite personnel. 
Use the following format to present the desired detail.

7.3.2.1 Accident Analyzed. Identify the accident, the location or portion of the facility involved, and the type of accident. Discuss each accident sequentially.

1. Cause of the Accident--For each accident analyzed, describe and list the sequence of events leading to the initiation of the accident. Identify with respect to natural phenomena, human error, equipment malfunction, or equipment failure. Estimate probability, and indicate how this prohili,ilty octimatc was deterimiuled.

2. Accident Analysis--Analyze the efferts and, particularly; any radiological consequences of the accident. As with the abnormal event analysis, show the methods, assumptions, and conditions used in estimating the consequences, the recovery from the consequences, and steps used to mitigate the accident. Assess the consequence of the accident to persons and property offsite.

In addition to the assumptions and conditions employed in the course of events and conserpenses, supply oufficient iirfulllation co:

a. Identify the mathematical or physical model employed, describing any simpliftcation intrndired to porform the analysis, ind identify assumpliums used that are known to differ from those normally IIsed by tho NRC.

b. Ilentify any digital computer program or analog simulation used in the analysis, with principal emphasis on the input data and the extent or range of variables investigated. Include figures showing the analytical model, flow path identification, actual computer listing, and complete listing of input data. (Thr drtailed descripliun of mathematical models and digital computer programs or listings may be included by available reference with only summaries provided in the PSAR text.)

c. Dessrihe the phyeical or matliemalical mudels used in the analyses and the bases for their use with specific reference to: (.1) the distribution and fractions of fission produce inventory assumed to 
be released from the source material into ventilation systems; (2) the concentrations of radioactive or fission product inventory airborne in the confinement atmosphere and buildup on filters during the past accident time intervals analyzed; and (3) the conditions of meteorology, topography, or other circumstances, and combinations of adverse conditions, considered in the analyses:

d. Identify the time-dependent characteristics, activity, and release rate of the fission products or other transmissible radioactive materials within the confinement system that could escape to the environment through leaks in the confinement boundaries and leakage through lines that could exhaust to the environment.

e. Consider uncertainties in calculational methods, in equipment performnace, in instrumentation response characteristics, or other indeterminate effects taken into account in the evaluation of the results.

f. Explain the conditions and assumptions associated with the events analyzed, including any reference to published data or. research and development investigations in substantiation of the assumed calculated conditions.

g. Discuss the extent of system interdependency (confinement system and other engineered safety features) contributing directly or indirectly to controlling or limiting leakages from the confinement systems, or other sources as the contribution of: (1) confinement air systems; (2) air purification and cleanup systems; and the like.

h. Indicate the results and consequences derived from each analysis and the margin of protection provided by the system(s) depended on to limit the extent or magnitude of the consequences.

i. For the accidents, discuss the results of calculations of potential integrated whole-body and critical organs doses from exposure to radiation as a function of distance and time after the accident (presented in terms of a lifetime dose commitment). 
Chapter 8

LONG-TERM WASTE ISOLATION

\subsection{CRITERIA FOR WASTE ISOLATION}

In this chapter (1) provide information concerning the composition and physical characteristics of the nuclear waste, (2) identify and describe the waste-environment interactions, (3) identify any geological and geophysical phenomena that may affect the waste disposal location, and determine if any of these phenomena may prevent proper containment of the waste, (4) summarize the ways the waste may escape into the biosphere, with an assessment of the likelihood of each path, and (5) determine the effect of the waste on the biota for each pathway. Indicate the criteria required to ensure proper containment of the nuclear waste in the geologic environment of the radioactive components. Identify all processes associated with the waste, the local geologic environment, and waste-environment interactions, and evaluate the potential of each process, or combination of processes, for interfering with the waste containment. Cross-reference material presented in previous chapters when it is used in this chapter. Tn sectionc 8.1.1 througli 0.1 .4 , discuiss the criteria selected to evaluate the waste containment procedure.

\subsubsection{Selection of a Stable Formation}

The geologic formation selected for the disposal site must be capable of containing the waste for several hundreds to thousands of years. For very long-lived nuclides, this period may be tens or hundreds of thousands of years ur mure. It must be certain, therefore, that the formation will not be subject to any process that may interfere with the containment of the waste. 
This implies that significant deformation of the formation should not currently be occurring and should not be likely to occur during the waste containment period. Such deformation could include diapirism or diastrophism, as well as any volcanic, seismic, or climate-related (e.g., glacial) activity. If the site is in a region undergoing such deformation, or which underwent such deformation during the Quaternary, identify the type and amount of the deformarion, and the possibility of future recurrence; also evaluate its effect on the disposal site.

Specifically, consider the potential of the deformation to expose the formation to significant erosion or produce iractures that may inleisect the disposal site. Consider the effect of the deformation on subsurface fluids, particularly when climatic or seismic activity may be significant. Identify the various processes and their interactions with the waste and evaluate them for their potentlal to interfere with containment of the waste.

\subsubsection{Isolation from Subsurface Fluids}

Because the waste may be leached and transported, it is preferable that the waste be isolated from subsurface flulds. Huwever, if fluids are present, (1) identify the subsurface fluids and indicate their composition; (2) evaluate their potential fur leaching and transporting the waste (Section 8.1 .3 ); and (3) derermlue Llue patterno of oubcurface fluid flow that may bring the waste into contact with the biosphere. Also identify the paths of subsurface fluid flow near the sice and lu the surrounding formations.

Consider changes in the fluid flow pattern caused by mining or drilling activities during the burial of the waste, or by pumping or irrigation at the surface. Determine the role of fluid flow processes external to the site currently vccurituy. These proceaves alght iuclude climatic activity (e.g., rainfall and glaciation), seismicity, regional deformation, hydrothermal or volcanic activity, and local subsidence, as well as other processes. 
Identify any phenomena likely to affect subsurface fluid flow that occurred in the recent geologic past (i.e., a period equivalent to the waste containment period), are currently occurring, or that may recur during the lifetime of the site. Determine how these phenomena may alter fluid flow (now or in the future) at the disposal site. In particular, indicate whether the ability of the fluid to transport the waste from the disposal site will be affected.

\subsubsection{Leachability of Waste}

If subsurface fluids are present, the fluid and waste may interact. The fluid may leach radionuclides from the waste-containing material (and transport them from the disposal site; refer to Section 8.1.2). Therefore, determine the specific fluid-container* and fluid-waste interactions.

Consider processes that may affect the leaching (and transporting) of the waste shortly after disposal. Examples of such processes may include ion exchange with the rock near the disposal site, low solubility of the waste, and low permeability of the surrounding formation. To determine the effects of these processes, identify (1) the physical and chemical properties of the fluids, waste, and waste-containing materials; and (2) the interactions among these materials.

Because the formation containing the disposal site may be affected by the decay of the radionuclides and external events (e.g., human activities such as drilling or pumping, climatic changes, or tectonic events such as a renewal of diapiric activity or volcanism) during the

\footnotetext{
*A distinction is made between the waste material and the waste container. The container is not primarily the metal cannister in which the waste is placed, but the material in which the waste is incorporated, if any. To be general, the cannister is considered as containment, but it is not expected to provide an impervious barrier for a significant period. The waste material itself may be chemically bound, or physically mixed homogeneously or nonhomogeneously with the "containing" material. Therefore, some reactions may be controlled by the properties of the host or. "containing" material, whereas others may be controlled by the properties of the waste material itself.
} 
lifetime of the waste, identify these processes and the effect these processes may have on the ability of the pore fluids to leach and transport the waste (Section 8.1.2). It is likely that the fluid's ability to leach and transport the waste will change with time because of (1) changes in the composition of the waste as the radionuclides decay; (2) changes in the physical properties of the waste and waste-containing material as they are altered by contact with the solutions, radiation damage or interaction with volatiles from the radionuclide decay, and thermal degradation caused by the release of heat from the decay process; (3) degradation of the surrounding rock; and (4) changes in the fluid properties. Consequently, Identify all these processes and evaluate their effect on waste containment.

A $\perp$ of the processes above may be modified if the properties of the fluids are changed by human intervention. If, for example, buffering of the fluids or altering the ion exchange capabilities of the surrounding medium (such as by packing the site with clays) is proposed, the ability of the fluids to leach or transport the waste may be significantly changed. As before, identify the interactions and processes involved in such alteration, and evaluate each in terms of its effect on the containment of the waste.

\subsubsection{Waste-Surrounding Medium Interaction}

In this section, discuss how the waste may modify its local environment and the effect this modification may have on the surrounding medium.

While the radionuclides decay, volatiles and heat will be generated (in addition to the changing waste compnsitinn afferting the ability of any pore fluids present to leach and transport the waste). As the local temperature increases, new interactions between pore fluids, waste, and waste-containing materials may occur--with original interactions altered--as well as interactions among these materials and the host rock. The pressure at the site. may change as volatiles are released by radioLuclides decay or degradation of the host rock. The temperature and pressure gradients, aided by radiation damage to the material, may fracture 
the host rock, and all these effects may alter pore fluid migration. Consequently, identify these processes and their interactions, and evaluate them in terms of their effect on the containment of the waste.

\subsection{WASTE CHARACTERISTICS}

In this section, describe all waste processes and waste-surrounding medium interactions.

\subsubsection{Waste and Waste Container Processes}

8.2.1.1 Waste Properties. Describe the composition of the waste and its physical and chemical properties. Specify the type and amount of radionuclides present, their physical and chemical forms (e.g., solid, liquid, or gas; compounds containing the radionuclides; grain size if powdered). Determine their physical and chemical properties. Identify the decay path of each nuclide, and determine what volatiles may be evolved. Specify the type and amount of radiation emitted from nuclides and decay products. Specify the physical and chemical form and properties of decay products. Support these determinations with appropriate data.

\subsubsection{Waste Container Properties. Specify how the waste is to be} contained (e.g., canisters, fuel elements, glass, and ceramic powder). Determine the composition, and the physical and chemical properties of the container. Determine the susceptibility of containing materials to radiation damage and to changes in physical and chemical properties that may occur during the containment of the waste and decay products (refer to Section 8.2.1.1). Support these conclusions with the appropriate data.

8.2.1.3 Thermal Effects. Determine the amount of heat evolved by the waste as it decays. Identify the effects this may haye on the waste, the waste containers, and subsequent waste and waste container interactions.

* This will have to be estimated, based on assumptions concerning the generation, decay, and processing of the mix of wastes to be handled in the facility during its operational phase. 
8.2.1.4 Volatiles. Determine the quantity and composition of the volatiles evolved during decay of the radionuclides. Determine how the volatile evolution may be affected by the thermal effects in section 8.2.1.3.

8.2.1.5 Radiation Effects. Determine the type and quantity of radiation evolved during the decay process. Identify the effect this will have on the waste and waste container, and indicate subsequent waste and container interactions (e.g., the effect of structural damage on the container, ionization of volatiles, devitrification of waste encapsulated in glass).

8.2.1.6 Waste and Waste Container Transformations. Determine changes in the composition of the waste as the radionuclides decay. Identify the effects of temperature, pressure, volatiles released, radiation damage, and similar factors on the physical and chemical properties of the waste material. Determine what effects will occur in the wastecontaining material.

\subsubsection{Surface Effects. Discuss the surface area availability of} radionuclides within the waste body under various conditions of degradation.

\subsubsection{Surrounding Medium Modifications}

If the characteristics of the waste itself or the disposal medium are intentionally altered to mitigate a particular proress nr interaction, describe the alteration and the effect such alterations will have on the waste itself, and on waste-container, waste-pore fluid, and waste-surrounding medium interactions. Such modifications may include buffering the pore flulds to alter their $\mathrm{pH}, \mathrm{Eh}$, and/or the leachability of the waste in the pore fluids; and packing the surrounding medium with clay to inhibit (by ion exchange) transport of the radionuclides by pore fluids. Document such modification with the appropriate data. 


\subsubsection{Waste-Surrounding Medium Interaction}

8.2.3.1 Waste-Pore Fluid Interaction. Consider the effect of those pore fluids near the disposal location (refer to Sections 8.1.2 and 8.3.6). Determine the composition of the pore fluids and pore-fluid flow patterns in the formation. Identify pore-fluid effects on the waste, such as leaching and transport. Evaluate the effects of temperature and pressure gradients.

8.2.3.2 Thermal Effects. Consider the effect on the host rock of the heat evolved by radionuclide decay. Determine the temperature change with time of the host rock. Identify transformations and modifications of the surrounding medium caused by the temperature increase, such as release of volatiles by the host rock, fracturing, phase changes of the minerals in the rock, changes in composition of the rock, local melting, and any other effects produced by the temperature change.

8.2.3.3 Changes in In Situ Stress Fields. Identify how the stresses at the waste disposal location may change because of the increased temperature and release of volatiles. Evaluate the effects of stress changes on any preexisting fractures and their potential for creating new fractures. Determine the effects of stress change on waste processes and interactions. Determine effects on pore fluid flow.

8.2.3.4 Radiation Effects. Determine the effect of radiation from. the radionuclide decay on the waste containing materials and the host rock. Identify changes in the structural or mechanical properties of the waste containing materials and the rock. Consider the effect of radiation on chemical reactions due to ionization of the interacting species.

\subsubsection{Changes in Cumpusition and Quanity of Reactants. Because} the waste must be contained for possibly tens or hundreds of thousands of years, changes in the surrounding medium produced by the effects considered in Sections 8.2.3.1 through 8.2.3.4 may be quite significant. 
Determine how the waste-surrounding medium interactions may change during the necessary containment period of the waste. Determine what changes (e.g., physical or chemical) may occur in the waste, the material containing the waste, the host rock, and the properties of the pore fluids. Evaluate the effect of these changes on thc transport by pore fluids of the radionuclides.

\subsection{GEOPHYSICAL PHENOMENA}

Because of the variety of geologiçal, genphysical, and tecturic phenomena that may occur during the necessary antalnment periud of che waste, and because of the variety of physical-chemical environments to be considered for waste storage, the containment of the waste may be influenced by a variety of the geophysical and geological phenomena. Therefore, in this section determine what tectonic and external events have occurred in the recent (i.e., a time span comparable to the necessary waste containment period) geologic past, what events may happen during the necessary waste containment period, and how these events may affect proper containment of the waste.

\subsubsection{Tectonic Events}

Identify the tectonic features at the site. Describe them in terms of their relationship to the disposal site. Provide maps (plan view and cross section) with these features indicated. Detcrmine the age of the features. Discuss the possibility that these events may orcur again during the necessary containment period of the waste. Specifically, bul not exclusively, consider the events listed below when applicable.

\subsubsection{Gradual Effects}

1. Diastrophism--regional uplift or subsidence

2. Diapirism

3. Vulcan1s̈m--fissure eruptions

4. Intrusion of Magma into the Site 
5. Intrusion of Hydrothermal Fluids

6. Sedimentation

7. Erosion and Weathering

8. Eustatic Sea Level Changes

9. Continental Drift.

\subsubsection{Catastophic Events}

1. Volcanism--central eruptions

2. Seismic Activity.

3. Local Subsidence (e.g., caused by seismic activity, such as slumping in regions underlain by thixotropic materials; or solution by ground waters, such as in areas where karsts are present).

4. Sedimentation or Deposition of Materials (e.g., produced by major tectonic events, such as landslides assoctated with earthquakes, or ash or lava deposited by volcanoes).

5. Erosion (associated with major tectonic or climatic events; e.g., erosion produced by rejuvenation of a river during a period of glaciation).

\subsubsection{External Events}

These are events, which although they may produce deformations of the earth, are not strictly tectonic or associated with tectonic events. As in Section 8.3.1, Identify the events in this category that may have occurred at, or influenced, the disposal site. Describe them in terms of their relationship to the site. When applicable, provide maps with these features and their relationships to the site indicated. Determine the age of these features. Determine whether these events may occur again during the necessary disposal period of the waste. Consider the following events when applicable:

8.3.2.1 Glaciation. 


\subsubsection{Climate Changes. Consider the distribution of surface}

waters and their effect--or lack thereof--at the site.

\subsubsection{Geomagnetic Field Changes. Also consider their effect} on telluric currents.

8.3.2.4 Telluric Currents. Consider the effect on groundwater flow.

8.3.2.5 Changes in the Earth's Rotation Rate. Consider the possibility of a changed rotation rate that produces seismic activity at the site.

\subsubsection{Meteor Impact.}

8.3.2.7. Other. Consider when applicable.

\subsubsection{Human Intervention}

Determine the types of human intervention that may occur at the site. Consider the following: the effects of pumping subsurface fluids; irrigation; injection of fluid wastes into formations near the site: alleration of the topography and the effect of such alteration on surface waters; effect of construction or failure of structures in the area (such as dams); and redistribution, additinn, or depletion of surfaco waters, such as the construction of lakes, the removal of surface waters for distribution to other regions, or the channelizing of rivers. Identify the consequences of such actions and relate the consequences to the disposal site. Provide maps, diagrams, or other data when applicable. It is assumed that future civilizations that possess the technology to cunstruct mafor engineering works will also possess the intelligence to assess the implications of the buried wastes. The location will be adequately marked both at and below the surface as a radioactive waste disposal site. In addition, the written records and verbal traditions of the day can be expected to pass on relatively accurate records to future civilizations. Nevertheless, the possibility of the failure of these assumptions and expectations, and the resulting consequences, cannot be overlooked. 


\subsubsection{Combinations and Interactions}

Consider combinations of the events or processes indicated in Sections 8.3.1 through 8.3.3, using as a guide the partial list that follows. Identify specific combinations, associations, superpositions, and interactions. Determine the consequences of each and whether or not they have occurred at or near the site in the recent geologic past. Evaluate their potential for occurring again during the lifetime of the waste. Material in previous sections may be cross-referenced when applicable. The following are examples of possible combinations and interactions.

8.3.4.1 Volcanism and Hydrothermal Activity.

8.3.4.2 Erosion or Sedimentation during Glaciation.

8.3.4.3 Erosion or Sedimentation Produced by Climate Changes.

8.3.4.4 Geomagnetic Field Changes and Changes in Climate.

8.3.4.5 Volcanism and Seismic Activity.

8.3.4.6 Others not Previously Mentioned.

\subsubsection{Effect of Tectonic and External Processes on Waste Containment}

Identify tectonic and external processes (those delineated above as single factors and in combination with one another) and their consequences that have occurred in the recent geologic past at the site, that are occurring, and may occur during the lifetime of the waste at the site (previous material may be cross-referenced). Specify their effect on the stability of the formation. Determine whether or not they may produce fracturing near or at the disposal location. Determine their effect on the waste and various waste interactions (e.g., wastehost rock interactions). Identify processes that may prevent proper containment of the waste. 


\subsubsection{Effect of Tectonic and External Processes on Pore Fluid Flow}

Identify the tectonic and external processes (above or in combination) that occurred at the disposal site during the recent geologic past, that are occurring, or that may occur during the necessary disposal period of the waste (refer to Sections 8.3.1 through 8.3.5; previously discussed materlal may be cross-referenced). Determine the effects of each process on subsurface fluid flow. Identify any physical or chemical changes in the pore fluid that may result. Identify changes in the pattern of pore fluid flow that may result. Determine how these effects may alter the leaching or transport of the waste and how these changes may affect the waste-host rock interactions. Relate these effects to the physical and chemical changes that may occur in the waste, waste-containing material, and host rock. Identify changes that may occur in the migration of the waste from the disposal site, as well as any physical or chemical changes in the waste itself. Document these results with the appropriate material (e.g., maps, diagrams, and laboratory data).

\subsubsection{Interaction of Processes with Waste--Summary}

(Cross-reference material from previous sections in this section when appropriate.) Summarize the processes considered. Summarize their effects on the physical and chemical properties of the formation containing the waste (e.g., production of fractures, alteration of mechanics. 1, properties of formation due to temperature or pressure changes). Summarize their. effects on the pore fluid composition and migration patterns. Summarize their effect on the waste, waste-containing material, and host rock, and indicate the various interactions involved. Identify which effects and consequences may significantly influence the waste rontainment during the lifetime of the waste, and estimate the likelihood of occurrence for these effects. Identify specific changes in the physical and chemical properties of the waste if it migrates from the disposal site. Document these effects with the appropriate material (e.g., maps, diagrams, and 1.ahoratory data). 


\subsubsection{Waste Transport}

Identify the physical and chemical properties the waste is most likely to possess should it reach the ground surface (cross-reference material from previous sections if applicable). Determine the amount and composition of the waste that may enter surface waters for the processes considered in Sections 8.3.1 through 8.3.7. Determine if possible when; or if, the waste may enter surface waters. Consider how the amount of waste, with its associated physical and chemical properties, that enters surface waters may vary with time.

\subsection{ALTERNATIVE FUTURES}

(Cross-reference material from previous sections when applicable.) Identify the processes, or combinations of processes, and interactions considered in Sections 8.3.7 and 8.3.8 that are most likely to occur during the lifetime of the waste. Identify those physical and chemical properties that the waste is most likely to possess when, or if, it enters the surface waters. Identify the effects of these processes and interactions on the geologic formation. Systematically develop a set of plausible alternative scenarios depicting the occurrence of the various interactions that could bring waste in to the biosphere. Critically assess the consequences and the probability of occurrence of these scenarios. Show by this assessment That any plausible alternative is of vanishingly low probability or of little consequence when it may occur.

These alternative futures may be constructed and displayed as an event tree or fault tree analysis as discussed in the footnote on page $7-18$.

Evaluate the possibility of the geologic formation containing the disposal site becoming an economically valuable resource if the disposal site had not been located there. Evaluate the possibility that the gevlogic formation altered because of contart with the waste or the waste itself may become an economically valuable resource. Identify the physical and chemical properties of the lithologic units within the formation before and after contact with the waste in these evaluations. Consider the 
economic consequences if the formation, or any other formations in contact with the waste, cannot be used as a resource. Document these considerations with appropriate supporting data.

\subsection{POTENTIAL BIOLOGICAL PATHWAYS}

\subsubsection{Possible Biotas}

Identify the ecosystems that (1) might be expected on or near the site as a consequence of the changes considered in Section 8.4; (2) can be identified in the macro- or micro-fossil records for the last miliion years on or near the site; and (3) now occur within $1500 \mathrm{~km}$ of the site. Characterize these extant biotas with respect to the ways in which they would be expected to ditter from the present blotas on or near the sites with respect to their radiosensitivity or potential for transmission of radionuclides to man or organisms important to man. These characterizations should identify routes of radionuclide movement, rates of movement, and the factors controlling these pathways and rates.

When practicable, quantify and integrate these characterizations by use of appropriate models (e.g., compartment, specific activity motels). Summarize the data in both quantitative (tables, charts, and diagrams) and qualitative (e.g., narrative) forms. Give particular attention to the phys1cal, chemical, and biological mechanisms that either snnrentrate (e.g., food chain transfers) or disperse (e.g., erosion) radionuclides.

\subsubsection{Hypothetical Biotas}

To accommodate possible evolutionary changes during the period of concern, describe hypothetical ecosystems that differ significantly from the most extreme of these characterized in Section 8.5.1 with respect to their radiosensitivity or their ability to convey radionuclides to man or species important to man. Discuss the implications of these possible evolutionary changes as they present hazards to man and other living organisms. That is, explore the potential consequences of radionuclide release to the environment if the radiosensitivity of the vegetation 
existing at the time of release is, for example, twice that of the most radiosensitive current vegetation.

\subsubsection{Potential Human and Nonhuman Exposures}

Combine the scenarios of Section 8.4 with the extreme or otherwise significant ecosystems identified in Sections 8.5.1 and 8.5.2 to the range of potential hazards to man and other organisms, based on species known to exist, or to have existed, and on hypothetical species of greater radiosensitivity or greater ability to convey radionuclides to man or species important to man. 
Every applicant must describe, the Quality Assurance Program (Chapter 11) to be applied to the design, fabrication, construction, and testing of structures, systems, and components of the facility. Therefore, provide sufficient detail to indicate that all operations will ensure that a technically competent staff will be maintained to provide continued implementation of administrative and operating procedures and programs necessary to ensure safe operation.

The information contained in this chapter must respond to the requirements of appropriate sections, parts, and appendices of the Code of Federal Regulations, most of which are yet to be developed for radioactive waste repositories. Examples of the type of information that must be supplied, as exemplifled for fuel reprocessing facilities, follow:

1. $10 \mathrm{CFR} 50, \$ 50.34$, "Contents of Application--Technical Information"

2. 10 CFR 50, Appendix B, "Quality Assurance Criteria for Nuclear Power Plants and Fuel Reprocessing Plants"

3. 10 CFR 50, Appendix E, "Emergency Plans for Production and Utilization Plants"

4. 10 CFR 50, Appendix F, "Policy Relating to Siting of Fuel Reprocessing Plants and Related Waste Management Facilities"

5. 10 CFR 50, Appendix P, "General Design Criteria for Fuel Reprocessing Plants"

6. 10 CFR 55, "Operators' Licenses"

7. 30 CFR 57, Mine Enforcement and Safety Administration Regulations 


\subsection{ORGANIZATIONAL STRUCTURE}

Use the following format to present the organizational structure from PSAR submission through construction. Provide the organization as it will function through preoperational testing, start-up, facility operation and decommissioning in the FSAR.

\subsubsection{Corporate Organization}

Describe the corporate arrangement or organization related to waste isolation activity. If the corporation is comprised of two or more existing cntitico, crplain their rolationohip and tho delegation of roeponcibiliticc among them. As required in $10 \mathrm{CFR} 50, \S 50.33(\mathrm{f})$, "Contents of Applications," provide sufficient information to demonstrate the financial capabilities for construction, operation, and decommissioning of the waste isolation facility.

\subsubsection{Corporate Functions, Responsibilities, and Authorities.} Describe corporate functions, responsibilities, and authorities with respect to facility engineering and design, construction, quality assurance, testing, operation, and other applicable activities.

\subsubsection{Applicant's Inhouse Organization. Describe the applicant's} corporate management and technical support staffing and inhouse organizational relationşhips established for the design and construction, review, and quality assurance functions, and the responsibilities and authorities of personnel and organizations described in Section 9.1.1.1. Establish the extent of dependence of inhouse or onsite personnel on corporate or offsite personnel.

9.1.1.3 Interrelationships with Contractors and Suppliers. Describe working interrelationships and organizational interfaces among the applicant, the architect-engineer, and other suppliers and contractors. 
9.1.1.4 Applicant's Technical Staff. Describe the applicant's corporate (home office) technical staff that specifically supports the engineering, construction, and operation of the waste isolation facility; include the duties, responsibilities, and authority of the engineering technical staff, with numbers of personnel, their qualifications, educational backgrounds (disciplines), and technical experience. Indicate the technical support to the corporate technical staff to be provided by outside consultants. If such arrangements are to be used, provide the specific areas of responsibility and functional working arrangements of these support groups.

\subsubsection{Operating Organization}

Describe the structure, functions, and responsibilities of the facility operating organization. Include the following specific information:

9.1.2.1 Facility Organization. Comprehensively describe the facility personnel organizational arrangement, showing the title of each position, the flow of responsibilfty as depicted by an organization chart, the number of personnel in each unit, and an identification of those positions requiring licenses in accordance with 10 CFR 55, "Operators' Licenses." . Describe the organizational arrangement that assures safe operation. Indicate the personnel assigned to the safety committee, its mode of operation, and the responsibilities of committee members.

\subsubsection{Personnel Functions, Responsibilities, and Authorities.} Describe the functions, responsibilities, and authorities of all personnel positions; discuss specific succession to responsibility for overall operation of the facility if absences, incapacitation, or other emergencies occur.

\subsubsection{Personnel Qualification Requirements}

Describe the proposed minimum employment requirements for onsite facility personnel. In the PSAR, specify the minimum qualification 
requirements and, as known, the qualifications of assigned facility personnel. In the FSAR, present any changes in required qualifications and the description of staff personnel finally selected. Include the following specific information:

9.1.3.1 Minimum Qualification Requirements. State the minimum qualification requirements for all facility operating, technical, and maintenance support personnel.

9.1.3.2 Qualifications of Facility Personnel. Present in resume form the qualifications of the individuals assigned to the managerial and technical positions described. Identify individuals by position LILle alld, as. a mlitumil, describe thelr furmal educarton, craining, and experience. Provide complete staff qualifications in the FSAR.

\subsubsection{Liaison with Outside Organizations}

Discuss arrangements made with outside organizations, including those providing expertise on technical facets of details concerning site selection and evaluation, facility design and construction, process and equipment selection or development, and safety evaluations. Additionally, indicate any arrangements made with other government agencies, as well as the method or system used to monitor the intertaces between participants.

\subsection{PROOF TESTING AND OPERATION (FSAR)}

In the FSAR, describe the proof testing and operating plans. Emphasize those plans that demonstrate that the facility, equipment, and processes meet safety and design criteria discussed in previous chapters. Present test plans to verify the integrity of the facility, equipment, and operations, and to substantiate the safety analysis. Discuss the plans for operating under conditions of engineered retrievability. Describe the criteria for evaluating the effects of engineered retrievability. Emphasize the relationship of the results of the engineered retrievability phase to the safety considerations of the facility design, its operations, and long-term waste isolation. Report results obtained 
from carrying out the plans as an appendix to the FSAR submittal.

\subsubsection{Administrative Procedures for Conducting the Proof Test Program}

Describe the system used for preparing, reviewing, approving, and executing all proof testing procedures and instructions, and for evaluating, documenting, and approving the test results.

Describe the administrative procedures for incorporating any needed system modifications or procedure changes, based on the results of the tests (e.g., test procedure inadequacies or test results contrary to expected test results).

\subsubsection{Test Program Description}

Describe the test objectives and the general methods for accomplishing these objectives, the acceptance criteria that will be used to evaluate the test results; and the general prerequisites for performing the tests:

9.2.2.I Physical Facilities. For the physical facilities, components, and equipment, summarize the following test components: items tested, type of test, responses, and validation.

9.2.2.2 Operations. As above, itemize operations to be tested, together with additinnal information required.

\subsubsection{Test Discussion}

9.2.3.1 Test Name or System Under Test. For each preoperational test, provide the following information:

1. Purpose--Describe the purpose of the test.

2. Response and Acceptance Criteria--Define the response expected in terms of design bases and criteria discussed in previous chapters, and indicate the margin of difference acceptable for safe operation and waste isolation. When the results of the preoperational test do not confirm the 
expected response, discuss the changes required in detail and provide justification that the change will correct the problem.

\subsection{TRAINING PROGRAMS}

\subsubsection{Program Description}

Describe the proposed training program, including the scope of training in facility operations and design, instrumentation and control, methods of dealing with malfunctions, decontamination procedures, and emergency. procedures; in health physics, cover such suhjects as the nature and eourcç of radiation, methods of controlilimg contamination, interartions of radiation with matter, biological effects of radiation, and the use of monitoring equipment. Identify that job classifications correspond with the required training for the job.

\subsubsection{Retraining Program}

Describe the program for continued training through presentation of additional materials and refresher training.

\subsubsection{Administration and Records}

Identify personnel in the organization responsible for the training programs and for maintaining up-to-date records on the status of trained personnel, training of new employees, and refresher or upgrading training of present personnel.

9.4 NORMAT. MPF.RATTINS

\subsubsection{Facility Procedures}

In the.PSAR, indicate a commitment by submitting detailed written procedures to conduct safety-related operations: In the FSAR, include a list of titles of procedures with clear indication of their purpose and applicability, and describe, by compiling quality assurance and safety 
manuals, the review, change, and approval procedures for all facility operating, maintenance, and testing procedures.

\subsubsection{Facility Records}

In the FSAR, present the detailed management system for maintaining records relating to the historical operation of the facility: the quality assurance records required in $10 \mathrm{CFR} 50$, Appendix B, Section XVII, the operating records, including principal maintenance, alteration, or additions made; records of abnormal occurrences and events associated with radioactive releases; and environmental surveys.

\subsection{EMERGENCY PLANNING}

Describe the applicant's plans for coping with emergencies. The information to be included is described in 10 CFR 50, 550.34 (a)(10). The minimum items to be discussed in the PSAR are set forth in 10 CFR Part 50, Appendix E, "Emergency Plans for Production and Utilization Facilities," Section II.

The information to be included in the FSAR is described in 10 CFR $50, \S 50.34(\mathrm{~b})(6)(\mathrm{v})$. The minimum items to be discussed are set forth and detailed in $10 \mathrm{CFR}$ 50, Appendix E, Sections III and IV.

\subsection{DECOMMISSIONINC}

Provide information in the PSAR and FSAR to respond to the requirements of 10 CFR 50, Appendix F, Section 4, "Policy Relating to the Siting of Fuel Reprocessing Plants and Related Waste Management Facilities," which requires that adequate provisions be made for decommissioning the waste isolation facility.

\subsubsection{Decommissioning Program}

Present the planned program for decommissioning the facility. Describe procedures for dismantling the surface facility, disposing of contaminated surface objects. In the mine, decontaminating those 1tems that have intrinsic value or further utility, backfilling all tunnels, 
rooms, etc., sealing access and ventilation shafts, placing warning markers underground and on the surface, and revegetating and restoring surface land contours.

\subsubsection{Decontamination}

Discuss the procedures and arrangements to decontaminate or dispose of the facility components so that they will not present a hazard for an indeterminable period.

\subsubsection{Agreements with Outside Organizations}

Present the arrangements and agreements with other organizations that will ensure the continued safety of the dccommissioncd facility.

\subsubsection{Arrangements for Funding}

Discuss the means for funding the decommissioning and for isolating the facility from the public--in perpetuity if necessary. 
Chapter 10

TECHNICAL SPECIFICATIONS

\subsection{PRELIMINARY TECHNICAL SPECIFICATIONS (PSAR)}

In accordance with 10 CFR 50, $\$ 50.34$, an application for a construction permit for a production or utilization facility must include identification and justification for the selection of those variable conditions or other items, determined as a result of preliminary safety analysis and evaluation, to be probable subjects of technical specifications for the facility. Special attention should be given to items that may significantly influence the final design. By selecting probable technical specification subjects, those items that require special attention at the construction permit stage, will be identified. This identification will help to offset significant changes in design to support final technical specifications (e.g., particularly those specifications that include technical operating limits, conditions, and requirements imposed upon facility operation for public health and safety).

Throughout the previous sections of the SAR Standard Format, the necessity for identification of safety limits, limiting conditions, and surveillance requirements has been indicated. It is from such information that the technical specifications and supporting bases are developed.

The preliminary technical specifications and bases proposed by an applicant for its facility should be included in Chapter 10 of the PSAR. The preliminary technical specifications should be complete (i.e., to the fullest extent possible, they should provide numerical values and uther pertinent daca). The applicable sections that develop, through analysis and evaluation, the details and bases for each specification should be referenced. 


\subsection{PROPOSED TECHNICAL SPECIFICATIONS (FSAR)}

In accordance with 10 CFR 50, 550.36, each operating 1icense for a production or utilization facility issued by the NRC must contain technical operating limits, conditions, and requirements imposed upon plant operation for public health and safety. The technical specifications are proposed by the applicant for an operating license. After review by the staff, they are modified as necessary before becoming part of the operating license. A statement of the bases or reasons for all specifications, other than those dealing with administrative controls, must be included in the application, but this statement does not become part of the technical specifications. Technical specifications may not be changed without NRC approval.

The technical specifications and bases proposed by an applicant for its facility should be included as Chapter 10 of the FSAR. Except for the specifications covering design features and administrative controls, each specification should be provided with a summary statement of the technical and operational considerations that justify its selection. For each specification, the applicable sections of the FSAR that fully develop, through analysis and evaluation, the details and bases for the specification should be referenced.

Additional guidance on the contents of the teclmical specifications is provided in "Guide to Content of Technical Specifications for Nuclear Reactors," available from the NRC.

\subsection{CONTENT OF TECHNICAL SPECIFICATIONS}

Technical specifications should include both technical and administrative matters. Technical specifications related to technical matters consist of those features (process variables, systems, or components) of the facility that are instrumental for safety. In addition, technical specifications related to technical matters should include effluent and environmental monitoring and the attainment of ALARA levels of releases and exposures. Technical specifications related to administrative matters should address those organizational and functional requirements that are 
important to the achievement and maintenance of safe operation of the facility.

\subsection{BASES FOR TECHNICAL SPECIFICATIONS}

When a technical specification has been selected, the bases for its selection and its significance to safe operation should be defined. This can be done by the provision of a summary statement of the technical and operational considerations that justify the selection. The SAR should fully develop, through analysis and evaluation, the details of these bases. The physical format for technical specifications is, therefore, important. The collected specifications and their written bases comprise a document that delineates the facility features important to safe operation, the reasons for their importance, and the relations of the features to one another.

\subsection{DEVELOPMENT OF TECHNICAL SPECIFICATIONS}

The five categories for which technical specifications, are defined in 10 CFR 50, 550.36, have been derived from a consideration of factors that bear on the use and maintenance of physical barriers in the operation of a facility. Additional categories may be designated by the applicant.

\subsubsection{Safety Limits and Limiting Control Settings}

Specifications of this category apply to observable and measurable safety-related process variables (e.g., pressures, temperatures, rates, cumpusitions, volumes, and quant1ties). Control of such variables is directly related to the performance and integrity of equipment and confinement barriers.

\subsubsection{Limiting Conditions and Operation}

This category of technical specification covers two general classes, (1) equipment and (2) technical conditions and characteristics of the facility necessary for continued operation, as discussed below: 
10.5.2.1 Equipment. Technical specifications must establish the lowest acceptable level. of performance for a system or component and the minimum number of components or the minimum portion of the system that must be operable or availabie.

10.5.2.2 Technical Conditions and Characteristics. Technical conditions and characteristics should be stated in terms of allowable quantities (e.g., temperature, pressure, mass of fissionable material in certain systems, radiation levels in certain systems, chemical constitution of certain materials, or allowable arrangement of equipment).

\subsubsection{Surveillance Requirements}

The major omphaio in ourvcillanee specificatiuss slivuld be placed on those systems and components that are essential to safety during all modes of operation or are necessary to prevent or mitigate the rnnsequences of accidents. Tests, calibrations, or inspections are necessary to verify performance and availability of important equipment and to detect incipient deficiencies.

\subsubsection{Design. Features}

The technical specifications cover design rharacteristirs of special importance to each of the physical barriers and to the maintenance of safety margins in the design. The principal objective of this category is to control changes in the design of vital equipment.

\subsubsection{Administratıve Lontrols}

The SAR should fully describe and discuss organization and administrative systems and procedures for operation of the facility.

\subsubsection{Suggested Format for Technical Specifications}

Title (e.g., Temperature Control of Waste Evaporators)

Applicability--System(s) or portion(s) of the facility to which the specification applies should be clearly defined. 
Objective--The reason(s) for the specification and the specific unsafe condition(s) it is intended to prevent.

Specification--Safety limits and limiting control setting(s) for the important variable(s) or the condition or surveillance requirement imposed.

Bases--The SAR should contain all pertinent information and an explicit, detailed analysis and assessment supporting the choice of the item and its specific value or characteristics. The basis for each specification should contain a summary of the information in the SAR in enough depth to indicate the completeness and validity of the source material and to provide justification for the specification. Subjects that may be appropriate for discussion in the bases are:

10.5.6.1 Technical Basis. The technical basis is derived from technical knowledge of the process and its characteristics, and should support the choice of the particular variable, as well as the value of the variable. The results of computations, experiments, or judgments should be stated, and analyses and evaluations should be summarized.

10.5.6.2 Equipment. A safety limit often is protected by, or closely related to, certain equipment. Such relation should be noted, and the means by which the variable is monitored and controlled should be briefly mentioned.

For specifications in categories referred to in Sections 10.5.2 through 10.5.4, the bases are particularly important. The function of the equipment and how and why the requirement is selected and important to safety should be noted here. In addition, how survelllance takes place should be noted. If surveillance is required periodically, the basis for frequency of required action should be given.

10.5.6.3 Operation.. The margins and the bases that relate to the safety limit(s) and the normal operating zone(s) should be mentioned. The roles of operating procedures and of protective systems in guarding against exceeding a limit or condition should be stated. A brief discussion should be included of such factors as system response(s), 
process or operational tranșients, malfunctions, and procedural errors. Reference should be made to rellated specifications.

10.5.6.4 Assessment of Risk. The degree of confidence in the value of the variable or the condition specified, or the uncertainties associated therewith should be stated as precisely as possible. The potential results and effects of exceeding the limit should be mentioned, and the risk resulting therefrom should be evaluated. 
Chapter 11

QUALITY ASSURANCE

In 10 CFR 50, Appendix B, "Quality Assurance Criteria for Nuclear Power Plants and Fuel Reprocessing Plants," the regulations for quality assurance (QA) programs to be established by the applicant for use during design, construction, and subsequent operation are specified. In the PSAR, describe the QA Program to be established and executed during the design, construction, and decommissioning of the waste isolation facility. Additionally, discuss the provisions for smooth transition of the program from construction to operation to decommissioning. In the FSAR, describe the QA Program to be used during operation and decommissioning of the facility.

If portions of the QA Program have not yet been established at the time the SAR is prepared because activities will be performed in the future, include a schedule for the implementation of these portions.

When a portion of the QA Program to be implemented will conform to a particular QA standard, such as those adopted by the American National Standards Institute, the description in the QA Program may consist of a statement indicating the degree to which the particular standard will be followed.

\subsection{ORGANIZATION}

Provide organization charts for the construction project that denote the lines and areas of responsibility, authority, and communication within each major organization involved, such as applicant, architectengineer, and conslruction company, when these organizations are different. Additionally, discuss the relationship of responsibility and authority between the organizations, clearly indicating the organizational location, organization freedom, and authority of the individual or groups for 
checking, auditing, inspecting, or otherwise verifying that an activity has been correctly performed. On the charts and discussions, indicate the applicant's degree of involvement in the verification of the QA programs implemented by his contractors and suppliers. In the data, cover those cases where the applicant has delegated to other organizations the work of establishing and implementing the project QA Program, or any part thereof.

\subsection{QA PROGRAM PLAN}

Identify the structures, systems, and components to be covered by the QA Program, along with the major organizations participating in the program and the designated functions of these organizations. Describe the written policies, procedures, or instructions that implement or will implement the QA Program. When these written policies, procedures, or instructions are not yet effective, provide a schedule for their implementation. Include a positfve audit plan for monitoring the implementation of the QA Program.

\subsubsection{Design Control}

Describe the design control measures. Include (1) measures to ensure that appropriate quality standards are specified in design documents and that deviations from such standards are controlled; (2) measures for the selection and review of suitability of application of materials, parts, equipment, and processes; (3) measures for the identification and control of design interfaces and for coordination among participating organizations; (4) measures for verifying or checking adequacy of design such as by design reviews, alternative or simplified calculational methods, or suitable testing programs; and (5) measures to ensure that design changes, including field changes, will be subject to design control measures commensurate with those applied to the original design and will be reflected in accurate "as built" drawings and specifications. 


\subsubsection{Procurement Document Control}

Describe the procurement document control measures. Include measures to ensure that applicable NRC requirements, design bases, and other requirements such as $\mathrm{QA}^{\prime}$ Program requirements that are necessary to obtain adequate quality are included or referenced in procurement documents.

\subsubsection{Instructions, Procedures, and Drawings}

Describe the measures to ensure that activities affecting quality will be prescribed by documented instructions, procedures, or drawings, and wil1 be accomplished in accordance with these instructions, procedures, or drawings.

\subsubsection{Control and Identification of Purchased Material, Equipment, and Services}

Describe the measures for the control of purchased material, equipment, and services. Include measures for source evaluation and selection; for, assessing the adequacy by means of objective evidence of quality furnished by the contractor; for inspection at the contractor source; and the examination of products upon delivery. Also describe the measures taken to ensure that documentary evidence of material and equipment conformance to the procurement requirements is available at the facility site before installation or use of such material or equfipment.

Describe the measures for the identification and control of materials, parts, and components to ensure that incorrect or defective items will not be used.

\subsubsection{Inspection, Surveillance, and Testing}

Describe the program for inspection and surveillance of items and activities affecting quality; specifically indicate the items and activities to be covered. Include an organizational description of the individuals or groups performing inspections and their qualifications to perform inspections. Also indicate the independence of the inspection group from the group performing the activity being inspected, and describe how the inspection and surveillance program for the involved organizations has been or will be established.

$$
1.1-3
$$


Also discuss the test program to ensure that all testing required to demonstrate that structures, systems, and components will perform satisfactorily in service. Include an outline of the test program, procedures to be developed, the means for documenting and evaluating test results of the item tested, and designation of the responsibility for performing the various phases of the program. When a test program is used to verify the adequacy of a specific design feature, include a description of the qualification testing of a prototype unit.

\subsubsection{Nonconforming Materials, Components, and Fabrication and Construction Features}

Describe the measures to be taken to control nonconforming materials, parts, or components to prevent their inadvertent use or installation. Include the means for identification, documentation, segregation, and disposition of nonconforming material and notification to affected organizations. Also include means of control of nonconforming construction practices as related to the facility-approved drawings and specifications.

\subsubsection{Corrective Action}

Describe the corrective action measures established to ensure that conditions adverse to quality are identified and corrected, and that the cause of significant conditions adverse to quality is determined and corrective action taken to preclude repetition.

\section{2 .8 QA Records}

Discuss the program for the maintenance of records to furnish evidence of activities affecting quality. Include the means for identifying the records and the retention requirements for the records, inciuding duratinn, location, assigned responsibility, and means for retrieving the records when needed. 


\section{2 .9 Audits}

Describe the system of audits to verify compliance with all aspects of the QA Program and to determine the effectiveness of the QA Program. Include means for documenting responsibilities and procedures for auditing; required frequency of audits; audit results; designation of management levels to which audit results are reported; and a system of follow-up deficiencies.

\subsection{QA PROGRAM FOR FACILITY OPERATION (FSAR)}

In the FSAR, describe the proposed QA Program that will govern the quality of all safety-related items during facility operation. These activities include operating, maintaining, repairing, and modifying after the preoperational phase. Follow the format of Section 11.2 to provide this information, indicating procedures used in the repair, modification, or replacement to ensure that such changes are subject to the same control as the original approved designs and procedures. 


\section{RESEARCH RECOMMENDATIONS}

Research studies in the following areas are considered useful to the preparation of SARs for facilities for geologic isolation of radioactive wastes.

Macroenvironmental Studies

Studies of past climates and weather extremes

Extrapolation of past climates to future climates

Anthropogenic influence on future climates

Postglacial changes of runoff patterns and river courses

Role of telluric currents and geomagnetic fields

on tectonic processes

Microenvironmental Studies

Studies of glass degradation under temperature, pressure, and radiation

Migration of radionuclides within glass or degradation product matrix

Leaching properties of degraded glass

Studies of sorptive properties of heat-treated host rock

Leaching and sorption of radionuclides by mineralized groundwater

Migration of irule gastes lhrough host rock

Host rock and waste interaction under pressure, temperature, and radiation

Identification of analogs from natural geochemical processes.

\section{Systems Studies}

Scenariu building and assessment of radionuclide release processes. 
Regulation Studies

Organization effectiveness studies of design, implementation, operations and decommissioning within alternative regulatory environments

Intergovernmental relations and processes in waste isolation

Higher order socioeconomic impacts of waste isolation. 
The following reports contain information useful in the preparation of a waste isolation facility SAR. Table 1 indicates those chapters of the SAR for which each report contains relevant information.

1. Pacific Northwest Laboratories, Alternatives for Managing Wastes from Reactors and Post-Fission Operations in the LWR Fuel Cycle, ERDA-76-43 (May 1976).

Volume 1: Summary

$$
\begin{aligned}
& \text { Alternatives for the Back End of the LWR Fuel Cycle } \\
& \text { Types and Properties of LWR Fuel Cycle Wastes } \\
& \text { Projections of Waste Quantities } \\
& \text { Selected Glossary }
\end{aligned}
$$

Volume 2: Alternatives for Waste Treatment

Volume 3: Alternatives for Interim Storage and Transportation

Volume 4: Alternatives for Waste Isolation and Disposal

Volume 5: Appendices

2. U.S. Environmental Protection Agency, Office of Radiation Programs, Draft Environmental Statement, Environmental Radiation Protection Requirements for Normal Operations of Activities in the Uranium Fuel Cycle (May 1975).

3. U.S. Atomic Energy Commission, Draft Environmental Statement-Management of Commercial High Level and Transuranium-Contaminated Radloact1ve Waste, WASH-1539 (September 1974).

4. U.S. Atomic Energy Commission, Draft Environmental Statement Waste Management Operations, Hanford Reservation (Richland, Washington, September 1974).

Volume 1

Volume 2: Appendices

Volume 3: Predraft Comments and Suggestions, Glossary, List of Elements

5. U.S. Atomic Energy Commission, Directorate of Licensing, Fuels and Materials, Environmental Survey of the Nuclear Fuel Cycle (November 1972), 
6. W. P. Bishop and F. J. Miraglia, Jr., ed., Environmental Survey of the Reprocessing and Waste Management Portions of the LWR Fuel Cycle, NUREG-0116 (Supp. 1 to WASH-1248)(U.S. Nuclear Regulatory Commission, Washington, D.C., October 1976).

7. U.S. Nuclear Regulalory Commission, Final Generic Environmental

Statement on the Use of Recycle Plutonium in Mixed Oxide Fuel in

Light Water Cooled Reactors, NUREG-002 (August 1976).

Executive Summary

Volume 1

Volune 2

Volume 3

Volume 4

Volume 5

8. M. H. Campbel1, ed.; High-Leve1 Radioactive Waste Management, Advances in Chemistry Series 153 (American Chemical Society, Washington, D.C., 1976).

9. Panel on Engineered Storage, Committee on Radioactive Waste Management, National Research Council, Interim Storage of Solidified High-Level Radioactive Wastes (National Academy of Sciences, Washington, D.C., 1975).

10. Office of Waste Isolation, National Waste Terminal Storage Program Information Meeting, December 7-8, 1976, Y/OWI/TM-11/1 (Oak Ridge, Tennessee, December 6, 1976).

Volume I

volume 11

11. Office of Waste Isolation, National Waste Terminal Storage Program Progress Report for Period April 1, 197.5 to September 30, 1976, Y/OWI-8 (Oak Ridge, Tennessee, Nuvember 30, 19.76).

12. Proceedings of the International Symposium on the Management of Waste from the LWR Fuel Cycle, July 11-16, 1976, Denver, Colorado, Energy Research and Development Administration, CONF-76-0701 (1976).

13. H. C. Claiborne and F. Gera, Potential Containment Failure Mechanisms and their Consequences at a Radioactive Waste Repository in Bedded Salt in New Mexico, ORNL-TM-4639 (Oak Ridge National Laboratory, Oak Ridge, Tennessee, October 1974).

14. Oak Ridge National Laboratory, 1972 Preliminary Safety Analysis Report Based on a Conceptual Design of a Proposed Repository in Kansas, ORNL-TM-5764 (Oak Ridge, Tennessee, 1977).

15. U.S. Environmental Protection Agency, Office of Radiation Programs, Radiological Quality of the Environment, EPA-520/1-76-010 (Washington, D.C., May 1976). 
16. U.S. Atomic Energy Commission, Directorate of Regulatory Standards, Regulatory Guide 3.25, Standard Format and Content of Safety Analysis Reports for Uranium Enrichment Facilities (December 1974).

17. U.S. Nuclear Regulatory Commission, Regulatory Guide 3.26 Standard Format and Content of Safety Analysis Reports for Fuel Reprocessing Plants (February 1975).

18. Panel on Land Burial, Committee on Radioactive Waste Management, Commission on Natural Resources, National Research Council, The Shallow Land Burial of Low-Level Radioactively Contaminated Solid Waste (National Academy of Sciences, Washington, D.C., 1976).

19. Roya1 Commission on Environmental Pollution, Sir Biran Flowers, Chairman, Sixth Report--Nuclear Power and the Environment (Her Majesty's

Stationery office, London, September 1976).

20. Regulatory Staff U.S. Atomic Energy Commission, Standard Format and Content of Safety Analysis Reports for Nuclear Power Plants, LMFBR Edition (February 1974).

21. F. Gera, Geochemical Behavior of Long-Lived Radioactive Wastes, ORNL-TM-4481 (Oak Ridge, Tennessee, July 1975).

22. Office of Nuclear Material Safety and Safeguards, Public Comments and Task Force Responses Regarding the Environmental Survey of the Reprocessing and Waste Management Portions of the LWR Fuel Cycle, (NUREG-0116) (U.S. Nuclear Regulatory Commission, Washington, D.C., March 1977).

23. International Atomic Energy Agency, Site Selection Factors for Disposal of Solidified High-Level and Alpha-Bearing Wastes in Geological Formations, Draft (July 1975).

24. L. L. Ames, D. Rai, and R. J. Serne, A Review of Actinide-Sediment Reactions with an Annotated Bibliography (Battelle Pacific Northwest Laboratories, P. 0. Box 999, Richland, Washington, February 10, 1976).

25. C. W. Kee, A. G. Croff, J. 0. Blomeke, Updated Projections of Radioactive Wastes to be Generated by the U.S. Nuclear Power Industry, ORNL/TM-5427 Oak Ridge National Laboratory, Oak Ridge, Tennessee, December 1976).

26. U.S. Nuclear Regulatory Commission, Office of Standards Development, Regulatory Guide 1.70.27, Information for Safety Analysis Reports, Radioactive Waste Management (April 1975).

27. B. L. Cohen, "High-Level Radioactive Waste from Light-Water Reactors," Review of Modern Physics, Vol. 49, No. 1, pp. 1-20 (January 1977). 
Table 1

REFERENCES-SAR CONTENT CORRELATION

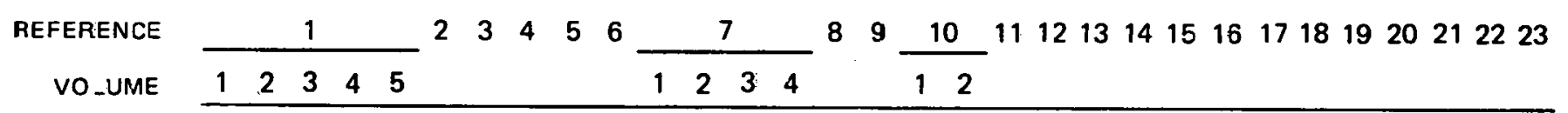

1. SITE CHARACTERISTICS

$x \quad x \times$

$x \times \times \times x$

$\times \times$

2. PRINCIPAL DESISN CRITERIA

$x \times x \times x$

$x \times \times \times \times$

$x \times$

$x \times x$

$x$

$\times \times$

3. FACILITY DESIEN

$x \times$

$x \quad x$

$x \quad x$

$x$

4. SYSTEM AND COMPONENT DESIGN

$x \times x$

5. RADIATION PRCTEOTION AND OPERATIONAL SAFETY

$x \times x \times \times \times \times \times \times x$

$x$

$x$

6. LONG-TERM WASTE ISOLATION

$x \times x \times$

$x \times$

$x \quad x$

$x$

$x \times$

$\mathrm{x}$

7. CONDUCT OF OPERATIONS

$x$

$x \times x \times x$

$x \times$

$\times \times x$

8. TECHNICAL SPECIFICATIONS

$\mathrm{x}$

$x$

9. Quality assuramce

$x$

$x$

10. REgulatory guiJe

$x \times$ 
Table 1 (Concluded)

REFERENCE

1. Site CHARACTERISTICS

2. PRINCIPAL DESIGN CRITERIA

3. FACILITY DESIGN

4. SYSTEM AND CCMPONENT DESIGN

5. RADIATION PROTECTION AND OPERATIONAL SAFETY

6. LONG-TERM WASTE ISOLATION

7. CONCUCT OF OPERATIONS

8. TECHNICAL SPECIFICATIONS

9. QUALITY assurance

10. REgULATORY GUIDE
25

26

27

$\times$

$x$

$x$

$\mathrm{x}$

$x$

$x$ 